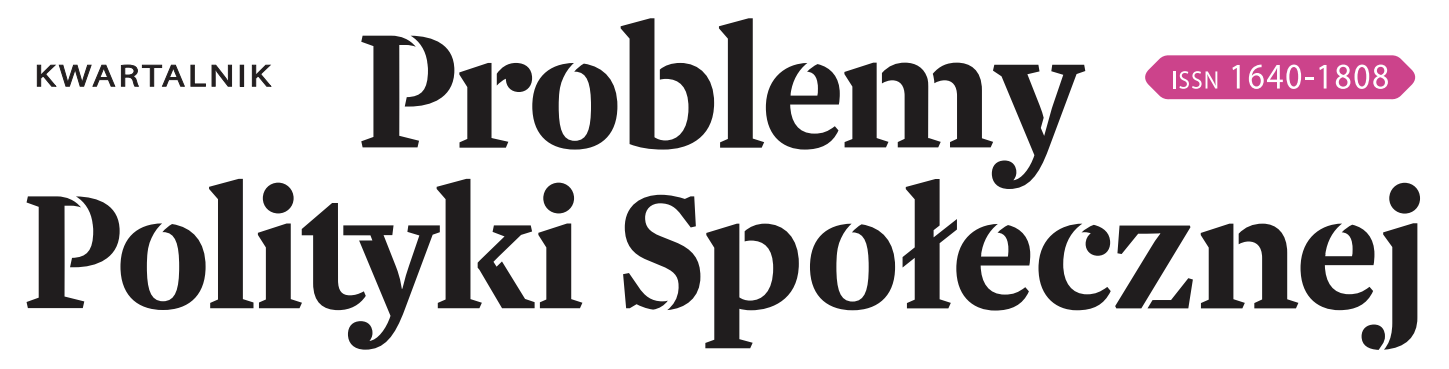

Social Policy Issues \#54 (3)/2021 
Publikacja dofinansowana Wydział Nauk Politycznych przez Wydział Nauk Politycznych i Studiów Międzynarodowych 


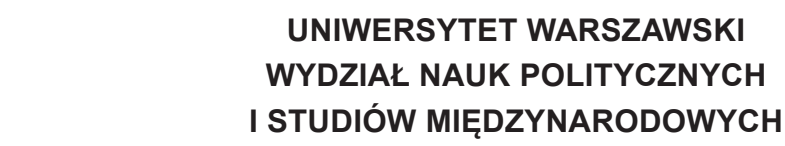

PATRONAT: KOMITET NAUK O PRACY I POLITYCE SPOKECZNEJ

POLSKIEJ AKADEMII NAUK

\section{Problemy \\ Politylki Społecznej}

\section{Social Policy Issues}

KWARTALNIK

\section{\#54 (3)/ 2021}




\section{EDITORIAL BOARD}

Maria Theiss, University of Warsaw, Poland: Editor-in-Chief; Anna Kurowska, University of Warsaw, Poland: Deputy Editor-in-Chief;

Justyna Kukaszewska-Bezulska, University of Warsaw, Poland: Editorial Office Assistant;

Michał Nadziak, University of Warsaw, Poland: Editorial Office Secretary;

Ewa Bacia, Technische Universität Berlin, Germany: Editor;

Łukasz Krzyżowski, University of Western Australia, Australia: Editor

\section{INTERNATIONAL ADVISORY BOARD}

Maciej Duszczyk, University of Warsaw, Poland: Chairman of the Council;

Jolanta Aidukaite, Lithuanian Social Research Centre, Lithuania;

Zdenko Babić, Zagreb University, Croatia;

Marsela Dauti, Uppsala University, Sweden;

Lenka Formankova, Czech Academy of Sciences, Czech Republic;

Marianna Fotaki, University of Warwick, United Kingdom;

Hanna Marikova, Czech Academy of Sciences, Czech Republic;

Nermin Oruc, Centre for Development Evaluation and Social Science Research Sarajevo, Bosnia-Herzegovina;

Martin Potůček, Charles University, Czech Republic;

Malina Voicu, Romanian Academy, Romania

\section{COOPERATING EDITORS}

Barbara Szatur-Jaworska, University of Warsaw, Poland;

Piotr Błędowski, Warsaw School of Economics, Poland;

Ryszard Szarfenberg, University of Warsaw, Poland;

Cezary Żołędowski, University of Warsaw, Poland;

Justyna Godlewska-Szyrkowa, University of Warsaw, Poland;

Mirosław Księżopolski, University of Warsaw, Poland; Bartosz Pieliński, University of Warsaw, Poland;

Stanisława Golinowska, Jagiellonian University,

Institute of Labour and Social Affairs, Warsaw, Poland;

Lutz Bellmann, Friedrich-Alexander University in Erlangen-Nuremberg, Germany;

Tomasz Inglot, Minnesota State University, USA;

Józef Orczyk, Poznań University of Economics, Poland;

Jeja-Pekka Roos, University of Helsinki, Finland;

Piotr Pysz, University of Finance and Management in Białystok, Poland;

Julian Auleytner, Janusz Korczak Pedagogical College in Warsaw, Poland

\section{LANGUAGE EDITORS \\ Helena Marzec-Gołąb}

Copyright by

WNPiSM UW

ISSN 1640-1808

e-ISSN 2719-7328

Corresponding address:

Nowy Świat 67, room 110

00-927 Warszawa

Tel./fax 0-22 826-66-52

www.problemypolitykispolecznej.pl

problemy.ps@uw.edu.pl

Wersją referencyjną czasopisma jest wersja on-line

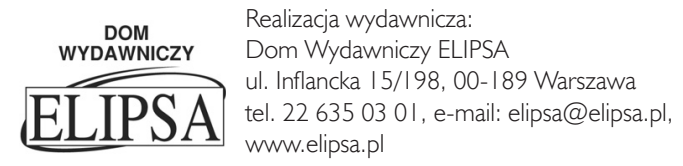




\section{Contents}

\section{Studies}

Agnieszka Chłoń-Domińczak, Wojciech Łątkowski, Evolution of the generational distribution of income, consumption and lifecycle deficit in Poland between 2004 and 2016: Facing the EU convergence and demographic challenges .......

Tomasz Mering, Activation and new governance of labor market policies in Central and Eastern European Countries ..................... 31

Sławomir Kalinowski, Aleksandra Łuczak, Social (in)security - the ambivalence

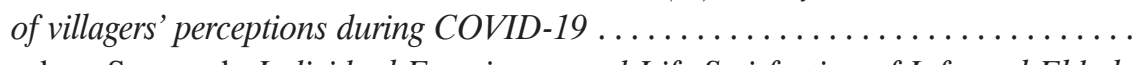

Klaudyna Szczupak, Individual Experiences and Life Satisfaction of Informal Elderly Caregivers in Poland: A Study Based on In-depth Interviews 
STUDIES 


\title{
Agnieszka Chłoń-Domińczak
}

ORCID: 0000-0001-5068-0276 Institute of Statistics and Demography, SGH Warsaw School of Economics ${ }^{1}$

Wojciech Łątkowski

ORCID: 0000-0002-1509-9774

Institute of Statistics and Demography, SGH Warsaw School of Economics

\section{Evolution of the generational distribution of income, consumption and lifecycle deficit in Poland between 2004 and 2016: Facing the $E U$ convergence and demographic challenges}

\begin{abstract}
The National Transfer Accounts approach is used to assess lifecycle deficit in Poland between the EU accession in 2004 and 2016. In this period, the overall consumption remained relatively stable relative to wages while labour income increased, mainly due

1 This article is based on research carried out within the project POLNTA "Narodowy Rachunek Transferów oraz Narodowy Rachunek Transferów Czasu dla Polski", financed by the National Science Centre (UMO-2013/10/M/HS4/00466), and research at the Institute of Statistics and Demography at Warsaw School of Economics (SGH), supported from the state budget funding for research in 2018. Authors would like to thank professor Irena E. Kotowska and anonymous reviewers for their comments and suggestions. Correspondence: Institute of Statistics and Demography, SGH Warsaw School of Economics, al. Niepodległości 162, 02-554, Warsaw, Poland; email: achlon@sgh.waw.pl.
\end{abstract}


to the increased economic activity at higher ages. There is a shift in the generational distribution of consumption and public transfers towards the older age groups, that reflects the changes in the age structure of the population. At the same time, the per capita age profiles of labour income, consumption, life cycle deficit and public transfers in Poland converge to the average levels observed in Europe, however, the gap remains, particularly in public transfers, including public consumption on health. With the continued population ageing it is important to maintain policies that stimulate growth of the labour income that is faster than consumption increases in order to maintain the balance between lifecycle deficit of the young and older generations and lifecycle surplus of the active generation.

Key words: national accounts, national transfer accounts, population ageing, generational accounting

\section{Introduction}

Population ageing in developed countries raises concerns about maintaining intergenerational stability. This is mainly related to the need of financing the increasing aggregate consumption of the more numerous senior generations, that is relying mainly on public transfers, such as pensions or public health care. The population ageing in Poland is an important concern from the perspective of both intergenerational stability and ability to meet the consumption needs of the non-active population. It is a rising challenge for social policies that shape the public transfers addressed to people at different stages of their life course.

In the paper, we focus on the evolution of the consumption, labour income and resulting lifecycle deficit in Poland between 2004 and 2016, as well as public transfers that finance a part of consumption of different generations, with particular focus on generations in non-active ages, who are the main beneficiaries of intergenerational transfers. These changes indicate the future challenges for the public policies from the perspective of maintaining generational stability in the light of the projected population ageing.

This article contributes to the generational economy by providing an assessment of the development of lifecycle deficit in Poland - the country that faces very dynamic social, economic and demographic changes. We focus on the period from 2004 to 2016, i.e., after the accession to the European Union until recent time. During these years Poland experienced dynamic economic growth and remarkable social progress. The real GDP increased by $56.1 \%$, the employment rate for people aged $20-64$ increased from $57 \%$ to $69.3 \%$ while the unemployment rate declined from $19 \%$ to $6.1 \%$. The real average wage increased by $53.9 \%$. At-risk-of-poverty rate declined from $20.5 \%$ to $17.3 \%$ from 2005 to 2016 (compared to an increase from $16 \%$ to $17.3 \%$ in the EU). Even during the 2008 crisis the economy in Poland performed quite well and contrary to other EU Member States the economic growth rate remained positive. At the same time, the age composition of the population changed: labour force shrinking as well as population ageing progressed and maintaining a generational balance in the future is increasingly challenged. 
The economic, social and demographic changes also have an impact on the generational distribution of income and consumption and as well as an intergenerational balance. The article aims to reflect on the following three research questions:

1) How generational distribution of lifecycle deficit and consumption were affected by economic, social and demographic changes?

2) Is there a convergence of the outcomes of public policies in Poland to a particular type of welfare state in Europe, as measured by labour income, consumption and public transfers?

3) Do the observed changes in consumption, labour income and lifecycle deficit indicate that the economic dependency will be sustained in the future with progressing population ageing?

The article is structured as follows. First, we present the main issues related to generational economy and generational transfers. Then, we present the methodology and data used for the estimation of the age profiles in Poland. This is followed by a short description of major demographic trends in Poland. Then, the changes in the main national accounts aggregates between 2004 and 2016 are analysed, including the impact of demographic and per-capita age profile changes on their overall change. In the following part, we focus on the evolution of the per-capita and aggregate age profiles of consumption, labour income, and the resulting lifecycle deficit. This includes also changes in the distribution of resources between generations through the public transfers. We compare the results for Poland to selected countries in Europe representing different welfare regimes as well as to the EU average. In the conclusions, we present implications from the social policy perspective.

\section{Generational transfers in the literature}

Measuring and projecting the balance of intergenerational transfers have drawn particular attention of economists, who subsequently have developed different conceptual and analytical proposals contributing to the generational economy. One of the first approaches to measure the net wealth of current and future generations was presented by (Auerbach et al., 1991), who proposed how to measure the net present value of payments of existing and future generations to the governments. They concluded that, unless policies are altered, the future generations will face a net tax burden that will be by a one-fifth larger compared to the generations born in 1990. (Diamond, 1996, p. 597) underlined that the development of generational accounts has three strands: (i) normative considerations of government activity, (ii) use of generational accounting in a positive theory of human behaviour and (iii) presentation of a generational balance as a both normative criterion and a useful target for a political economy.

An important contribution to the generational economy, along to the three strands of deliberation defined by Diamond, are the National Transfer Accounts - NTA (Lee $\&$ Mason, 2011) that provide a comprehensive accounting for not only public, but also private resource reallocation by age. 
The NTA approach is based on the assumption that at each stage in their life, generations have different patterns of consumption and labour income that result in the lifecycle deficit. The main focus of the NTA approach is to identify lifecycle deficit (LCD) and sources of its financing. This follows the basic equation that relates to the main national accounts' aggregates. Namely, at each stage of the lifecycle generations show different patterns of consumption and labour income, that result in lifecycle deficit. This can be denoted as:

$$
L C D(x)=C(x)-Y^{\prime}(x)=\tau^{+}(x)-\tau^{-}(x)+Y^{A}(x)-S(x),
$$

where:
$\operatorname{LCD}(x)$ - lifecycle deficit
$C(x)$ - consumption
$Y^{l}(x) \quad$ - labour income
$\tau^{+}(x) \quad$ - transfers received
$\tau^{-}(x) \quad$ - transfers paid
$Y^{A}(x) \quad$ - income from assets
$S(x) \quad$ - savings

The left-hand side of the equation (1) denotes lifecycle deficit, while the right-hand side is comprised of net transfers $\left(\tau^{+}(x)-\tau^{-}(x)\right)$ and reallocation of resources $\left(Y^{A}(x)-S(x)\right)$. The NTA method is designed to assess these flows, divided to public and private parts, taking into account cross-sectional age profiles for each of the variables in the equation (1).

The NTA show a more complex picture of government activities in the lens of public transfers paid and received, extended by activities at a household level, and the role of intra-household private transfers in financing consumption of the young and senior generations. This area of research is dynamically developing, both by covering a wide range of countries worldwide and by widening the analytical approach, focusing not only on generational differences, but also, among others, taking into account the gender and the socioeconomic status of households (Lee \& Mason, 2019).

An application of the NTA approach in the historical context by comparing the age profiles at different points in time, allows for better understanding of the development of government activities, measured by public transfer flows addressed to different generations, as well as interactions between public policies and cross-generational transfers at a household level. Such studies for European countries were performed for France and Sweden (d'Albis et al., 2015; Lindh et al., 2011). Moreover, the NTA quantify lifecycle deficit, i.e., the part of consumption of two population groups (young and old) that is not financed by labour income. That approach allows comparing the allocation of public and private resources to finance lifecycle deficit over the life course: at the beginning and at the end of the life course.

In Europe, the harmonised National Transfer Accounts for majority of countries were assessed in the EU-funded AGENTA project (Istenič et al., 2016), for year 2010. These 
estimates were then applied to identify clusters of countries with regard to the generational focus of public policies (Chłon-Domińczak et al., 2019). They identified three clusters of countries: (i) European, 14 countries in which the age profiles of public transfers are close to the EU average. This cluster is comprised of both liberal and continental welfare regimes that seem to exhibit similar age patterns for public transfers, including for levels of public consumption (including Poland, Germany and Spain), (ii) Underdeveloped cluster, which is characterised by below-average transfers by age, with five new member states $^{2}$ and (iii) Scandinavian, which is characterised by above-average publics transfer and consumption levels by age (including Sweden). This analysis contributed to the literature discussion of the welfare regimes, that was initiated by the seminal book by (Esping-Andersen, 1990).

\section{Data and methodology}

In the article, we use the NTA estimates in Poland for years 2004 and 2016. The estimates were made following the common methodology, which is presented in the NTA manual (United Nations Department of Economic and Social Affairs Population Division, 2013). The assessment is based on existing administrative, demographic and survey data, including income and household budget surveys. The estimates for Poland were made using three main types of data sources:

- the survey data (EU-SILC and Household Budget Survey - HBS) to estimate age profiles of private consumption and labour income,

- the public sources, including the data from National Health Fund, to estimate public consumption on health and education statistics to assess the public consumption on education, and finally,

- the national accounts to calculate aggregates aimed at adjusting the survey-dataderived age profiles to match the total flows in the economy.

The main source of data for private consumption was the Household Budget Survey (HBS). The HBS in Poland is conducted annually on a sample of 37.5 thousand households. From 1992 on the survey is based on the monthly rotation - each month the survey covers over 3.1 thousand households. The methodology of the HBS is comparable annually, which ensures comparability of the obtained estimates (Statistics Poland, 2018).

The age profiles of the consumption components have been estimated by use of different analytical methods. The private education consumption profile has been obtained using the regression method, following the recommendations from the NTA manual (UN, 2013, p. 98). It is calculated from age 0 until age 54 (we also include expenditure on lifelong learning). The education expenditure for each household member is allocated according to the obtained regression coefficients. The private health consumption for all ages is assessed by use of an iterative approach - an alternative to a regression method (UN, 2013, p. 100). Other private consumption by age is calculated according

2 Bulgaria, Estonia, Latvia, Romania, and Slovenia. 
to a piecewise linear profile, with weights for private consumption ranging from 0.4 for children aged 4 and younger and increasing linearly to 1 for adults aged 20 and over. Public education consumption profiles are calculated for each year. They are based on the data on education expenditures for each level of education, coming from the state budget and local government budgets' reports, which are combined with information on enrolment at different stages of education by age from Eurostat. Public health consumption is assessed on the data from the National Health Fund. Other public consumption obtained from national accounts (i.e., defence, police, justice) is distributed equally over the population according to the NTA methodology. The labour income of workers and self-employed are estimated using the EU-SILC data on individual income.

The obtained profiles are smoothed across ages using the Friedman (1984) method, in line with the approach proposed in the NTA manual. Public consumption on education is an exception, as remaining unsmoothed allows for capturing differences resulting from different expenditure at different educational stages. At the end of the estimation procedure, all age profiles are adjusted using the relevant aggregate from national accounts.

In the analysis we use:

(i) the per-capita age profiles, which reflect the average levels of labour income, consumption, lifecycle deficit and transfers for representatives of each age cohort.

(ii) the aggregate age profiles, which take into account the population age structure to investigate, how demographic changes affect the aggregate distribution of the analysed flows.

Age profiles are estimated in nominal currency values (nominal profiles) as well as in relative terms, using the labour income of prime-aged cohorts in the age groups 30-49 as normalisation factor (normalised profiles). The normalisation method follows the NTA manual. The normalisation allows comparisons of the age profiles between countries as well as in time. As shown in the Table 1, between 2004 and 2016 the real income used for normalisation increased by $38.4 \%$ in per-capita terms and $49.7 \%$ in aggregate terms, which are below the real GDP growth between 2004 and 2016 (56.1\%).

Table 1. Average labour income (30-49) in real value for 2016

\begin{tabular}{|l|c|c|c|c|c|}
\hline & $\mathbf{2 0 0 4}$ & $\mathbf{2 0 0 8}$ & $\mathbf{2 0 1 2}$ & $\mathbf{2 0 1 6}$ & Index 2016/2004 \\
\hline per-capita (in PLN) & 35726 & 43426 & 42433 & 49458 & 138.4 \\
\hline aggregate (in million PLN) & 4769 & 5700 & 5827 & 7140 & 149.7 \\
\hline
\end{tabular}

Source: Own calculations.

The normalised data also allows international comparisons. For the comparison purpose we use the normalised NTA age profiles developed within AGENTA project (Istenič et al., 2016) to identify relative differences stemming from different socioeconomic developments and the welfare regime characteristics. The following countries are used for comparisons: Germany (continental regime and European cluster), 
Spain (Mediterranean regime and European cluster) and Sweden (socio-democratic Scandinavian regime and Scandinavian cluster). The reference year for the EU estimates is 2010, so the 2016 age profiles in Poland are compared to the ones observed 6 years before in other EU countries. The comparison of the normalised values still allows to provide valid comparisons. While comparing national normalised data it is important to keep in mind the nominal differences between countries. The average labour incomes of those aged 30-49 vary significantly between countries, which is shown in Table 2.

Table 2. Average labour income of people aged 30-49 in EUR in Poland and selected countries

\begin{tabular}{|l|c|}
\hline \multicolumn{1}{|c|}{ Country } & Average nominal income in EUR \\
\hline Poland (2016) & 11337 \\
\hline Germany (2010) & 32979 \\
\hline Spain (2010) & 24255 \\
\hline Sweden (2010) & 40525 \\
\hline
\end{tabular}

Source: Own calculations for Poland, for other countries (Istenič et al., 2016).

As one can see, the ratio of labour income used for the normalisation between the country with the highest nominal income (Sweden) and the lowest one (Poland) exceeds 3.5. This also has implications for comparisons. Namely, the share of labour income needed to finance consumption needs in Sweden is much lower compared to Poland. This also means that the Swedish population can devote higher share of the income to savings, which in turn affects the ability to finance consumption of the senior generations from asset-based reallocations.

\section{Results}

\section{Demographic developments in Poland between 2004 and 2016}

The evolution of the population in Poland between 2004 and 2016 is an important factor shaping the aggregate consumption, labour income and lifecycle deficit by age, contributing to the changing need for the inter-generational allocations. The Polish population is characterised by two large baby-boom generations, one composing by cohorts born after World War II and the second by cohorts born in the end of 1970s and the beginning of the 1980s. Since 1989, fertility remains below replacement, approaching in 1998 the low fertility levels (TFR below 1.5). As a result, the size of the youngest generations (below age 20) is gradually declining while the two baby-boom generations progressing in age with time impose changes in the age structure of the population.

Between 2004 and 2016, the number of people below the age of 20 declined by 1.7 million and the population above age 65 increased by 1.3 million. The population in working age (20-64 years) was increasing to reach its peak in 2011 and started to decline afterwards (Figure 1, Table 3). Consequently, the young dependency ratio declined 
from 39 to 31 people below 20 years per 100 people aged 20-64 years while the old-age dependency ratio increased from 21 to 26 people older than 65 per 100 people aged 20-64 years.

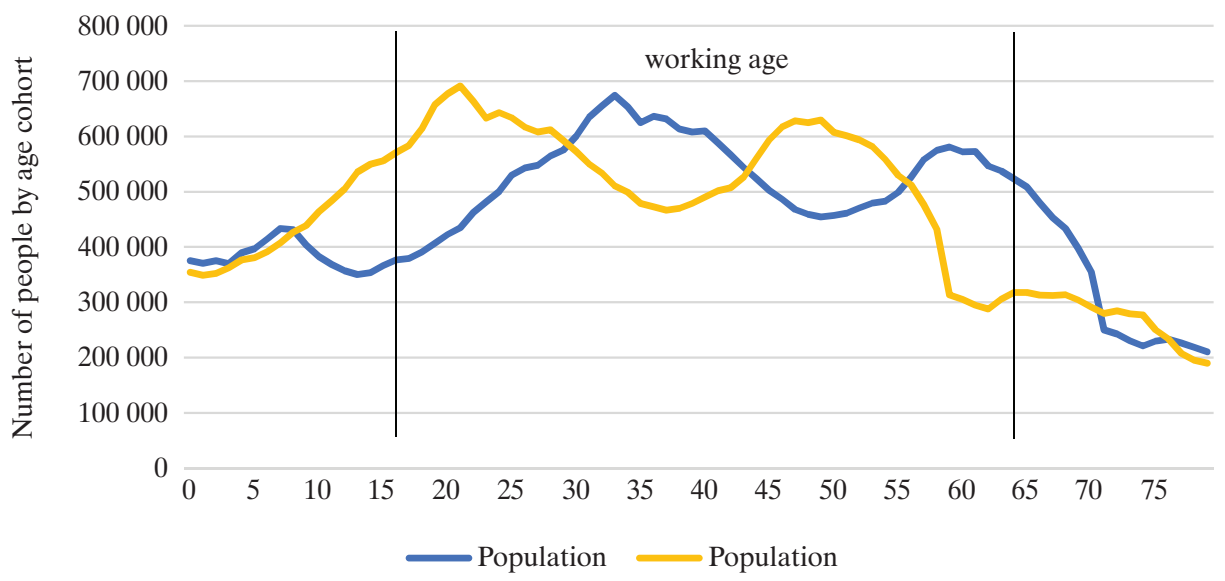

Figure 1. Age profile of the population in Poland, 2004 and 2016

Note: people aged 80 and over are not shown for the clarity of the picture

Source: EUROSTAT [extracted on 15.12.2019].

Table 3. The size of the broad age groups and demographic dependency ratios

\begin{tabular}{|l|c|c|}
\hline & $\mathbf{2 0 0 4}$ & $\mathbf{2 0 1 6}$ \\
\hline \multicolumn{3}{|c|}{ Number of people in age groups } \\
\hline $0-19$ & 9357711 & 7693130 \\
\hline $20-64$ & 23797851 & 24436457 \\
\hline $65+$ & 5018273 & 6303405 \\
\hline \multicolumn{3}{|c|}{ Demographic dependency (per 100 people aged 20-64) } \\
\hline Young DR (0-19) & 39 & $\downarrow 31$ \\
\hline Old-Age DR (65+) & 21 & $\uparrow 26$ \\
\hline Total DR & 60 & $\uparrow 57$ \\
\hline
\end{tabular}

Source: EUROSTAT [extracted on 15.12.2019].

\section{Change of the main NTA aggregates}

As highlighted in the introduction, Poland experienced the remarkable economic growth after the EU accession in 2004. This also translated into the significant growth of the real aggregate consumption and the even faster growth of the real aggregate labour income. As a result, the real aggregate lifecycle deficit grew by around a fifth (Table 4). 
Table 4. Real value of main NTA aggregates in 2004 and 2016 and their change

\begin{tabular}{|l|rr|c|}
\hline & \multicolumn{2}{|c|}{ Million PLN* $^{*}$} & $\mathbf{2 0 0 4}=\mathbf{1 0 0}$ \\
\hline & $\mathbf{2 0 0 4}$ & $\mathbf{2 0 1 6}$ & $\mathbf{2 0 1 6}$ \\
\hline Lifecycle Deficit & $\mathbf{4 9 6 8 2}$ & $\mathbf{6 0 1 8 6}$ & $\mathbf{1 2 1 . 1}$ \\
\hline Consumption & $\mathbf{2 0 8} \mathbf{2 4 0}$ & $\mathbf{3 0 1} \mathbf{7 9 8}$ & $\mathbf{1 4 4 . 9}$ \\
Public Consumption & 53683 & 83068 & 154.7 \\
Public Consumption, Education & 13159 & 19275 & 146.5 \\
Public Consumption, Health & 11150 & 19560 & 175.4 \\
Public Consumption, Other & 29374 & 44233 & 150.6 \\
Private Consumption & 154557 & 218730 & 141.5 \\
Private Consumption, Education & 2112 & 2140 & 101.3 \\
Private Consumption, Health & 6476 & 12208 & 188.5 \\
Private Consumption, Other & 145968 & 204381 & 140.0 \\
\hline Public Transfers, Inflows & 100499 & 155169 & 154.4 \\
Public Transfers, Outflows & 101787 & 158648 & 155.9 \\
\hline Labour Income & $\mathbf{1 5 8} \mathbf{5 5 9}$ & $\mathbf{2 4 1 6 1 2}$ & $\mathbf{1 5 2 . 4}$ \\
\hline
\end{tabular}

"Measured according to real PLN of 2016

Source: Own calculations.

The increases in aggregate consumption and lifecycle deficit were not equally distributed across generations, defined according to the NTA limits of the economically active age for Poland, that is young, active and senior generations. The generations divided according as the ages at which the LCD turns to negative, that is the ages when labour income exceeds the consumption. These limits in Poland in 2016 were estimated as 27 years and 57 years. To demonstrate these changes the ratios of main NTA aggregates for people aged 57 and more (senior generations) to people below 27 (young generations) are derived (Figure 2).

Comparing the ratios of lifecycle deficit (LCD), consumption and public transfers attributed to young generations and senior generations shows a clear change in the generational pattern. There is a steady shift towards higher consumption and also lifecycle deficit of senior generations in relation to young ones. By the same token, the share of public transfers received by senior generations also increased. 


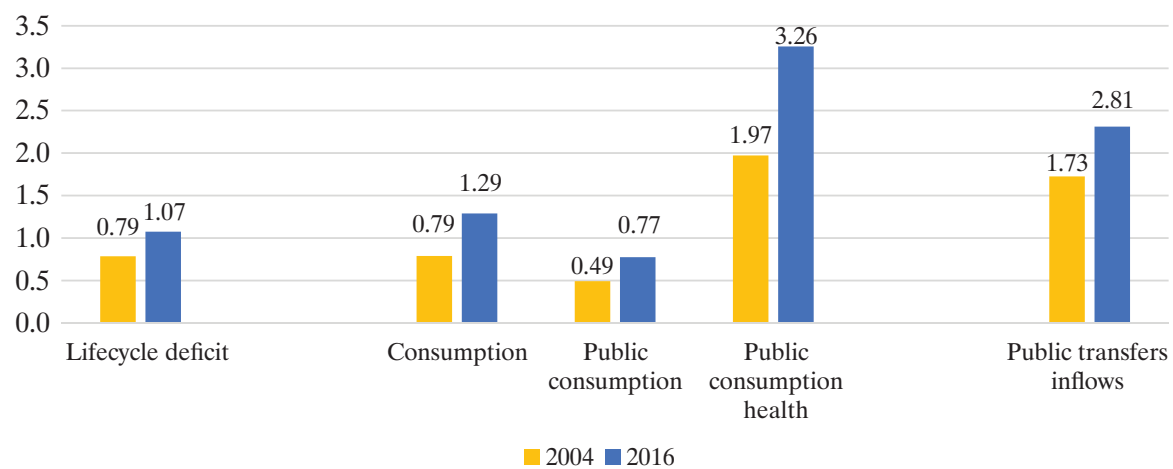

Figure 2. Ratios of the aggregate consumption and the aggregate lifecycle deficit of senior generations (57 and over) compared to young generations (below 27) in 2004 and 2016

Source: Own calculations.

In 2016 the aggregate LCD of the senior generations was higher than the young generations (by 7 points), while in earlier years the young generations had the higher aggregate lifecycle deficit (the LCD of the senior generations was 21 points smaller). The generational change in the aggregate consumption was even more pronounced. In 2016, the senior generations consumed 30 points more than the young generations, while in 2004 the aggregate consumption of younger generations was higher, as the senior generations consumed 21 points less than young generations. There is also a significant generational shift in public consumption and public transfers. The public consumption on health of the senior generations increased from almost 2 times to more than 3 times of the young generations between 2004 and 2016. In 2016 the senior generations received 2.3 times more public transfers than the young generations, compared to 1.73 times more in 2004 .

These results clearly confirm that with population ageing the aggregate consumption and lifecycle deficit of the senior generations increases relative to the young generations, along with the increase of public transfers that are to a large extent used to finance consumption of this part of the population.

\section{Impacts of the age structure and per-capita age profiles on the NTA aggregates}

In order to identify the impact of changes in the age structure and the per-capita age profiles on the dynamics of the NTA aggregates, the observed growth of the NTA aggregates is decomposed into: (i) the change of the population age structure, (ii) the impact the per-capita age profile and (iii) the impact of the per-capita normalised age profile, that is deducting the impact of the wage growth of people aged 30-49 (Table 5) ${ }^{3}$.

3 According to the NTA manual (UN 2013), the normalisation used for the age profiles is labour income of people in age group 30-49. 
Due to the change in the age composition only, lifecycle deficit would increase by $5.2 \%$, while the total aggregate consumption and labour income would decline by $1.7 \%$ and $3.5 \%$ respectively. Interestingly, only education consumption would increase, following the increase of the number of children in the school age resulting from the temporary increase in births in 2004-2009. The public transfers (both inflows and outflows) would also decline.

Table 5. Indices of changes in the NTA aggregates between 2004 and 2016 and their decomposition to demography and per-capita age profile impacts (according to real PLN of 2016)

\begin{tabular}{|l|c|c|c|c|}
\hline \multirow{2}{*}{} & \multirow{2}{*}{$\begin{array}{c}\text { Total change } \\
\mathbf{( 2 0 0 4}=\mathbf{1 0 0})\end{array}$} & $\begin{array}{c}|c| \\
\text { The isolated effect of change in } \\
\text { pope structure }\end{array}$ & $\begin{array}{c}\text { per-capita } \\
\text { age profile }\end{array}$ & $\begin{array}{c}\text { per-capita } \\
\text { age profile } \\
\text { normalised }\end{array}$ \\
\cline { 3 - 5 } & & $\mathbf{( i )}$ & (ii) & (iii) \\
\hline Lifecycle Deficit & $\mathbf{1 2 1 . 1}$ & $\mathbf{1 0 5 . 2}$ & $\mathbf{1 1 5 . 2}$ & $\mathbf{7 6 . 9}$ \\
Consumption & $\mathbf{1 4 4 . 9}$ & $\mathbf{9 8 . 3}$ & $\mathbf{1 4 7 . 5}$ & $\mathbf{9 8 . 5}$ \\
Public Consumption & 154.7 & 102.9 & 150.5 & 100.5 \\
Public Consumption, Education & 146.5 & 128.4 & 114.1 & 76.2 \\
Public Consumption, Health & 175.4 & 89.4 & 196.2 & 131.1 \\
Public Consumption, Other & 150.6 & 97.7 & 154.2 & 102.9 \\
Private Consumption & 141.5 & 96.5 & 146.6 & 97.9 \\
Private Consumption, Education & 101.3 & 124.4 & 81.4 & 54.4 \\
Private Consumption, Health & 188.5 & 89.9 & 209.7 & 140.1 \\
Private Consumption, Other & 140.0 & 96.6 & 144.9 & 96.8 \\
Public Transfers, Inflows & 154.4 & 92.9 & 166.3 & 111.0 \\
Public Transfers, Outflows & 155.9 & 94.9 & 164.2 & 109.7 \\
Labour Income & $\mathbf{1 5 2 . 4}$ & $\mathbf{9 6 . 6}$ & $\mathbf{1 5 7 . 8}$ & $\mathbf{1 0 5 . 4}$ \\
\hline
\end{tabular}

Note: The multiplication of (i) and (ii) provides with the total change.

Source: Own calculations.

The decomposition shows that the per-capita age profiles in real terms (the column (ii) in Table 5) had a larger impact on the growth of the analysed aggregate values compared to the age structure changes. In particular, the development of per-capita age profiles led to the remarkable increases of consumption and labour income while it resulted in a smaller increase of lifecycle deficit. The largest increases caused by the evolution of per-capita age profiles are due to the changes in health consumption, both public and private, which doubled. At the same time, the public consumption on education did 
not grow substantially, showing that overall growth of the economy and wages did not translate to public investments in human capital development. The private consumption on education declined, which may indicate the policy changes - namely children in primary and lower secondary schools were equipped with textbooks by schools and parents do not need to buy them anymore. It is also worth noting that the growth of public transfers (both inflows and outflows) was higher than the growth of labour income. This indicates a fiscal expansion, which leads also to higher public transfers. These issues are discussed later in the article.

The impact of per-capita age profiles is even more visible when changes of the NTA aggregates are investigated using normalised values (the column (iii) in Table 5). The normalised age profiles allow to estimate the effect of the change in the age profile, rather than its shape combined with the growth of wages. Using normalised age profiles, we find that the lifecycle deficit declines, following the small drop in the aggregate consumption and the rise of labour income. Even when excluding the impact of the wage growth, the high increase of consumption on health, both public and private, is revealed respectively by 31 and 40 p.p. and the drop of consumption on education, both public and private, respectively by 24 and 46 p.p. The public transfer inflows and outflows increased faster than wages.

\section{The evolution of the normalised NTA age profiles in Poland compared to selected EU countries}

In this section, our focus is on the evolution of the per-capita and the aggregate age profiles of consumption, public transfers, labour income, and lifecycle deficit in Poland. We analyse the evolution of the age profiles for Poland between 2004 and 2016, referring to normalised values of per-capita and aggregate age profiles. We also compare the 2016 per-capita age profiles in Poland to those in selected EU countries representing different welfare regimes (Germany, Spain, Sweden). The age profiles are designed for the broad age groups: 0-19 years (young generations), 20-64 years (working-age generations), 65 years and older (senior generations). Contrary to the previous section, here we use traditional borders of the economically active age to derive some comparable age-specific and cross-country indicators.

\section{Consumption}

The evolution of the per-capita consumption age profiles in Poland between 2004 and 2016, similarly to most of developed countries, shows consumption increases for older age groups, but also in case of young age groups, particularly in the ages related to participation in public education. Last but not least, it also increased for the people in the prime-aged group (30-49), which is presented in Figure 3 (the left panel).

Looking at the aggregate consumption, we see the visible shift of consumption peeks related to the two baby-boom generations (Figure 3, the right panel). In 2016, the aggregate consumption of young people declined (below 30), but also those between 
ages 43 and 57, following the population decline in these groups. The age shift of the baby boom generations translated into increased consumption of people between ages 33 and 44 , as well as $57-72$ years.

Per-capita

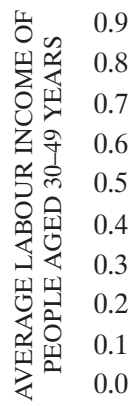

$0 \quad 5101520253035404550556065707580$

$\longrightarrow$ C per capita C per capita
Aggregate

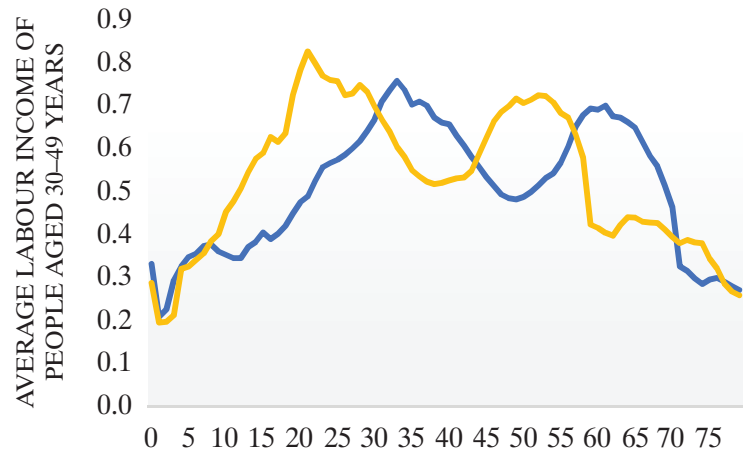

$\longrightarrow$ C aggregate $\longrightarrow$ aggregate

Figure 3. Normalised age profiles of consumption in Poland, 2004 and 2016

Source: Own calculations.

The normalised per-capita consumption by the three broad age groups in Poland slightly differs from the other EU countries (Table 6). Consumption of the young generations is below the EU average, but higher compared to normalised levels in Germany or Sweden. This difference is explained by higher nominal labour income of people in ages 30-49 in the latter two countries. Consumption of the senior generations (65 and more) in Poland in 2016 is relatively higher compared to the EU average, but similar to the one observed in Germany.

Table 6. Normalised per-capita consumption by the broad age groups, Poland vs. selected EU countries

\begin{tabular}{|c|c|c|c|c|c|c|c|c|}
\hline \multirow{2}{*}{ Age group } & \multicolumn{2}{|c|}{ Poland } & EU 25 & DE & ES & SE & \multicolumn{2}{|c|}{$\begin{array}{c}\text { Poland } \\
(\text { EU } 25 \text { average } 2010=100)\end{array}$} \\
\hline & 2004 & 2016 & \multicolumn{4}{|c|}{2010} & 2004 & 2016 \\
\hline all & 49.87 & 51.32 & 52.66 & 48.74 & 52.87 & 46.16 & 94.7 & 97.4 \\
\hline 0-19 & 9.65 & 10.56 & 11.17 & 9.35 & 11.34 & 9.51 & 86.4 & 94.6 \\
\hline $20-64$ & 28.63 & 28.98 & 29.89 & 27.46 & 30.22 & 26.14 & 95.8 & 96.9 \\
\hline $65+$ & 11.59 & 11.78 & 11.61 & 11.93 & 11.31 & 10.51 & 99.9 & 101.5 \\
\hline $0-19 / 65+$ & 0.83 & 0.90 & 0.96 & 0.78 & 1.00 & 0.90 & 86.5 & 93.2 \\
\hline
\end{tabular}

Relative to average labour income of people aged $30-49$ years

Source: Own calculations. 
The ratio of per-capita consumption between young and old generations in Poland in 2016 is lower compared to the EU average, that means that young people consume (relatively) less. However, there are differences to countries representing different welfare regimes. While the generational ratio in Poland is similar to the one in Sweden, it is higher than in Germany (which is related to lower consumption of young generations in Germany). On the other hand, in Spain the generational ratio is higher, as the young generations consume relatively more than in other analysed countries.

\section{Public consumption}

As discussed earlier, the public consumption increased more than the total consumption. Additionally, the public consumption is more likely to face intergenerational shifts. Therefore, we take a closer look at this part of the total consumption. As depicted in Figure 4 (the upper panel), the public consumption per-capita age profiles in Poland increased for all generations. The increases were visible particularly for the young people (up to age 23), which is due to increased public spending on education. The public consumption increased for people in prime age, which reflects the increase in public consumption other than education and health. Another visible development is the increase of per-capita public consumption for those aged 65 and over in subsequent estimates, related to the higher public consumption on health (Figure 4, the lower panel).

The evolution of per-capita profiles for broad age groups is presented in Table 7. Between 2004 and 2016 the total public consumption increased for all age groups. The growth of the public consumption of the young generations was higher than the one of the senior generations. As a result, the ratio of the public consumption of the young generations relative to the senior generations increased.

However, when we compare these values to the EU average, we clearly see that despite this increase, the public consumption for all age groups remains below this benchmark. The largest gap is for the senior generations, while the public consumption of young generations is the closest to the EU average. The total per-capita normalised public consumption in Poland is similar to the one observed in Germany, but lower compared to Spain and Sweden. It is also worth noting that the generational ratio of public consumption in Poland is more favourable for the young generations, compared to the values observed in the EU 25 as well as all selected countries.

The gap between the public consumption in Poland and the EU average is larger for health consumption. Regarding the working-age generations it is only slightly above two thirds of the EU average and even less when we compare to Sweden or Germany. The comparison is better for the young generations, as between 2004 and 2016, the ratio of the values for Poland to the EU average in 2010 increased by 15.2 p.p. Also, the senior generations noted the increase of public consumption by 19.8 p.p. As a result, the generational ratio of the public consumption on health, similarly to the total public consumption, is more favourable towards the young generations in Poland compared to the European average, Germany and Spain, but smaller than in Sweden. Between 
2004 and 2016, following the increase of the public consumption on health of the senior generations, the generational ratio in per-capita consumption shifted towards the older generations.

\section{Public consumption}

Per-capita

0.35

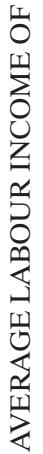

品

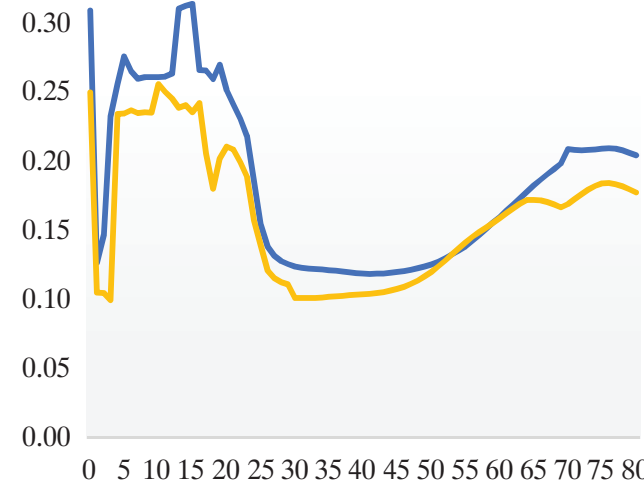

CG per capita CG per capita
Aggregate

0.40

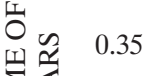

0.30

乙 守 0.25

m

○ิ

0.20

0.15

0.10

0.05

0.00

$0 \quad 51015202530354045505560657075$

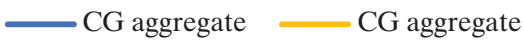

\section{Public consumption on health}

Per-capita

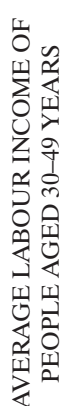

0.25

0.20
0.15
0.10
0.05
0.00

$0 \quad 51015202530354045505560657075$

$\longrightarrow \mathrm{CGH}$ per capita $\longrightarrow \mathrm{CGH}$ per capita
Aggregate

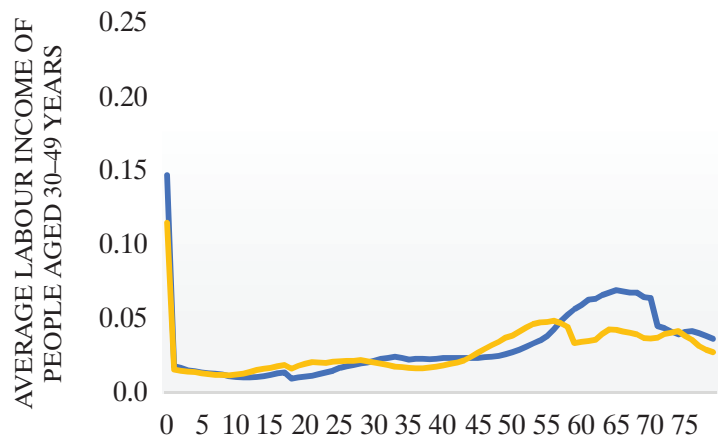

$\longrightarrow \mathrm{CGH}$ aggregate CGH aggregate

Figure 4. Normalised age profiles of public consumption in Poland, 2004 and 2016

Source: Own calculations. 
Table 7. Normalised per-capita public consumption by the broad age groups, Poland vs. selected EU countries

\begin{tabular}{|c|c|c|c|c|c|c|c|c|}
\hline \multirow[t]{2}{*}{ Age group } & \multicolumn{2}{|c|}{ Poland } & EU 25 & DE & ES & SE & \multicolumn{2}{|c|}{$\begin{array}{c}\text { Poland } \\
(\text { EU } 25 \text { average } 2010=100)\end{array}$} \\
\hline & 2004 & 2016 & \multicolumn{4}{|c|}{2010} & 2004 & 2016 \\
\hline \multicolumn{9}{|c|}{ Public consumption (CG) per-capita } \\
\hline all & 12.96 & 14.86 & 16.84 & 14.65 & 16.71 & 19.44 & 77.0 & 88.2 \\
\hline 0-19 & 4.27 & 5.18 & 5.67 & 4.56 & 5.59 & 5.55 & 75.3 & 91.3 \\
\hline $20-64$ & 5.87 & 6.45 & 7.40 & 6.47 & 7.39 & 9.13 & 79.4 & 87.1 \\
\hline $65+$ & 2.82 & 3.24 & 3.77 & 3.61 & 3.73 & 4.76 & 74.7 & 85.8 \\
\hline $0-19 / 65+$ & 1.51 & 1.60 & 1.50 & 1.26 & 1.50 & 1.17 & 100.7 & 106.4 \\
\hline \multicolumn{9}{|c|}{ Public consumption on health $(\mathrm{CGH})$ per-capita } \\
\hline all & 3.0 & 3.5 & 4.5 & 4.8 & 4.8 & 5.0 & 67.3 & 78.0 \\
\hline $0-19$ & 3.05 & 3.54 & 4.53 & 4.79 & 4.81 & 4.96 & 81.1 & 96.3 \\
\hline $20-64$ & 0.49 & 0.58 & 0.60 & 0.66 & 0.61 & 0.77 & 66.9 & 68.3 \\
\hline $65+$ & 1.39 & 1.41 & 2.07 & 2.25 & 2.19 & 2.28 & 63.2 & 83.0 \\
\hline $0-19 / 65+$ & 0.41 & 0.37 & 0.32 & 0.35 & 0.30 & 0.40 & 128.4 & 115.9 \\
\hline
\end{tabular}

Relative to average labour income of people aged 30-49

Source: Own calculations.

\section{Public transfers inflows}

Apart from the public consumption, individuals also receive public cash transfers, mainly in the form of pensions as well as other cash benefits that finance consumption, particularly of the senior generations. When we account for all public transfers, there is a significant shift towards the senior generation, which is indicated by the generational ratio. While the evolution of the public transfers for the young generations is mainly explained by the developments of public consumption for education and care, the changes for the working-age and senior generations are also driven by public policy regulations related to cash transfers. Increased public transfer inflows towards the working-age people in 2016 (between ages 26 and 45) is explained by the introduction of the new universal family 500+ benefit for families with at least two children below age 18, from April 2016. In the case of the senior generations, there is an observable downward shift of public transfer inflows between ages 50 and 69, which indicates delayed take up of pension benefits. This can be contributed to the increases in legal and effective retirement age (Chłoń-Domińczak, 2019). 
Per-capita

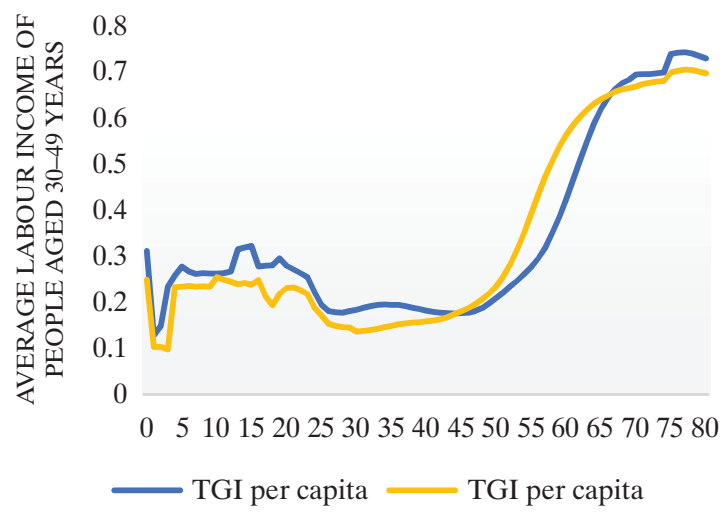

Aggregate

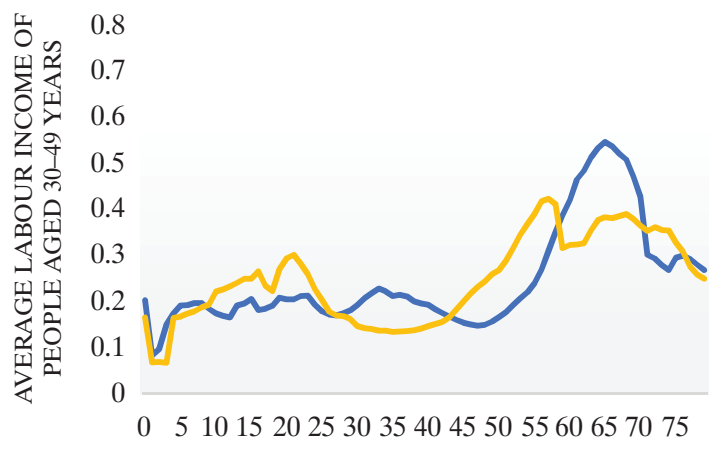

TGI aggregate TGI aggregate

Figure 5. Normalised age profiles of public transfer inflows in Poland, 2004 and 2016

Source: Own calculations.

Changes of the aggregate age profile of public transfer inflows in the analysed period show that with ageing of the post-war baby boom generations the peak of these inflows shifted from age 57 in 2004 to age 65.

Summarised per-capita public transfer inflows for all age groups in Poland in both analysed years are between 27- and 28-times average labour income of people aged 30-49 (Table 8). The per-capita public transfers received by the young generations are around half of those received by the senior generations. In 2016, this ratio in Poland (0.47) was below the EU average (0.52), but similar to the ratio in Germany and Sweden. The total public transfer inflows for all age groups are below the EU average, with the gap smallest for the senior generations and largest for the working-age generations. The distribution of public transfer inflows by generations in Poland is similar to the one observed in Germany, while in Spain and Sweden the public transfer inflows are relatively higher.

Table 8. Normalised per-capita public transfer inflows by the broad age groups, Poland vs. selected EU countries

\begin{tabular}{|l|r|r|r|r|r|r|r|r|}
\hline \multirow{2}{*}{ Age group } & \multicolumn{2}{|c|}{ Poland } & EU 25 & \multicolumn{2}{c|}{ DE } & ES & SE & \multicolumn{2}{c|}{ Poland } \\
\cline { 2 - 10 } & $\mathbf{2 0 0 4}$ & $\mathbf{2 0 1 6}$ & \multicolumn{3}{c|}{$\mathbf{2 0 1 0}$} & $\mathbf{2 0 0 4}$ & $\mathbf{2 0 1 6}$ \\
\hline all & 27.12 & 27.78 & 31.18 & 27.53 & 29.65 & 32.18 & 87.0 & 89.1 \\
$0-19$ & 4.31 & 5.30 & 6.01 & 4.86 & 5.77 & 5.89 & 71.7 & 88.2 \\
$20-64$ & 11.95 & 11.28 & 13.55 & 11.80 & 12.95 & 14.04 & 88.2 & 83.3 \\
$65+$ & 10.86 & 11.19 & 11.62 & 10.87 & 10.94 & 12.25 & 93.5 & 96.3 \\
$0-19 / 65+$ & 0.40 & 0.47 & 0.52 & 0.45 & 0.53 & 0.48 & 76.7 & 91.6 \\
\hline
\end{tabular}

Relative to average labour income of people aged $30-49$ years

Source: Own calculations. 
Concluding the consumption assessment, the analysis of the NTA age profiles clearly shows that while the total consumption in Poland gradually converges to the European average (relative to labour income of those aged 30 to 49), the public consumption and public transfers remain below the EU average. This shows that the welfare state in Poland is still less developed compared to the representatives of the European countries: Germany, Spain and Sweden, and it is significantly distant in particular from the most generous Scandinavian model. The evolution of per-capita age profiles indicates that there is a shift towards a higher share of consumption of the senior generations, particularly between 2004 and 2012, while this trend slightly reversed in 2016. Furthermore, the consumption gap between Poland and the EU average declines regarding both the total and public consumption.

\section{Labour income}

The normalised per-capita age profiles of labour income show that between 2004 and 2016, there was an increase of the labour income of people aged 40 year or over, relative to the average income of people in age group 30-49. This indicates extending working lives and later retirement due to the increased retirement age and limitation of early retirement routes in Poland (Figure 6, the left panel), which was also reflected in later take up of pensions, as discussed in the previous section. As a result, there is a visible increase of earnings of those in the working age, but also for people aged 65 and over. There are also changes of the aggregate labour income age profile - from the bimodal shape with two humps: lower for those in age group around 30 and larger for people in mid-40s to the curve with one maximum for generations in their mid-30s. This illustrates the impact of the changing age structure, in particular shifting the post-war baby boom cohorts from working generations to senior generations (Figure 6, right).
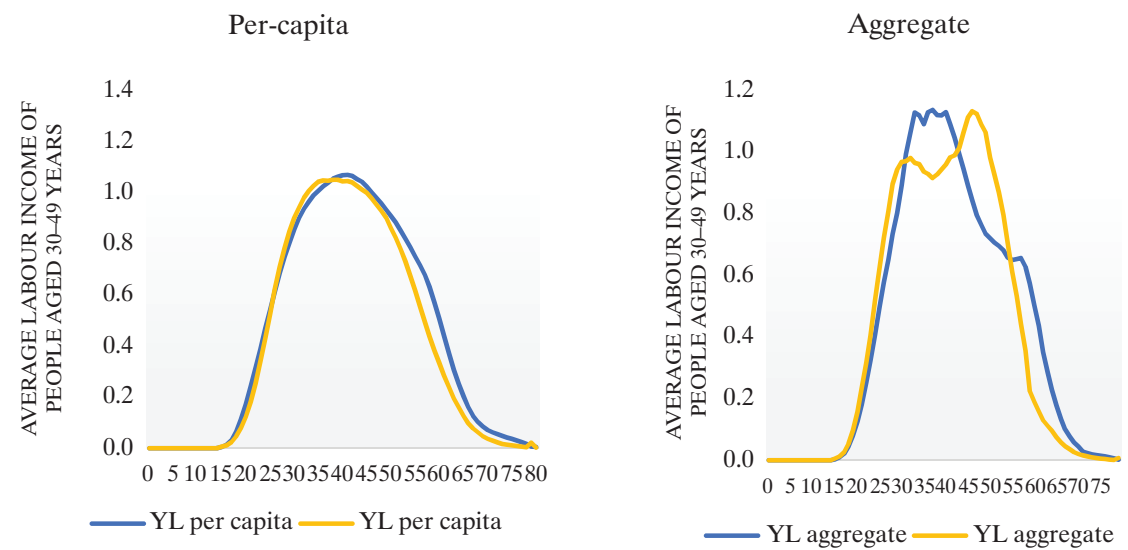

Figure 6. Normalised age profiles of labour income in Poland, 2004 and 1016

Source: Own calculations. 
The observed shifts in the per-capita profiles make them more similar to the EU average of 2010, as our reference point (Table 9). However, labour income of those in working age in 2016 still remains below the EU average and much below the values observed in Sweden in 2010. It is also worth noting that labour income of the youngest group (0-19) in Poland also remains below the EU average, which can be explained by the organisation of the educational system in Poland, with the lower share of dual education system, compared particularly to Germany or Sweden. As a result, the young people in Poland enter the labour market once they complete their education, usually after they turn 18 or above. The most important change in the age profile can be noted in labour income of people aged 65 and over. While in 2004 their income was much below the EU average of 2010, in 2016 it exceeded this benchmark. There is also a convergence of labour income of those aged 20-64 towards the EU average, however, it remains below the values observed in Sweden, Spain and Germany.

Table 9. Normalised per-capita labour income by the broad age groups, Poland vs. selected EU countries

\begin{tabular}{|c|c|c|c|c|c|c|c|c|}
\hline \multirow[t]{2}{*}{ Age group } & \multicolumn{2}{|c|}{ Poland } & EU 25 & DE & ES & SE & \multicolumn{2}{|c|}{$\begin{array}{c}\text { Poland } \\
(\text { EU } 25 \text { average } 2010=100)\end{array}$} \\
\hline & 2004 & 2016 & \multicolumn{4}{|c|}{2010} & 2004 & 2016 \\
\hline Total & 33.1 & 35.7 & 37.0 & 37.3 & 37.8 & 40.8 & 89.6 & 96.6 \\
\hline 0-19 & 0.2 & 0.2 & 0.3 & 0.4 & 0.2 & 0.4 & 54.8 & 75.4 \\
\hline $20-64$ & 32.4 & 34.4 & 35.7 & 36.2 & 36.7 & 38.9 & 90.7 & 96.5 \\
\hline $65+$ & 0.6 & 1.1 & 1.0 & 0.8 & 0.9 & 1.5 & 58.1 & 108.1 \\
\hline
\end{tabular}

Relative to average labour income of people aged $30-49$ years

Source: Own calculations.

\section{Lifecycle deficit}

Between 2004 and 2016, the normalised per-capita age profile of lifecycle deficit (LCD) did not change much (Figure 7), with notable exception of people between ages 47 and 67, in which there is some decline in the lifecycle deficit as well as increase of the lifecycle surplus, caused by the extended working lives and postpone retirement. As a result, the total number of years with the LCD surplus (that is labour income exceeding the total consumption increased from 26 years (from age 24 to 57) in 2004 to 30 years (from age 27 to 57) in 2016. The evolution of the aggregate profiles shows that the declining number of people aged 0-19 led to the smaller aggregate LCD for the young generations in parallel to the higher aggregate LCD for the senior generations, which size increased. 
Per-capita

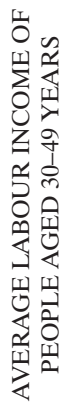

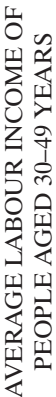

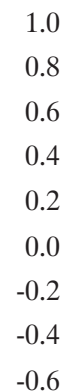

$0 \quad 5101520253035404550556065707580$

LCD per capita

LCD per capita
Aggregate

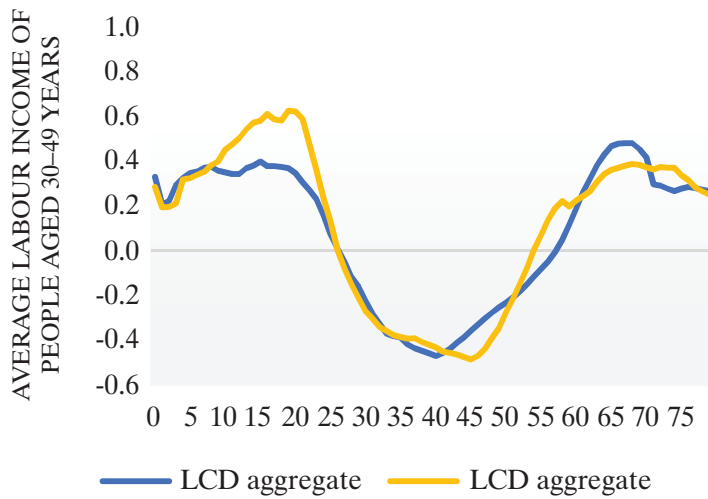

Figure 7. Normalised age profiles of lifecycle deficit in Poland, 2004 and 1016

Source: Own calculations.

Table 10 shows the normalised per-capita lifecycle deficit (LCD) in Poland for the broad age groups to the EU average, Germany, Spain and Sweden. The values from 2016 for Poland are similar to the EU average, after the increase of lifecycle surplus for the generations 20-64 observed in 2016. The LCD of the young generations relative to wages, is smaller in Sweden and Germany while for the working-age generations lifecycle surplus is larger in these two countries. Furthermore, the normalised LCD of the senior generations is lower in Sweden. The boundaries of the LDC economically active age in Poland are becoming similar to the EU average due the increase of the upper limit in 2016. However, the upper limit is still below the one observed in Germany, Spain or Sweden.

Table 10. Normalised per-capita lifecycle deficit by the broad age groups, Poland vs. selected EU countries

\begin{tabular}{|c|c|c|c|c|c|c|c|c|}
\hline \multirow{2}{*}{ Age group } & \multicolumn{2}{|c|}{ Poland } & EU 25 & DE & ES & SE & \multicolumn{2}{|c|}{$\begin{array}{c}\text { Poland } \\
(\text { EU } 25 \text { average } 2010=100)\end{array}$} \\
\hline & 2004 & 2016 & \multicolumn{4}{|c|}{2010} & 2004 & 2016 \\
\hline \multicolumn{9}{|c|}{ Lifecycle deficit } \\
\hline all & 16.77 & 15.61 & 15.71 & 11.41 & 15.04 & 5.35 & 106.8 & 99.3 \\
\hline 0-19 & 9.49 & 10.34 & 10.87 & 9.00 & 11.11 & 9.10 & 87.3 & 95.1 \\
\hline $20-64$ & -3.74 & -5.44 & -5.78 & -8.70 & -6.43 & -12.72 & 64.6 & 94.2 \\
\hline $65+$ & 11.02 & 10.71 & 10.62 & 11.11 & 10.37 & 8.96 & 103.8 & 100.9 \\
\hline \multicolumn{9}{|c|}{ Economic active age (boundaries of the negative LCD) } \\
\hline Low & 27 & 27 & 27 & 27 & 27 & 27 & & \\
\hline High & 53 & 57 & 57 & 59 & 59 & 63 & & \\
\hline \multicolumn{9}{|c|}{ Economic dependency rate } \\
\hline young & 0.35 & 0.34 & 0.34 & 0.28 & 0.34 & 0.25 & 102.7 & 100.8 \\
\hline old age & 0.44 & 0.35 & 0.34 & 0.33 & 0.31 & 0.22 & 130.8 & 105.0 \\
\hline Total & 0.78 & 0.69 & 0.67 & 0.61 & 0.65 & 0.47 & 116.7 & 102.9 \\
\hline
\end{tabular}

Relative to average labour income of people aged 30-49

Source: Own calculations. 
Changes in the aggregate lifecycle deficit implied also some shifts in the economic dependency rate, which is defined as a ratio of aggregate lifecycle deficit of generations below and above the economically active age to the aggregate labour income (as proposed by Loichinger et al., 2017). The total economic dependency rate in Poland in 2016 was lower than in earlier years, which results from both the declining young economic dependency and the declining old-age dependency. The decline in the economic old-age dependency rate is the joint outcome of the increase of the economic activity age and the increase of labour income of people aged 50 years and over, that can be attributed to the rising retirement age. Despite these improvements, the economic dependency in Poland remains still above the 2010 level in Spain, Germany and particularly in Sweden and close (but above) EU the average.

\section{Conclusions}

The application of the National Transfer Accounts approach to analyse changes of the generational distribution of labour income, consumption (including the public and lifecycle deficit (LCD) in time provides a useful framework to assess the shifts in the generational balance under the remarkable changes in both economic and social developments as well the population age structure in Poland after 2004. The estimated per-capita age profiles of the NTA components and their aggregates, considered also for the broad age groups reflecting the young, working-age and senior generations respectively, allow for in-depth insights into evolving generational distributions, including responses to the research questions that were formulated in the introduction.

With regards to the first research question, we see that the generational distribution of lifecycle deficit and consumption were affected by economic, social and demographic changes. The dynamic economic growth led to the increase of major aggregates of national accounts, most notably consumption and labour income. The decomposition of the national accounts aggregates revealed that the total changes in the aggregate consumption, labour income, but also the lifecycle deficit derived from the NTA approach between 2004 and 2016 were affected mainly by the wage growth and shifts in per-capita age profiles. The population change itself would lead to a decline of both consumption and labour income would decline in real terms, the former more than the latter. The changing age structure would also lead to the increase of the total aggregate lifecycle deficit. The potential demographic impact was reversed by growing wages and evolving age profiles of labour income and consumption.

We have also shown that intergenerational transfers evolved with the changes in the public policies as well societal preferences and behaviours that shape private consumption and intra-household transfers. The growth of public cash transfer inflows was faster than the public consumption, which indicates the increasing relative generosity of the social policies associated with cash transfer payments. This means that with the economic growth, there is an increased capacity of the welfare state to provide public transfers, particularly to the population groups that require support - the young and senior generations. 
The changes in the generational distribution of lifecycle deficit are under impact of shifts in the population age structure, as the per-capita LCD of younger generations slightly increased, while for the senior generations it declined. This means that the demographic developments affected mainly the age structure of the LCD and not its size, which is mitigated by the changes of the per-capita age profiles.

With regards to the second research question on the convergence of the outcomes of public policies in Poland to a particular type of welfare state in Europe, we observe that the slow reduction of the observe differences to EU average, Germany and Spain, while the distinction compared to Sweden remains. This confirms the conclusions of (Chłon-Domińczak et al., 2019) who show distinct public transfers in the Scandinavian countries (including Sweden), compared to the largest group of countries, that includes Germany, Spain and Poland.

The age distribution of total consumption in Poland becomes similar to the EU-25 average, but also quite similar to Spain, particularly in the case of young generation. There is also a gradual reduction of the gap in public consumption between the EU average and Poland for all generations. The total public consumption, particularly of the young and senior generations, became closer to the EU average, and similar to the ones observed particularly in Spain, but still lower compared to those in Sweden. The consumption part that increased the most in the analysed period is the aggregate health consumption. The increase of per-capita consumption, particularly at older ages, led to a total increase by 30 p.p. in the case of public consumption and 40 p.p. in the case of private consumption on health. This is similar to the developments observed in other counties, such as the US or Sweden. With the technical progress and population ageing, the per-capita public consumption on health rises mainly for the pre-natal and post-natal health services as well as for those aged 65 and over. With population ageing progressing, it can be expected that this trend is most likely to continue. While the gap in the public consumption in health declined, particularly for the young and senior generations, it is still below the levels in the European countries. This indicates that in the future there might be a further pressure to increase per-capita public health consumption of the senior generations.

Another convergence that we observe is the extension of the boundaries of the economically active age. While the lower age limit remained similar to the other countries in Europe compared here, the upper age limit increased. However, it remains still below the EU average, Spain and Germany and, in particular, Sweden (63 years).

Finally, with regards to the third research question related sustainable evolution of the economic dependency in the future with progressing population ageing, our findings indicate that there were some developments that can support the stability of the economic dependency of the non-active population. We have shown that the growth of the aggregate lifecycle deficit caused by the population ageing in Poland was significantly mitigated by the evolution of the per-capita age profiles, including higher growth of labour income and relatively lower growth of consumption. If the direction of these developments were maintained in the future, Poland would be able to slow down the growth of the aggregate lifecycle deficit, despite the progress in population ageing. This 'opportunity window' 
is conditioned on labour income growth being faster than consumption increase. The policy regulations implemented until 2016, particularly related to increasing effective retirement age, were conducive to such developments. Unfortunately, the 2017 regulation on a withdrawal from the higher retirement age can lead to a slower growth of labour income, and in turn impact the faster increase of the aggregate lifecycle deficit in the future.

Our findings indicate that the important role in mitigating the growth of the aggregate lifecycle deficit is played by the labour income at all ages, including the fast transition of young people to economic activity, but most importantly postponed transition to inactivity at older ages. Therefore, it is important to pursue policies that increase per-capita labour income, through investment in human capital and productivity. One of the important conclusions that can be drawn from our analysis is that with the increased consumption on health, the expenditure on public (and private) education declines, which may have an impact on the development of human capital in the future.

This is potential risk for implementing policies aiming at raising labour income at all ages, particularly of those in age groups 50 and over. The increased per-capita labour income, combined with slower growth of the consumption, can contribute to sustaining the generational balance in the future, despite advances in population ageing.

\section{References}

Auerbach, A. J., Gokhale, J., \& Kotlikoff, L. J. (1991). Generational Accounts: Meaningful Alternative Accounting. Tax Policy and the Economy, 5(1991), 55-110.

Chłon-Domińczak, A. (2019). Impact of retirement age changes on the old-age pension take up in Poland after 1990. Ubezpieczenia Spoteczne. Teoria i Praktyka, (4), 1-25.

Chłoń-Domińczak, A., Abramowska-Kmon, A., Kotowska, I. E., Lątkowski, W., \& Strzelecki, P. (2019). Welfare state and the age distribution of public consumption and public transfers in the EU countries. Vienna Yearbook of Population Research, 17, 71-97. https://doi.org/10.1553/populationyearbook2019s071

d'Albis, H., Bonnet, C., Navaux, J., Pelletan, J., Toubon, H., \& Wolff, F. C. (2015). Lifecycle deficit in France, 1979-2005. Journal of the Economics of Ageing, 5, 79-85. https:// doi.org/10.1016/j.jeoa.2014.09.005

Diamond, P. (1996). Generational Accounts and Generational Balance: an Assessment. National Tax Journal, 49(4), 597-607.

Esping-Andersen, G. (1990). The Three Worlds of Welfare Capitalism. Princeton University Press.

Friedman, J. H. (1984). A variable span smoother. Laboratory for Computational Statistics, Department of Statistics, Stanford University: Technical Report(5).

Istenič, T., Hammer, B., Šeme, A., Lotrič Dolinar, A., \& Sambt, J. (2016). European National Transfer Accounts, http://www.wittgensteincentre.org/ntadata

Lee, R., \& Mason, A. (2011). Population Aging and the Generational Economy. A Global Perspective. Edward Elgar Publishing Limited. 
Lee, R., \& Mason, A. (2019). Analyzing population ageing and intergenerational redistribution: NTA and AGENTA. Vienna Yearbook of Population Research, 17, 1-5. https:// doi.org/10.1553/populationyearbook2019s001

Lindh, T., Oeberg, G., \& Sanchez-Romero, M. (2011). Backcasting National Transfer Accounts in Sweden from 1800 to 2009, 1-5, https://www.ntaccounts.org/doc/repository/Thomas, Gustav and Miguel.pdf

Loichinger, E., Hammer, B., Prskawetz, A., Freiberger, M., \& Sambt, J. (2017). Quantifying Economic Dependency. European Journal of Population, 33(3), 351-380. https:// doi.org/10.1007/s10680-016-9405-1

Statistics Poland. (2018). Methodological report. Household budget survey. Warsaw.

United Nations Department of Economic and Social Affairs Population Division. (2013). National Transfer Accounts Manual: Measuring and Analysing the Generational Economy. 


\title{
Tomasz Mering
}

ORCID: 0000-0002-5091-9520

Faculty of Political Science and International Studies, University of Warsaw ${ }^{1}$

\section{Activation and new governance of labor market policies in Central and Eastern European Countries}

\begin{abstract}
The essential feature of activation turn in labor market policy in Western European countries is reform of the labor administration, which affects the provision and delivery of the policy. The principles underlying governance reforms include decentralization and strengthened coordination, which help to reconcile local flexibility with the national ownership of the active labor market policy. However, few articles examine how these reforms are implemented in Central and Eastern European countries. The activation turn and territorial reforms there took place later than in Western European countries and possibly followed a different trajectory. Based on various materials, including legal acts, public employment services reports, expert releases, and others, the article traces the activation policies' reforms and their impacts on the organizational arrangements in Latvia, Hungary, and Poland. The findings show that some organizational arrangements of the national PES in countries covered in this study predate the accession to the EU. The critical governance characteristics seem to be affected by the general administration reforms. Public employment services in the three countries have different levels of vertical

${ }^{1}$ Correspondence: Wydział Nauk Politycznych i Studiów Międzynarodowych/Katedra Metodologii Badań nad Polityką, Uniwersytet Warszawski, Krakowskie Przedmieście 26/28, 00-927 Warszawa; email: tomasz.mering@uw.edu.pl
\end{abstract}


specialization, which determines the scope of reforms carried out in subsequent years. Further research should take into account the challenges of vertical coordination of the active labor market.

Key words: activation, governance, decentralization, coordination, autonomy

The activation turn has been one of the most significant social welfare and labor market policy reforms in the United States and Western European countries since the 80s (López-Santana, 2015). The transformation towards active labor market schemes changed both the 'demanding' and 'enabling' policy instruments. The social protection support for the unemployed and economically inactive people of working age became less generous and more conditional. Simultaneously, the introduction of investments in job-seekers' skills in training, vocational guidance, individual counseling, and others improved their employability (Eichhorst \& Konle-Seidl, 2008). A hallmark of reforms was the changing ratio of active and passive labor market policy expenditures in favor of the former (OECD, 2021).

The activation altered the policy content and the organization of active labor market programs, leading to profound changes in governance structures and arrangements. Nowadays, providing activation services and income support is a task of multiple organizations from both the public and non-public sectors acting at the national and subnational levels. New modes of governance include implementing new public management instruments to increase the labor market programs' efficiency. Strengthening the interagency cooperation and partnership between public sector organizations (i.e., public employment services and social assistance administration) and other services providers is also an essential feature of governance reforms (van Berkel et al., 2011). Activation also resulted in the territorial reorganization of the welfare administration state and decentralization, but Public Employment Services (PES) remain the leading actor in employment policy. PES, which match labor force and demand on the labor market through various instruments, including job placement, vocational counseling, and active support measures, are considered to be authorities or government institutions, which act at local and national levels. However, when studied in detail, it turns out that organizational arrangements in which PES operate significantly differ between countries.

\section{Organizational models of Public Employment Services}

The main aspects of the contemporary Public Employment Services' organizational model are autonomy, decentralization, and management structures, including coordination measures (Manoudi et al., 2014).

Autonomy usually refers to the judicial status, i.e., whether PES are executive agencies or independent public bodies. In the latter case, the PES is not a part of the ministry's organizational structure (or department) and has its own governing body (European 
Commission, 2020). In other words, the independent body might be supervised by the ministry, but it is not a part of the government department (Manoudi et al., 2014). The level of autonomy of the PES regarding national governments has profound consequences for the flexibility of Active Labor Market Policies. Greater independence of the PES can facilitate quick changes to its working model, which is essential in turbulent times such as recession or the last COVID-19 crisis (Lauringson \& Lüske, 2021). On the other hand, a system with high PES autonomy requires a complex accountability framework and coordination measures to adjust ALMP to changing national priorities.

Recently OECD has offered a detailed framework to compare and classify the institutional set-up of active labor market policy (Lauringson \& Lüske, 2021). It distinguishes five PES organizational models, ranging from very low independence to a very high degree of autonomy. These models are as follows:

- National PES that are part of a ministry (very low degree of autonomy)

- National PES that are not directly part of a ministry but are fully managed by a ministry (low degree of autonomy).

- National PES that have a tripartite management body (medium degree of autonomy);

- Sub-national PES with a national coordinating agency (high degree of autonomy)

- Sub-national PES with no national coordinating agency (very high degree of autonomy). The majority of the EU countries represent an organizational model of Public Employment Services with a low or medium level of autonomy. This group consists of seventeen countries representing different social policy regimes and different systems of territorial units. However, we can see the significant presence of countries with the conservative-corporatist welfare state regime, such as Austria, Germany, and France, all above with a medium level of autonomy. Countries in that group are mainly unitary (notable examples here would be Sweden and France), but there are also examples of federal states such as Austria and Germany. In five EU countries (Cyprus, Luxemburg, Finland, Hungary, Ireland), public employment services are entirely integrated into the ministry, marking a very low degree of autonomy. The PES is organized as a national executive agency in next eight countries and fully managed by a ministry. This organizational set-up leaves a low degree of autonomy for the agency implementing ALMPs regarding the national government. The last two groups include countries in which the responsibilities to implement ALMPs lie within regional or local governments, which enjoy a significant level of independence in respect to the national government. This is a case in countries that have sub-national Public Employment Services (i.e., employment offices managed by a local or regional government) either with a national coordinating agency (Denmark, Spain, Italy) or subnational PES without a national coordinating agency (Belgium and Poland).

Decentralization, which is the second important feature of contemporary public employment services, changes intergovernmental relations as it shifts responsibilities for the state's labor market policy. In the last two groups of countries, decentralization is the most profound as local and regional government is responsible for the most of tasks in labor market policy implementation and design. However, decentralization takes place in 
other countries too, as it is one of the most important features of management structures of public employment services.

Public policy literature shows that we can distinguish between political (devolution), administrative and financial types of decentralization (Schneider, 2006). Devolution is a situation in which the central government gives territorial authorities (regional or local) power to pass the law specifying access to activation services and support forms. Since there are only unitary states in Central and Eastern Europe, this type of decentralization of labor market policy does not occur. Financial decentralization includes both the income and expenditure side, but this article looks mainly at shifts in responsibilities to finance ALMP. Administrative decentralization refers to the formal transfer of responsibilities in the organization, management, and implementation of the active labor market policies. It seems that this type of decentralization occurs most often in the context of active labor market policies. Administrative decentralization covers the overall service delivery process, including regulating organizational structures and work processes within public employment services. However, we can distinguish here some additional critical dimensions or administrative decentralization 'components' (Mosley, 2011; Weishaupt, 2014).

Subnational PES entities may have the power to adjust or reframe the centrally designed policy programs to local circumstances. In the most extreme instances here, the subordinate units would enjoy the possibility to develop their own strategies. On the other end of the spectrum, local employment offices may have to fulfill centrally defined targets and priorities with no or limited flexibility. Secondly, a key element is whether local, regional (or both) units are free to allocate financial resources between budget lines for activation policy. Sub-national units of public employment services may have global budgets and, therefore, decide how to use their financial resources. In other countries, local and regional units may have limited or no budget flexibility (Mosley, 2011; Weishaupt, 2014). This article looks mainly at the level of administrative and financial decentralization of the sub-national public employment services. In the analysis section of the text, we will screen whether and possibly to what extent local and regional actors have a program, delivery, and budget flexibility.

Since labor market policy remains a national priority in the majority of countries, it requires national coordination. Horizontal coordination depends on a partnership approach and intensity and quality in the involvement of social partners. The work of coordination bodies and structures is crucial for the institutionalization of cross-policy field coordination and holistic governance, which, for instance, can create one-stop institutions at the local level (Dingeldey et al., 2017). Vertical coordination usually takes the form of performance management (or management by objectives - MBO) schemes (Weishaupt, 2014). The ministry of labor (or PES headquarters) sets overall goals and operational targets, which are then adjusted to local labor markets' situations. Sub-national units have a varying degree of flexibility on how to achieve centrally agreed targets. We can distinguish two broad models of management by objective in Public Employment Services: the output or outcome-oriented model where performance is assessed against targets and the input-oriented model with more focus on controlling the adherence to detailed rules, 
regulations, and procedures (Mosley, 2011). The first one mentioned above emphasis ex-post coordination and control. It looks at whether subordinate units have accomplished the desired goals and whether it is necessary to conduct corrective actions. The typical elements of output-oriented coordination are objective setting, monitoring, evaluation, and sanctions (Verhoest et al., 2005). The second one emphasis ex-ante coordination and control. It usually incorporates input measures such as level of spending or number of staff employed in local public employment services (Nunn, 2012).

Performance management is not the only coordination mechanism that we can find in public employment services. Building on public organization literature (i.e., Verhoest et al., 2007), we can conclude the persistence of a more traditional, i.e., structural coordination mechanism in the PES operations, which allows the head (or the ministry) to influence the decisions of the subordinate unit through strict hierarchical lines. Structural instruments include the possibility of a reshuffle of competencies and lines of control, conducting organizational mergers, splits, and other organizational measures.

\section{Labor market policies and governance reforms in CEE Countries}

During the 1990s, all the CEE countries changed their centralized, command economies to the free-market system. The transition came at a high cost as the whole region had to cope with an economic crisis, a severe decline of income, inflation, and an increase in unemployment. In response to the social problems, many countries developed initial policy responses, including, among others, unemployment benefit schemes and social assistance provisions. In the following years, we saw further development of social policy programs, and many scholars started to trace the emergence of new welfare states in Central and Eastern Europe (Aidukaite, 2010).

While there is a broad agreement that CEE countries share some common features like lower social protection expenditures than Western European countries, it is debatable whether they form a distinctive social policy model. Alfio Cerami defined the existence of the CEE welfare model on three elements: pre-communist legacy (Bismarckian social insurance), communist legacy (universalism, corporatism, and egalitarianism), and post-communist trajectory of reforms towards market-based schemes and solutions (Cerami, 2006). Tomasz Inglot revealed in his study that due to distinct and profound institutional and political legacies, Visegrad countries (Czech Republic, Hungary, Poland, Slovakia) developed heterogeneous social policy institutions, however with a strong Bismarckian characteristic (Inglot, 2008). In a more recent study, Kati Kuitto neglects the emergency of a single model CEE welfare state and provides information on differing hybrid models of social policies in post-communist countries (Kuitto, 2016). Although the main organizational feature of CEE welfare state regimes is their Bismarckian blueprint, the output of social policies differs in terms of the level of social protection. In general, CEE countries spend less than old member states of the EU. Still, some countries are even less generous, especially concerning the expenditures for unemployment benefits (i.e., Hungary, Lithuania, Poland, and Slovakia). 
Markus Ahlborn, Joachim Ahrens and Rainer Schweickert demonstrated that Central and Eastern European countries' economic systems cluster into two broad groups (Ahlborn et al., 2016). The first one shares many common features (i.e., limited social spending and a relatively higher degree of inequality) with the liberal model and consists of six countries (Bulgaria, Estonia, Latvia, Lithuania, Romania, and Slovakia). The remaining four CEEC countries (Czech Republic, Hungary, Poland, and Slovenia) share many institutional characteristics with the Continental model with a more generous social spending and focus on income equality.

Initially, the labor market policy consisted mainly of passive measures, including benefits for the unemployed and social security compensation, primarily for older workers (Deacon, 2000). Compared to the OECD countries, spending in labor market policies (especially in ALMP) in the CEEC region was reasonably low through the 1990s and 2000s. The situation started to change after the accession to the EU; however, the following years revealed essential differences across countries, i.e., Poland in 2004 spent a share of its GDP that was three times higher that spent by Latvia on ALMP.

All CEE countries have adopted measures similar to those in other OECD countries. However, when we look closer at those policy instruments, it turns out that they differed significantly in terms of benefit, coverage, and duration of their programs (Ribound et al., 2002). The ALPM consisted of various programs, including job search assistance and counseling, training for the unemployed, employment subsidies, direct job creation, and special programs for disadvantaged groups on long-term unemployed. Countries in the region had adopted similar organizational arrangements for LMP at the beginning of the 1990s, but the situation started to change in the following years. Nevertheless, we can trace both some common characteristics and across CEE countries regarding their ALMP.

The capacity of the Active Labor Policies system is moderate compared to Western European countries. The level of expenditures on placement and related services per unemployed person as a percentage of GDP per capita, which indicates staff levels and caseloads in the employment services was in 2018 shallow (i.e., the indicator's value was less than 1\%) in five countries (Romania, Latvia, Bulgaria, Lithuania, Slovakia). PES capacity was moderate (less than 3\%) in four countries (Poland, Slovenia, Hungary, and the Czech Republic) and only high in Estonia (3,5\%) (Lauringson \& Lüske, 2021).

In most CEE countries, public employment services have low or very low autonomy, with a government closely supervising and leading the majority of their task. In six countries, the PES is either a department of the ministry or forms a state agency fully managed by a ministry. Only in three countries PES have a tripartite management body, and therefore a medium level of autonomy.

The organizational model of public employment services remains also centralized in CEE region. Poland is the only country with sub-national PES (employment offices managed by the local and regional government) without a national coordinating agency.

Although we can acknowledge the essential characteristic of organizational models of Active Labor Policies in Central and Eastern European countries, we know less about the trajectory of their governance reforms, which started after the collapse of the communist 
system. Thus, the dominant question is whether the institutional setups changed due to the activation of labor market policy, or their core features stayed relatively intact. In the old EU member states, the drive towards the activation of jobseekers produced profound institutional changes. For instance, in 2014 in Belgium, the regional PES received more power regarding the implementation of ALMP to raise their efficiency. Germany had even a more radical transition in the early 2000s marked by Hartz Commission reforms, which sought to make the German labor market more effective and labor administration more efficient (Finn \& Peromingo, 2019).

To study governance changes in the CEE countries, we use the OECD typology of public employment organizational model, which will help us to track whether the major governance reform took place or not (for instance, from low to medium level of autonomy). Then, drawing on various materials, including legal acts, documents published by public employment services, expert reports, and others, we shall screen other possible changes, including decentralization and usage of coordination measures within a given organizational model.

Considering the 'hybrid' nature of CEEC's social policies and different organizational settings of ALMPs, we decided to include three countries in our study. First, Latvia is an example of the liberal CEE model based on welfare state spending and income inequality indicators. At the same time, Latvia's PES represents a low autonomy model, a standard in many countries in the region. Second, we decided to choose two Visegrad countries (Hungary and Poland). Although their share some standard features of the continental economic model, the two countries are very different in terms of their ALMP institutional systems, with very low (Hungary) and very high (Poland) PES autonomy.

\section{Latvia}

Latvia regained its independence in autumn 1991 and soon after implementing 'standard' transformation reforms, which consisted of introducing the market mechanism, the liberalization of prices, and eliminating government subsidies for consumer goods and services (Åslund \& Dombrovskis, 2011). The rise of transformation unemployment lasted until 1996, when the rate of unemployment reached the historical level of 20 percent, and then the situation improved gradually through the next twelve years. The financial and economic crisis of 2007-2008 had a severe impact on the Latvian economy, leading to recession and worsening the situation on the labor market. The unemployment rate rose from 2008 for three consecutive years and peaked again to almost 20 percent in 2010. As the economic recovery has strengthened over the last years, Latvia has seen improvements in the unemployment rate, which stood at 7.41 percent by 2018. As shown in Table 1., Latvia, as the majority of OECD countries in the period 2004-2018, continued to spend the highest percentage of its labor market policy budget on unemployment benefits. The expenditures on labor policy were relatively modest throughout the period, except for 2009-2010 when the number of jobseekers claimants rose dramatically. As far as active measures are concerned, we can see some improvements after 2004 when Latvia 
joined the EU and started participating in the European Social Fund-sponsored programs. However, it seems that 'activation turn' hardly took place in Latvia as the budget of active labor programs stayed on a low level of merely 0.18 percent of GDP in 2018.

In 1991, the Latvian government established the State Employment Service, a civil office under the supervision of the Ministry of Welfare (State Employment Agency (SEA), 2021b). The main goal of the service was to reduce unemployment, support the unemployed and the job seekers. The 1999 reform strengthened the organizational unity of the PES. The government transformed the public employment service into a non-profit association State joint-stock company State Employment Service (the holder of State capital share was the Ministry of Welfare). In October 2003, the government again changed the State joint-stock company into the State Employment Agency, a direct administrative authority. Since 2007, Agency is a part of the government civil service institutions and stays under the close supervision of the ministry of welfare (State Employment Agency (SEA), 2021b). We can see that the public employment service in Latvia enjoys internal integrity and is accountable to the central government. The Support for Unemployed Persons and Persons Seeking Employment Law Act from 2002 stipulates only the Agency's generic tasks. The status of the State Employment Agency is specified in government regulations and can be easily amended when necessary.

The PES organization of Latvia has only two levels: a central body and 28 regional offices, whose managers are subject and accountable to the central management (Kalvāne, 2015). Decentralization is limited, as the financial management, planning, including the design of strategies and targeting, and supporting functions (i.e., accounting, personnel management, and others) are restricted to the head office. The Latvian PES is governed through management by objectives. The ministry sets out policy goals to be implemented by the SEA (State Employment Agency (SEA), 2021a). In 2018 these goals covered improving the transition of the long-term unemployed to employment and supporting people with disabilities in the labor market (State Employment Agency (SEA) [Nodarbinātības valsts aǵentūra], 2019). Based on the goals set, the Agency director determines an annual plan for their implementation and raises assignments for local employment offices. Within regional offices, goals for individual staff members are set up, and performance is assessed quarterly (OECD, 2019). Based on the goals set for employees, priorities for local employment offices are integrated into sets of targets that reflect SEA objectives. Indicators for evaluating the performance of regional offices include a share of unemployed and job seekers engaged in active labor market programs, participation of long-term unemployed in ALMP, and the transition of ALMP participants in employment (Kalvāne, 2015). In setting targets for local offices, differences between regions and the characteristics of the unemployed are taken into account (OECD, 2019). Since the organizational structure of the Public Employment Service is centralized, the structural coordination through influencing the local employment decisions via hierarchical lines towards head office also takes place. 
Hungary

Hungary was a unique country in the region, as the communist party had started economic reforms before the socialist system collapsed (Ẑ́dek, 2014). After the parliamentary elections in spring 1990, the first government not dominated by Communists continued gradual reforms. The country did not avoid the transformation recession, and unemployment rose to $11 \%$ in 1993 and started to decline soon after. However, the unemployment rate in Hungary was low compared to most countries in the region, especially Poland. Unemployment increased again due to the 2008-2010 crisis, reaching 11 percent of the labor force.

Hungary's expenditures on LMP were below an average level among OECD countries (Table 1). They were equal to 0.46 percent of GDP in 2004 and stayed reasonably stable until 2018, except for 2009-2010, in which the expenditures amounted to 0.66 percent of the country's GDP. The size of spending on active and passive measures was similar when the country joined European Union, but in 2012, the former exceeded the latter and stayed on until now. It means that, at least in quantitative terms, the 'active turn' did take place. However, expenditures stayed on relatively low level compared to the OECD average.

Table 1. Spending on Labor Market Policies as a percentage of GDP

\begin{tabular}{|l|l|c|c|c|c|c|c|c|c|}
\hline & \multirow{2}{*}{$\begin{array}{c}\text { Type } \\
\text { of LMP }\end{array}$} & \multicolumn{8}{|c|}{ Spending on LMP } \\
\cline { 3 - 11 } & $\mathbf{2 0 0 4}$ & $\mathbf{2 0 0 6}$ & $\mathbf{2 0 0 8}$ & $\mathbf{2 0 1 0}$ & $\mathbf{2 0 1 2}$ & $\mathbf{2 0 1 4}$ & $\mathbf{2 0 1 6}$ & $\mathbf{2 0 1 8}$ \\
\hline \multirow{2}{*}{ Hungary } & ALMP & 0.23 & 0.24 & 0.22 & 0.31 & 0.24 & 0.36 & 0.36 & 0.31 \\
\cline { 2 - 11 } & PLMP & 0.23 & 0.21 & 0.18 & 0.35 & 0.23 & 0.22 & 0.18 & 0.14 \\
\hline \multirow{2}{*}{ Latvia } & ALMP & 0.12 & 0.24 & 0.12 & 0.56 & 0.23 & 0.19 & 0.19 & 0.18 \\
\cline { 2 - 11 } & PLMP & 0.36 & 0.27 & 0.33 & 0.7 & 0.26 & 0.36 & 0.44 & 0.4 \\
\hline \multirow{2}{*}{ Poland } & ALMP & 0.36 & 0.45 & 0.55 & 0.68 & 0.43 & 0.48 & 0.44 & 0.36 \\
\cline { 2 - 11 } & PLMP & 1.01 & 0.7 & 0.35 & 0.34 & 0.32 & 0.31 & 0.24 & 0.15 \\
\hline \multirow{2}{*}{$\begin{array}{l}\text { OECD } \\
\text { Countries }\end{array}$} & ALMP & 0.52 & 0.49 & 0.45 & 0.58 & 0.52 & 0.53 & 0.52 & 0.48 \\
\cline { 2 - 11 } & PLMP & 0.85 & 0.72 & 0.65 & 0.96 & 0.88 & 0.83 & 0.74 & 0.64 \\
\hline
\end{tabular}

Source: OECD. (2021).

The origins of Hungarian contemporary public employment service lay in the communist period. In 1984 the government established the State Wage and Labor Office with subordinate regional units (i.e., employment county councils and local offices) in a uniform national agency logic (however, without the legal status of agency) (Györgyi, 2018). The communist government took out employment services from the general public administration; therefore, the level of specialization was high, and these organizational arrangements survived the change of economic system. In 1991, the new employment 
act upheld the three-level structure, which consisted of the National Labor Centre (the national tier), the capital, and twenty county centers that formed the regional level and 183 local offices. The county centers and local offices functioned within a single organizational system (but never as a single legal person) under the management of the NLC (Györgyi, 2018). The ministry of labor provided financial resources for the PES operations.

In 1997, the government limited the autonomy of the public employment service. The ministry of labor took over the management of the PES, which has stayed within the general public administration ever since. The PES head office that operated under different names at the beginning of the 2000s was subordinate to the cabinet ministers. Later on, the government made several further amendments in public employment services organization, including, among others, the institutional merger with occupational safety offices and swings concerning the affiliation to the different ministries within the government.

The complete integration of the PES into the general administrative structure took place in 2011. Four years later, the reforms abolished the head office (the National Labor Office) and subordinated the public employment services to different government departments (Hungary: Closure of national employment office | Eurofound, n.d.). The Ministry of National Economy supervised the core functions of the PES. At the same time, the Ministry of Interior governed the public works schemes, and the Ministry of Human Capacities controlled occupational rehabilitation services (the ministry responsible for interior affairs took over later on the responsibility for the social inclusion). These reforms produced a complicated situation in which strategic management was divided between the different government departments without good liaison, which indicated low horizontal specialization. What is more, the supervision and management control of the line ministries over the PES network was weakened by the fact that the Prime Minister's Office controlled the human resources and infrastructure of the PES network.

Viktor Orbán's government (in power since 2010) carried out reforms of the territorial organization of labor administration. The 2011 reform amalgamated the county labor centers and 170 branch offices with county general government offices. Since 2015 the National Employment Service (the new label of Hungarian PES) has been fully integrated into the general government offices both at the county (NUTS3) and micro-region (district level) (ICON Institut Public Sector GmbH, 2015). One-stop shops deliver various active labor market programs and overall support of the unemployed at the grass-roots level by 172 district employment offices, which marks the administrative decentralization. However, the program and financial decentralization are limited as the PES governance structure is highly centralized with a strong power of the prime minister's office and governmental departments. The financial resources for PES come from the (contributionbased) Nation Employment Fund. The subordinate units had no budget flexibility as they cannot move financial resources between the budget lines. The program decentralization is limited as local units were only consulted on the scope of national programs, and they have no power to design their strategies (Weishaupt, 2014). 
Since 2015 the National Employment Service has developed a complicated vertical coordination system that consists of both, i.e., structural and performance management instruments. The district PES units report to the employment department of the county-level offices, but the head of the government at the district level employs their staff. The status of county-level offices is again complex as the government commissioners of counties employ their team, but the head of department reports to the three different government departments (ICON Institut Public Sector GmbH, 2015). The district PES offices are in close cooperation with regional and central management. There are regular reporting and control mechanisms between district and county and between the county and central level on general performance (related to financial/input and output targets) (ICON Institut Public Sector GmbH, 2015). By 2018 the coordination of the active labor policies was fragmented. The part of ALMP measures that the Ministry for National Economy supervised was based on input indicators and targets negotiated between the region (county) and the ministry. On the other hand, the Ministry of Interior that oversaw the public work schemes relied more on top-down input targets.

\section{Poland}

One of the underlying principles of Polish social policy in the communist times was full employment. The participation rates were much higher throughout the whole period than in capitalist countries. The communist economy suffered from a chronic, recurrent labor shortage, threatening the centrally planned economic goals (Kornai, 1992). Job placement remained the primary labor market policy tool since the late 1940s. Labor administration was a part of the communist state bureaucracy. It worked with publicly funded companies and schools using mainly administrative job brokerage measures. Official unemployment of the registered kind was absent, and as a consequence, the unemployment benefit (although the unofficial unemployment has not disappeared).

In 1990, the first post-communist government of Tadeusz Mazowiecki initiated reforms, which rapidly converted the central planning economic model into a free-market system. After introducing the reforms, the situation in the labor market changed abruptly, and the number of claimants registered in the labor offices rose from nothing to 1.2 million in December 1990 and then doubled through the following year. The rise of transformation unemployment lasted until mid-1990s, when the harmonized ILO unemployment rate reached level of 16 percent in 1993. In late 1990s and at the beginning of the 2000s, Polish labor market suffered from stagnation resulting from the Russian financial crisis in 1997 and a subsequent economic slowdown. The situation quickly improved after 2004 due to economic growth after the EU accession and thanks to the labor migration. As shown in Table 1., Poland, as the majority of OECD countries in the beginning of the 2000s, has spent the highest percentage of its labor market policy budget on unemployment benefits. However, the expenditures on labor policy were higher than in Latvia and Hungary. As far as active measures are concerned, we can see substantial improvements after 2004 when 
Poland joined the EU. Since 2008, the size of spending on active measures has exceeded the budget of passive programs and stayed on until now.

The state response to the transformation unemployment was quick. The Act on Employment of 1989 (entered into force on January 1, 1990) established the labor administration, registering claimants and paying out the unemployment benefit. The labor administration was a part of the employment and social affairs departments of regional and provincial offices operating since communist times and, therefore, a general state administration. In 1991, the parliament passed a new law (the Employment and Unemployment Act) that changed the PES status to a specific governmental labor administration, which acted in agency-like logic. The Public Employment Services formed a three-level system in which national headquarters coordinated subordinate regional and district labor offices through strict lines of structural control. As we can see, the 1991 reform increased the level of vertical specialization, and the solutions adopted in Poland were similar to those existing at that time in Latvia and Hungary. District offices dealt with registration of the unemployed, payment of benefits, job placement, and implementation of active labor market programs (the latter were limited at that time mainly due to the lack of sufficient financial resources).

The 1998-2000 reform delegated responsibility for labor market policy to regional and local self-government administration. It was a part of a broad decentralization reform of a state. From 1999 a new administrative system includes three authority levels: communal (gmina), county (poviat), and regional (voivodship). Since decentralization, labor market policy has been implemented through 16 voivodship labor offices and 340 poviat labor offices. The minister of labor coordinates the public employment services at all levels. In practice, the governmental coordination proved to be complex as each territorial level is autonomous with no hierarchical relationship (Kalužná, 2009). The Marshal (board chairman) of the voivodship self-government director employs the director of the regional labor office. The mayor (again, board chairman) of the poviat self-government appoints the director of the county labor office. The changes introduced in 1999 brought a comprehensive reform of the public employment services in Poland. A horizontal system has emerged in place of vertical accountability, contributing to the fragmentation of regional and local labor market policies (Baron-Wiaterek, 2008). The system shift was stable as amendments that came into force in the following years, including the adoption of a new law in 2004 (act on the promotion of employment and labor market institutions) did not change the core characteristics of the PES organization.

Since 1999, Poland represents a decentralized model of the labor market. Administrative decentralization occurs as county labor offices took responsibility for the organization, management, and implementation of the active labor market policies. They register the unemployed and job seekers, initiate and organize labor market services and instruments, and grant unemployment-related benefits. There are national regulations on the eligibility criteria for active labor policy are. However, local labor administration enjoys the discretionary power to choose between different policy instruments in specific target groups, including the tailor-made 'individual plans' for long-term unemployed. 
The LMPs financing comes from the central contribution-based Labor Fund, but local units are relatively free to allocate financial resources between budget lines. Program decentralization also occurs as poviat labor offices design their strategies of employment promotion and activation of the labor market. Vertical coordination consists of both the standardization of labor market services and input-oriented financial planning. However, since 2014, the allocation of funds among local labor offices partially depends on the effectiveness of the ALMP. In the same year, the amendment to the promotion of employment and labor market institutions act introduced regional programs that slightly strengthened the coordination of labor market policy at the voivodship tier.

\section{Summary}

Various studies show that labor market policies had differed across the CEE countries before they acceded to the EU and stayed diverse until now (Csillag et al., 2013; Ribound et al., 2002). However, many scholars confirm that European integration accelerated the labor market reforms in the 2000s and, in general terms, shifted LMPs from more passive-oriented to more active measures (Mailand, 2008). The last one is only partially confirmed by quantitative data. Overall expenditure on labor market policy usually rises when the unemployment rate (and the number of claimants) is high, as it happened in the early 1990s due to the transformation recession and in the economic crisis 2008-2010. Both unemployment benefits and active measures in the CEE countries are financed from the same funds. When unemployment increased, and the fund was on the same level, fewer financial resources remained for active programs. However, spending on active labor market policies was supported after 2004 thanks to the European Social Fund. The Central and Eastern European countries used the ESF to increase the labor market participation rate, reduce structural unemployment, promote lifelong learning, social inclusion, and combat poverty. These were consistent with the European Employment Strategy and its employability approach (Raveaud, 2007). As a result, Europeanisation has contributed to relative shifts from passive to active labor market policies in the CEEC and, in general terms, supported the paradigm of activation.

The public employment services remained the critical instrument for the implementation of employment policies.

In Latvia, Hungary, and Poland, the growth of unemployment produced similar policy responses at the beginning of the transformation. Governments set up specialized labor administrations, where territorial units were linked to the national public employment services headquarters through strict vertical lines of control and accountability. This system solution was in use until the late 1990s, when crucial institutional reforms took place. In Hungary government limited the autonomy of the public employment service and took over the management of the PES in 2015. In Poland, decentralization resulted in the municipalization of the PES, which came into force in 1999 and was accomplished in 2002. In the two countries, the core governance structure has not changed since then. 
We can notice here that in all three countries at the beginning of the transition, national PES were not directly part of ministries responsible for labor affairs but were fully managed by ministries. Therefore, they had a low degree of autonomy. This situation has not changed in Latvia, where PES operated as a state agency or an executive agency under the control of the government through the whole period. However, in the case of Hungary, we can find one major policy shift from a low to very low autonomy, which was marked by the abolition of the National Labor Office in 2015 and the dispersal of its power and responsibilities to different ministries within the government. On the other hand, in Poland, we can distinguish two significant policy changes. In the first wave of reform, decentralization came into force, but the National Labor Office (Krajowy Urzad Pracy) coordinated an employment policy. Therefore, it was a shift from a low to a high degree of autonomy. In 2002, the National Labour Office was abolished, and since then, Poland has had sub-national PES with no national coordinating agency (a very high degree of autonomy).

The rationale for this policy shifts was different from policy changes in Western European countries. In Germany, the restructuring of the Federal Employment Agency came into force due to the reforming labor market and social welfare system (Hartz reforms, 2003-2005). In the UK, establishing the Jobcentre Plus in 2001-2003 and its subsequent amendments were part of the broad welfare reforms within the activation paradigm. Contrary to the countries mentioned above, reforming national public employment services was overshadowed by the general changes of the public administration aiming at centralization reinforced by financial constraints (Hungary) (Ágh, 2013) and reforms of the territorial government system (Poland). In this last country, the reform was an element of decentralization driven by a reluctance to the previous overly centralized system (Mosley, 2011). The situation in Latvia was different as in the beginning, the national PES took shape of the agency model and have stayed still until now.

When the general models of the public employment service have been set up in three countries covered in this paper, they determined the scope of reforms carried out in subsequent years. In Latvia, the agency model allowed the implementation of the performance management with the system of input and output-oriented benchmark targets. In Hungary, subordination of the PES to the central government resulted in vast structural reforms. The managerial mergers, reshuffling of competencies, and centralization are here the standard features of reforms. In Poland, the constitutional principles of self-government and subsidiarity gave the government less room for structural reforms. The amendments to the employment act were frequent, but they presented fairly minor changes to the existing system. In 2014, the government attempted to strengthen the vertical coordination at the regional level.

Decentralization remains a relatively stable feature of the public employment services in the three countries. The subordinate units performed their actions mainly at normative regions and microregions and stayed intact for years. In turn, the reforms aiming at improving both vertical and horizontal coordination of the public employment services are the main features of recent changes. The main challenge is to reconcile local flexibility with the proper level of coordination and control. 
References

Ágh, A. (2013). Bumpy Road of the Hungarian Administrative Reforms: From Political Over-Centralization to Public Policy Failures. Croatian and Comparative Public Administration, 13(4).

Ahlborn, M., Ahrens, J., \& Schweickert, R. (2016). Large-scale transition of economic systems - do CEECs converge toward western prototypes? Comparative Economic Studies, 58(3). https://doi.org/10.1057/s41294-016-0009-x

Aidukaite, J. (2010). WELFARE REFORMS IN CENTRAL AND EASTERN EUROPE: A NEW TYPE OF WELFARE REGIME? Ekonomika, 89(4).

Åslund, A., \& Dombrovskis, V. (2011). How Latvia came through the financial crisis. Peteron Institute for International Economics.

Baron-Wiaterek, M. (2008). Instytucjonalno-prawne aspekty rynku pracy i promocji zatrudnienia. Instytut Pracy i Spraw Socjalnych.

Cerami, A. (2006). Social Policy in Central and Eastern Europe: the Emergence of a New European Welfare Regime. LIT Verlag.

Csillag, M., Samu, F., \& Scharle, Á. (2013). Job Search and Activation Policies in Central and Eastern Europe. GRINCOH Working Paper Series, No. 4.05.1.

Deacon, B. (2000). Eastern European welfare states: The impact of the politics of globalization. Journal of European Social Policy, 10(2).

Dingeldey, I., Assmann, M.-L., \& Steinberg, L. (2017). The strengths and weaknesses of policy coordination and policy outcomes in a system of multi-level governance: A comparative analysis. NEGOTIATE working paper no. 8.3.

Eichhorst, W., \& Konle-Seidl, R. (2008). Contingent convergence: a comparative analysis of activation policies. IZA Discussion Paper, 3905.

European Commission. (2020). Assessment Report on PES Capacity.

Finn, D., \& Peromingo, M. (2019). Key developments, role and organization of Public Employment Services in Great Britain, Belgium-Flanders and Germany. International Labour Organization.

Györgyi, I. (2018). History of the Hungarian Public Employment Service. In T. B. Borbély-Pecze (Ed.), The History of the Hungarian Public Employment Service in Narratives 1991-2016 (pp. 35-62). Ministry for National Economy, Department for Employment Service.

Hungary: Closure of national employment office | Eurofound. (n.d.). Retrieved May 13, 2021, from https://www.eurofound.europa.eu/publications/article/2015/hungary-closure-of-national-employment-office

ICON Institut Public Sector GmbH. (2015). Benchlearning Initiative External Assessment Summary report - NES Hungary. http://dashboard.pes-benchlearning.eu/summary_ reports/Hungary PES_Summary report_short_rev.pdf

Inglot, T. (2008). Welfare states in East Central Europe, 1919-2004. In Welfare States in East Central Europe, 1919-2004. https://doi.org/10.1017/CBO9780511510175 
Kalužná, D. (2009). Main Features of the Public Employment Service in Poland. Social, Employment and Migration Working Papers No. 80 (Issue 80). OECD.

Kalvāne, I. (2015). Business Model Choice for Latvian Public Employment Service: What is the Best for Labour Force Competitiveness? Procedia - Social and Behavioral Sciences, 213.

Kornai, J. (1992). The Socialist System: The Political Economy of Communism. Princeton University Press.

Kuitto, K. (2016). Post-communist welfare states in European context: Patterns of welfare policies in central and eastern Europe. In Post-Communist Welfare States in European Context: Patterns of Welfare Policies in Central and Eastern Europe. https://doi. org/10.4337/9781784711986

Lauringson, A., \& Lüske, M. (2021). Institutional set-up of active labour market policy provision in OECD and EU countries: Organisational set-up, regulation and capacity (No. 262; OECD Social, Employment and Migration Working Papers).

López-Santana, M. (2015). The new governance of welfare states in the United States and Europe: between decentralization and centralization in the activation era. In The New Governance of Welfare States in the United States and Europe: Between Decentralization and Centralization in the Activation Era. State University of New York Press.

Mailand, M. (2008). The uneven impact of the European Employment Strategy on member states' employment policies: A comparative analysis. Journal of European Social Policy, 18(4).

Manoudi, A., Nevala-Hall, A. M., Scharle, Á., Csillag, M., Metcalfe, H., Duchemin, C., \& Maillart, I. (2014). EEPO 2014 Small Scale Study on PES Business Models.

Mosley, H. (2011). Decentralisation of Public Employment Services. Analytical Paper. July, 35. https://ec.europa.eu/social/main.jsp?catId=1163\&langId=en

Nunn, A. (2012). Performance management in public employment services Analytical paper. https://ec.europa.eu/social/main.jsp?catId=1163\&langId=en

OECD. (2019). Evaluating Latvia's Active Labour Market Policies. OECD Publishing. https://www.oecd-ilibrary.org/employment/evaluating-latvia-s-active-labour-marketpolicies_6037200a-en

OECD. (2021). Public expenditure and participant stocks on LMP. https://stats.oecd.org/ Index.aspx?QueryId=8540

Raveaud, G. (2007). The European employment strategy: Towards more and better jobs? Journal of Common Market Studies, 45(2). https://doi.org/10.1111/j.14685965.2007.00716.x

Ribound, M., Sanchez-Parmo, C., \& Silva-Jauregui, C. (2002). Does Euroscleros: is Matter? Institutional Reform and Labor Market Performance in Central and Eastern Europe. https://openknowledge.worldbank.org/bitstream/handle/10986/14093/multi0page. pdf;sequence $=1$

Schneider, A. (2006). Who gets what from whom? The impact of decentralisation on tax capacity and social spending. Commonwealth and Comparative Politics, 44(3). 
State Employment Agency (SEA). (2021a). State Employment Agency (SEA) (Nodarbinātības valsts aǵentūra). https://www.nva.gov.lv/en/state-employment-agency-sea

State Employment Agency (SEA). (2021b). The history of State Employment Agency (Nodarbinātības valsts ağentūra). https://www.nva.gov.lv/en/history-state-employmentagency

State Employment Agency (SEA) [Nodarbinātības valsts aǵentūra]. (2019). State Employment Agency Year 2018 Public Report. https://www.nva.gov.lv/en/publications-andreviews

van Berkel, R., de Graaf, W., \& Sirovátka, T. (2011). The Governance of Active Welfare States. In The Governance of Active Welfare States in Europe. Palgrave Macmillan UK.

Verhoest, K., Bouckaert, G., \& Peters, B. G. (2007). Janus-faced reorganization: Specialization and coordination in four OECD countries in the period 1980-2005. International Review of Administrative Sciences, 73(3), 325-348. https://doi. org/10.1177/0020852307081144

Verhoest, K., Peters, G. B., Beuselinck, E., Meyers, F., \& Bouckaert, G. (2005). How coordination and control of public organizations by government interrelate: an analytical and empirical exploration. 1-36. https://soc.kuleuven.be/io/pubpdf/io02060016_coordination_scancor.pdf

Weishaupt, J. T. (2014). Central Steering and Local Autonomy in Public Employment Services Analytical Paper. October. https://ec.europa.eu/social/main.jsp?catId=1163\&langId=en

Żídek, L. (2014). Evaluation of economic transformation in Hungary. Review of Economic Perspectives, 14(1). 


\title{
Stawomir Kalinowski
}

ORCID: 0000-0002-8068-4312 Instytut Rozwoju Wsi i Rolnictwa Polskiej Akademii Nauk1 Institute of Rural and Agricultural Development, Polish Academy of Sciences

\section{Aleksandra Luczak}

ORCID: 0000-0002-3149-7748

Uniwersytet Przyrodniczy w Poznaniu ${ }^{2}$ Poznań University of Life Sciences

\section{Social (in) security - the ambivalence of villagers' perceptions during COVID-19}

\begin{abstract}
The aim of the study is to provide a subjective assessment of security in the social dimension of rural households during the COVID-19 pandemic. To achieve the objective, a four-stage primary study of households in Poland was designed and conducted. Subjective assessments of households' perceptions about social security are presented. The possibility of loss of financial stability, job loss and deterioration of the household situation was assessed. The respondents also assessed the possibility of a worsening of the

1 Correspondence: ul. Nowy Świat 72, 00-330 Warszawa; email: skalinowski@irwirpan.waw.pl; www.skalin.pl

2 Correspondence: ul. Wojska Polskiego 28, 60-637 Poznań; email: aleksandra.luczak@up. poznan.pl
\end{abstract}


situation in the country, an increase in family poverty and an increase in unemployment in Poland. One of the most important findings is the dichotomy of the perceptions of the respondents, who assess the situation of their household better than that of the country. A different perspective on security is also provided by the rural optimism index, which can also be seen as a measure of vulnerability to social security. The considerations and analyses presented can be useful for both theoretical and practical purposes. The study improves knowledge on how households function under conditions of vulnerability. They also constitute a voice in the discussion on security in the social dimension.

Key words: social security, dichotomy of perceptions, rural households, COVID-19

\section{Introduction}

The pandemic has affected almost every person and almost every place in the world. However, it can be stated that coronavirus in Poland is more an urban than a rural disease. People living in rural areas are less likely to be affected by COVID-19. In large urban areas, vulnerability is mainly related to population density, which has necessitated the implementation of strict interventions in the form of lockdowns and social distancing practices. At the time of the pandemic, scientific research is being conducted worldwide on its human, social and economic impact. Domestic level analyses in the USA showed higher COVID-19 infection rates in urban areas compared to rural areas in the Northeast and Mid-Atlantic regions at the beginning of the epidemic. However, over time, the intensity of the epidemic has shifted to rural areas (Cuadros et al., 2021). Agnoletti, Manganelli and Piras (2020) state that it is interesting to note that in Italy, the lower number of COVID-19 cases cannot be explained by the lower population density of these areas or by other demographic, economic or environmental features. Kerbage et al. (2021) also highlight the distinctiveness of rural areas and their needs in the face of the pandemic. It can be assumed that the reasons for the different temporal dynamics between urban and rural areas may be varied.

It is an undeniable fact that COVID-19 has changed lives around the world and has become part of Bauman's (2000) liquid modernity. In addition to the direct impact of coronavirus on health and mortality, strong social and economic constraints and disruptions should be noted. These pandemic influences are likely to have far-reaching effects on human well-being for a long time (cf. Sumner et al., 2020). Despite that, individuals as well as entire societies are looking for appropriate solutions to this difficult situation. Changes in the daily life of households, the functioning of workplaces, or teaching in schools are manifested, for example, in the reorganisation of work-life, changes in shopping habits, or the transformation of schools to distance learning. The authorities are also adapting to the current situation by trying to counteract the effects of the pandemic on both the economy and society. At the same time, there is a great deal of research related to human adaptation to a new reality during the pandemic (Akhtar, 2021; Asmundson \& Taylor, 2020; Chulasiri et al., 2020; Cortes \& Forsythe, 2020; Halamska, 2020; Hall et al., 2020; 
Han et al., 2020; Kalinowski, 2020a; Kalinowski \& Wyduba, 2020; McCarthy, 2020; Naeem, 2021; Nolting, 2020; Tavares \& Betti, 2021; Zwęglińska-Gałecka, 2020). This leads to a conundrum and reflection related to the security of the rural population under conditions of uncertainty.

This article presented is part of extensive research conducted on the situation of the households during the coronavirus period. It should be added that this research is also part of the research related to living with uncertainty (cf. Beck, 2004; Kalinowski, 2014; Knight, 1921; Zalega, 2008), with the most acute problems being fears of the loss of job, income and an uncertain future. Hence, the study was designed to assess the situation of rural households in Poland during the COVID-19 pandemic.

There are various studies emerging worldwide related to rural analysis during pandemics. These studies address different aspects: health, social, economic, or psychological (Bu et al., 2020; Cuadros et al., 2021; de Luca et al., 2020; Dutta \& Fischer, 2021; Jia et al., 2021; Kansiime et al., 2021; Kerbage et al., 2021; Malatzky et al., 2020). Analyses of rural areas in countries such as Italy, the United Kingdom, the United States, Canada, China, Lebanon, or Ecuador reveal problems related to fewer health services, weaker health and sanitation infrastructure, inadequate social protection and numerous problems in rural governance and sometimes endemic poverty (e.g., in India). In a number of countries (including Norway, the United States, Canada, Australia), the migration of people from cities to the countryside has also become a problem, as rural areas have been considered oases of safety (Malatzky et al., 2020). These factors contribute to the difficulty of handling a pandemic. Furthermore, activities are often centralised in urbanised areas, while rural and peripheral areas may be neglected (Kerbage et al., 2021). The positive aspects include that living in the rural area has been credited as a protective factor against the negative effects of loneliness during a pandemic (Bu et al., 2020). Rural areas compared to urban areas have other additional advantages that are important during a pandemic, such as lower population density, tighter social networks, more green space, and better self-sufficiency of food supply (Jia et al., 2021).

Based on the quoted studies and the extensive analysis by Haghani et al. (2020) on security, it is possible to identify gaps in the security dimensions presented. It should be noted that there is a lack of research on the perceptions of social security of the population, especially those living in rural areas. Due to these reasons, an attempt was made to identify changes in the perceptions of social security of rural households in Poland that occur during the pandemic. Against this background, the main objective of the research emerges, which is the subjective assessment of the situation of rural households regarding their security in the social dimension during the COVID-19 pandemic. Achieving the main objective was also possible through the search for answers to the following research questions:

1. Do respondents feel that the situation in Poland and in their own household could get worse?

2. Are rural households worried about poverty during the pandemic?

3. Do respondents have a sense of job security? 
Three research hypotheses were also formulated indicating as follows:

H1: In the pandemic period studied, rural households had a strong sense of the possibility of deterioration in Poland and in their own household at the same time.

H2. The subjective perceptions of rural households about the fear of poverty increased during the pandemic period.

H3. Respondents living in rural areas are not worried about losing their own jobs despite the possibility of increased unemployment in the country.

The verification of the stated hypotheses is based on a four-stage primary study of rural households in Poland, conducted using the CAWI (Computer-Assisted Web Interview) method in April, June, and September 2020 and in April 2021.

We also used the statistical methods to verify the hypotheses. The structure indicators were used to present the shares of responses of rural households about perceptions of social security. The similarity of response structures between study stages was examined using the similarity of structures index. Consistency of criterion assessment between the situation in one's own household and the situation in Poland was checked using the Cronbach's alpha coefficient. We also examined optimism of rural households based on the rural optimism index.

The article is structured as follows. Section two presents a brief discussion on the definition of social security. Section three discusses data sources and research methods. Section four presents statistical findings on the households' subjective assessment of their security situation in the social dimension during the coronavirus pandemic in Poland. The final section provides a summary.

\section{Understanding social security}

In lexical terms, security is the state of not being threatened (Dictionary of the Polish Language, 2021) and, as stated by Ivan (2011), the last decade of the twentieth century witnessed the beginning of an extensive scientific discussion on this topic in all spheres of everyday life. The concept of security has evolved over time and today can be defined in different ways. Starting from the original and narrow definition of security in military terms, it is necessary to shift to its current broader conception. The broad meaning of the term includes security and protection against difficult situations, damage, or forced change, starting from natural events and ending with threats to a nation's independence (cf. Høyland, 2018). Gierszewski (2018) states that "a multidimensional view of security has now become the standard approach", however, it does not have a consistent definition. Webb and Wills-Herrera (2012) on the other hand, indicate that safety should address the interactions between different economic, social, political, cultural and now epidemiological systems. The last dimension, with the constantly increasing threat of disease, seems to be the most important in recent months.

Social security is one of the fundamental dimensions of human security and is closely linked to poverty and related problems. Its various definitional references can be found in the source literature "from social pathologies through social security, social assistance 
or economic and social activity improving (enabling) people's livelihoods" (Gierszewski, 2018). It should also be mentioned that the Copenhagen School distinguishes between societal security and social security within social (public) security. The first is related to the society and collective identity of the country, and the second is to the single person and individual identity (Gierszewski, 2018). In the full understanding of the concept of social security, the concept of human security as freedom from distress and fear for all individuals (Human Development Report, 1994), as opposed to national security focusing on the defence of the whole country against various threats, is important. In this view, a person is part of the collective population of a country. It should be noted, however, that the interests of states often take precedence over the interests of their individual residents.

Social security can be defined as the "protection of the existential basis of people's lives, ensuring the possibility of satisfying individual needs (material and spiritual), the fulfilment of life aspirations by creating conditions for work and education, health protection and pension guarantees" (Skrabacz, 2012). McKay and Rowlingson (1999) define them in a slightly different way, as "all the ways in which people organise their lives in order to ensure access to an adequate income". Høyland (2018) highlights that social security is about creating favourable conditions for people to live well. In contrast, $\mathrm{Yu}$ and $\mathrm{Li}$ (2021) argue that one of the main objectives of social security is to provide "financial support to those deemed to be poor or facing the threat of poverty". Moreover, it is worth adding that the subjective feeling of security is one of the main dimensions affecting development and well-being.

The combined insights from the literature review have resulted in a definition of social security that highlights the multidimensionality of the concept. We focus on a broader definition of the household's subjective security state concerning the social dimension and propose to adopt a general definition of it as: the household's perceptions of a state of not being threatened in relation to existing socio-economic, political, cultural and epidemiological conditions. More precisely, it should be added that it is a subjective feeling of satisfaction of fundamental and essential, material and non-material needs of a household and the ability of its members to obtain financial means for their own maintenance at least at the existing living standard and ensuring the fulfilment of life aspirations irrespective of the circumstances.

Haghani et al. (2020) identified key dimensions related to safety in the COVID-19 pandemic. These relate to medical aspects, social security, food safety, mental health and home security. In contrast, there is limited research interest in economic and social security, cyber security and supply chain security. They also emphasised that more research is justified "on the effectiveness, equity, and sustainability of implemented policies and legislative actions to help protect the economic safety of societies at both micro and macro levels to mitigate or manage the financial fallouts caused by the epidemic" (Haghani et al., 2020).

It should be noted that the involvement of local authorities in ensuring social security is also important. Dutta and Fischer (2021) observe that countering the COVID-19 pandemic needs to combine public health and basic social protection measures in a very 
short time frame and on an unprecedented scale. Igra et al. (2021) add that the negative effect of activities that directly impact the mitigation of the effects of coronavirus on human health is that existing economic vulnerabilities and gaps in the social safety net have been exacerbated because government assistance has been limited, delayed, and unevenly distributed.

\section{Data sources and research methods}

The data used in this study are part of a research project entitled My situation during the coronavirus period („Moja sytuacja w okresie koronawirusa”) (Kalinowski, 2020b; Kalinowski \& Luczak, 2021). The primary study was conducted using CAWI (Computer-Assisted Web Interview) method in four stages: in April, June and September 2020 and in April 2021. Due to the difficulty of direct contact with surveyed rural households during the pandemic, a computer-assisted interview using a website was used. The research sample at each stage of the study included 521 rural households represented in each voivodship in Poland. It should be added that the sample is larger than the minimum research sample size at the assumed significance level of 0.05 .

Rural households were subject to self-assessment and expressed opinions on the situation in the country. The possibility of a worsening of the situation in their own households, a loss of financial stability and a loss of jobs was assessed, as well as the possibility of a worsening of the situation in Poland, an increase in family poverty and unemployment. The study used a five-point ordinal measurement scale and verbal descriptions. The measurement scale used in the study features five categories, where 1 is the most optimistic response in relation to the criterion under study and 5 is the most pessimistic statement in relation to the criterion under study. In other words, the higher the rating value, the lower the feeling of social security.

The study used structure indicators that present the shares of responses of rural households expressed on a five-point ordinal scale. The similarity of response structures between study stages was examined using the similarity of structures index (Sobczyk, 2010):

$$
\operatorname{RSC}\left(\boldsymbol{w}_{t}, \boldsymbol{w}_{s}\right)=\frac{\sum_{j=1}^{P} \min \left(w_{j t}, w_{j s}\right)}{\sum_{j=1}^{P} \max \left(w_{j t}, w_{j s}\right)}
$$

where: $\boldsymbol{w}_{t}, \boldsymbol{w}_{s}$ - vectors of response structures in stages $t$ and $s ; \boldsymbol{w}_{t}=\left[w_{1 t}, w_{2 t}, \ldots, w_{P t}\right]^{T}$, $\boldsymbol{w}_{s}=\left[w_{1 s}, w_{2 s}, \ldots, w_{P s}\right]^{T}, P-$ number of response variants in the question. The value of the structure similarity index takes values from 0 to 1 . The closer the value of the index is to 1 , the greater the similarity of the response structures being compared.

The Cronbach's alpha coefficient $(\alpha)$ was also used to assess the consistency of criterion scores between the situation in one's own household and the situation in Poland. Cronbach's alpha coefficient is a measure of internal consistency and demonstrates what is the relationship between the criteria. The value of $\alpha$ should be between 0 and 1 . The 
higher the value of the coefficient, the greater the consistency (interrelatedness) of the assessments. Consistency is assumed if: $\alpha \geq 0.9$ - very high consistency, $0.8 \leq \alpha<0.9$ - high, $0.7 \leq \alpha<0.8$ - acceptable, $0.6 \leq \alpha<0.7$ - questionable, $0.5 \leq \alpha<0.6-$ poor, $\alpha<0.5$ - unacceptable.

Rural optimism index (Wskaźnik Optymizmu Wiejskiego, WOW) values were also calculated as part of the rural household's self-assessment of its situation and the situation in the country according to the formula (cf. Roszkowska \& Jefmanski, 2021):

$$
W_{(\cdot) t}=\frac{\sum_{i=1}^{p_{(\cdot)}} N_{1 i t}}{\sum_{i=1}^{p_{(\cdot)}} N_{1 i t}+\sum_{i=1}^{p_{(\cdot)}} N_{2 i t}}(t=1,2,3,4)
$$

where: $N_{1 i t}$ - the number of rural households that commented positively (responses 1 and 2) on the $i$-th criterion, $N_{2 i t}$ - the number of rural households that commented negatively (responses 4 and 5) on the $i$-th criterion, $t$ - the stage of the study $(t=1,2$, $3,4) ; p_{(\bullet)}$ - the number of features within the evaluation of the own household situation (country situation); $(\bullet)-(w)$ for own situation and $(k)$ for the country situation. The $W O W_{(\bullet) t}$ values range from 0 to 1 . The higher the value of the index, the greater the optimism of rural households.

The study assesses the perceptions of social security of rural households during the COVID-19 pandemic. Perceptions about the possibility of a worsening of the situation of their own household and the future situation in Poland were analysed. Changes in respondents' perceptions of the possibility that their own household situation will deteriorate in the near future, that they will lose financial stability, and that they will lose their jobs were presented in four research stages. The respondents' perceptions about the security of their own household were compared with their perceptions about the uncertainty of the future situation in Poland in terms of the possibility that the situation in the country will deteriorate in the near future, the possibility that family poverty will increase and that there will be an increase in unemployment in the country.
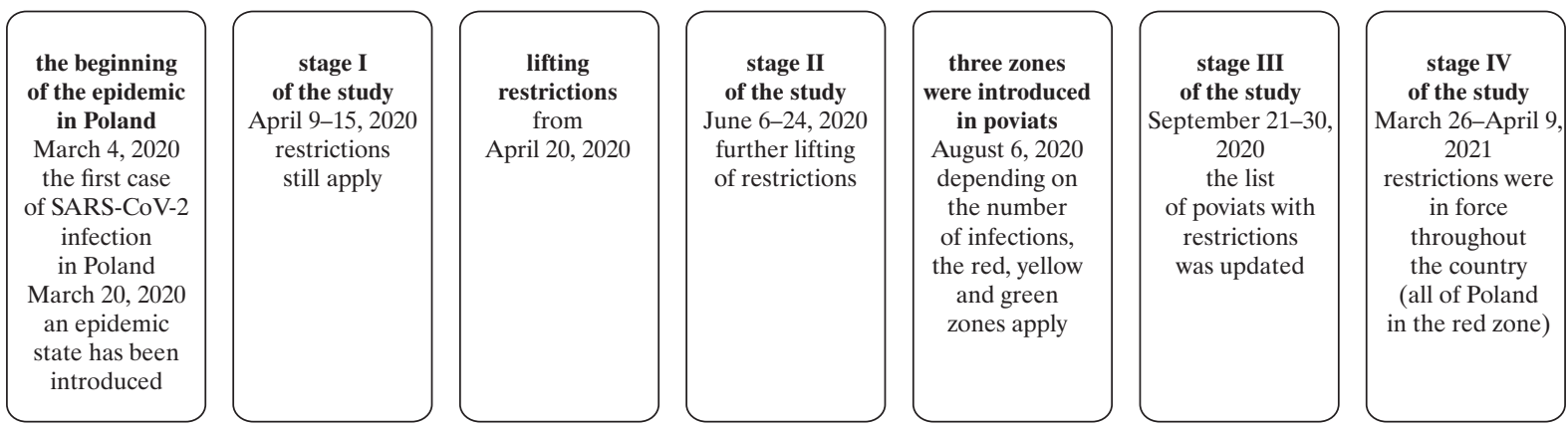

Figure 1. Stages of research in view of the situation in Poland

Source: Own work. 
At the beginning of the analyses, it is worth briefly presenting the background of the situation in the country as it was during the different stages of the study (Figure 1). After the pandemic was declared, many measures were taken internationally and in Poland too to limit the spread of infection. By the time of the first stage of the study in Poland, numerous restrictions had been introduced. They were related to travel, movement and assembly. The economy was frozen, and remote learning was introduced in schools and higher education institutions. Between stages I and II, the lifting of restrictions began. During stage II, further restrictions were lifted and the economy was slowly unfrozen. In stage III of the study, the country was divided into red, yellow, and green zones with different restrictions, depending on the number of infections. In stage IV, the red area with numerous restrictions was in force throughout the country.

\section{Research results}

In April 2020 (stage I of the study), more than 44\% of respondents believed that the situation in their household could worsen, while only around $19 \%$ of respondents were confident about this (Figure 2). In June (stage II of the study), the percentage of definitely pessimistic assessments decreased by more than 10 p.p. and no longer amounted to a full $8 \%$, with almost $22 \%$ of households still feeling that their situation could get worse. In September (stage III), the share of respondents assuming that the situation of their own household could deteriorate was similar. In contrast, in April 2021 (stage IV) the group of persons who thought deterioration was possible increased to over $37 \%$. This was compounded by another economic lockdown and the introduction of restrictions on social contact as a consequence of the increase in COVID-19 cases. It should be added that at each stage of the study, more than one in three respondents were uncertain (answers: maybe) about the direction of changes in the situation in their own household.

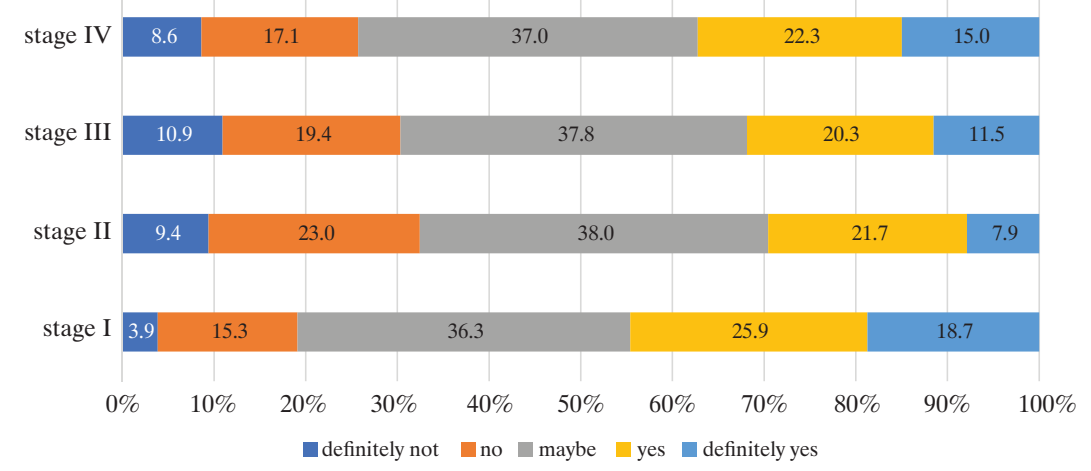

Figure 2. Respondents' perceptions of the possibility that the situation in their own household could deteriorate $(\%)$

Source: Own workwork based on the survey My situation in the coronavirus period (,Moja sytuacja w okresie koronawirusa") (Kalinowski, 2020b; Kalinowski \& Luczak, 2021). 
It should be noted that the surveyed households in rural areas were more pessimistic about the situation in the country than about their own security. In stage I of the rural study, more than $82 \%$ of respondents (answers: yes, and definitely yes) assumed that the situation in the country would deteriorate, of which more than $57 \%$ were sure about this (Figure 3). In stage II, approximately $63 \%$ of respondents were worried about the situation deteriorating, of which only about $36 \%$ were definitely sure. The situation was similar in stage III, with $64.5 \%$ of respondents believing that the situation in the country could deteriorate, and a slight increase (by approximately 4 p.p.) in the number of people who were certain that the situation would deteriorate. In contrast, stage IV witnessed a significant deterioration in the sense of social security and a return to the mood from the beginning of the pandemic. Almost $79 \%$ of respondents felt that the situation in the country could deteriorate, of which over $56 \%$ were definitely sure.

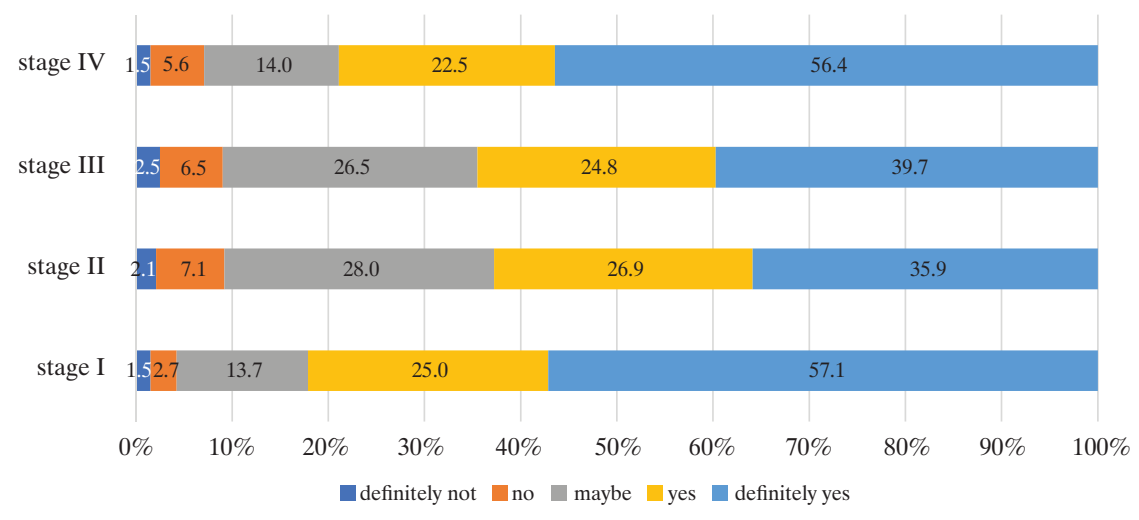

Figure 3. Respondents' perceptions of the possibility that the situation in Poland may deteriorate $(\%)$

Source: Own work based on the survey My situation in the coronavirus period (,Moja sytuacja w okresie koronawirusa") (Kalinowski, 2020b; Kalinowski \& Łuczak, 2021). 


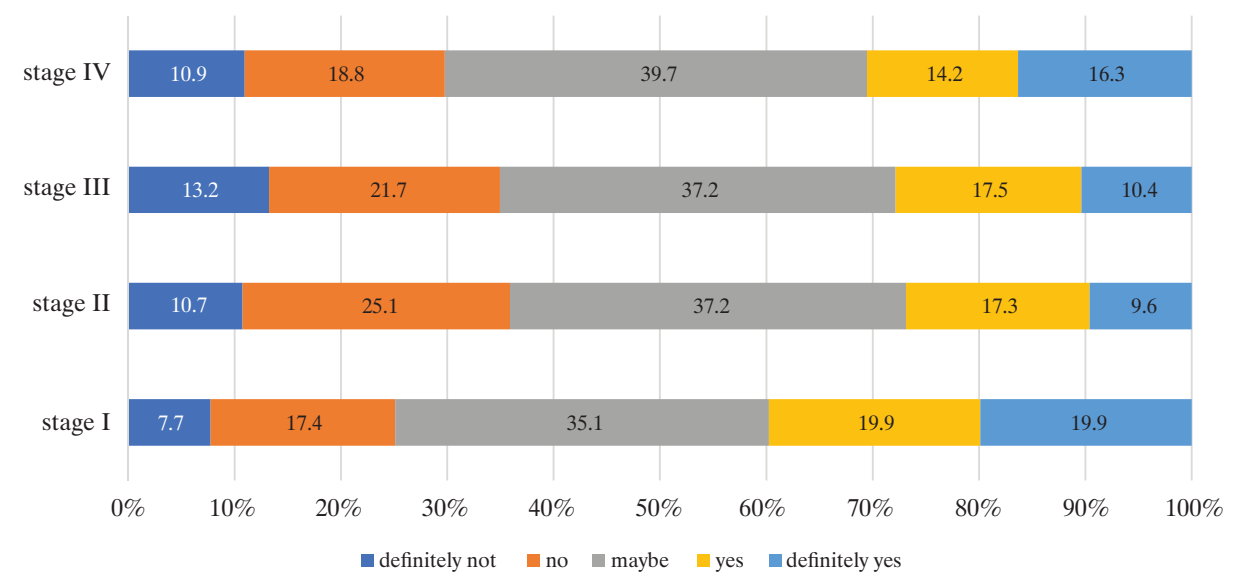

Figure 4. Respondents' perceptions of the possibility of losing financial stability in their own household (\%)

Source: Own work based on the survey My situation in the coronavirus period („,Moja sytuacja w okresie koronawirusa") (Kalinowski, 2020b; Kalinowski \& Łuczak, 2021).

In terms of the possibility of losing the financial stability of one's own household in stage I of the study, approximately $40 \%$ of the respondents perceived such a possibility (Figure 4). The optimism was even greater in stages II and III, with about $27 \%$ of respondents having a negative attitude to the issue in question. After one year of the pandemic, in stage IV of the study, approximately $30 \%$ of respondents were concerned about losing the financial stability of their own household. At the same time, in each stage of the study, the percentage of respondents who were uncertain about changes in their own household situation ranged from $36-38 \%$.

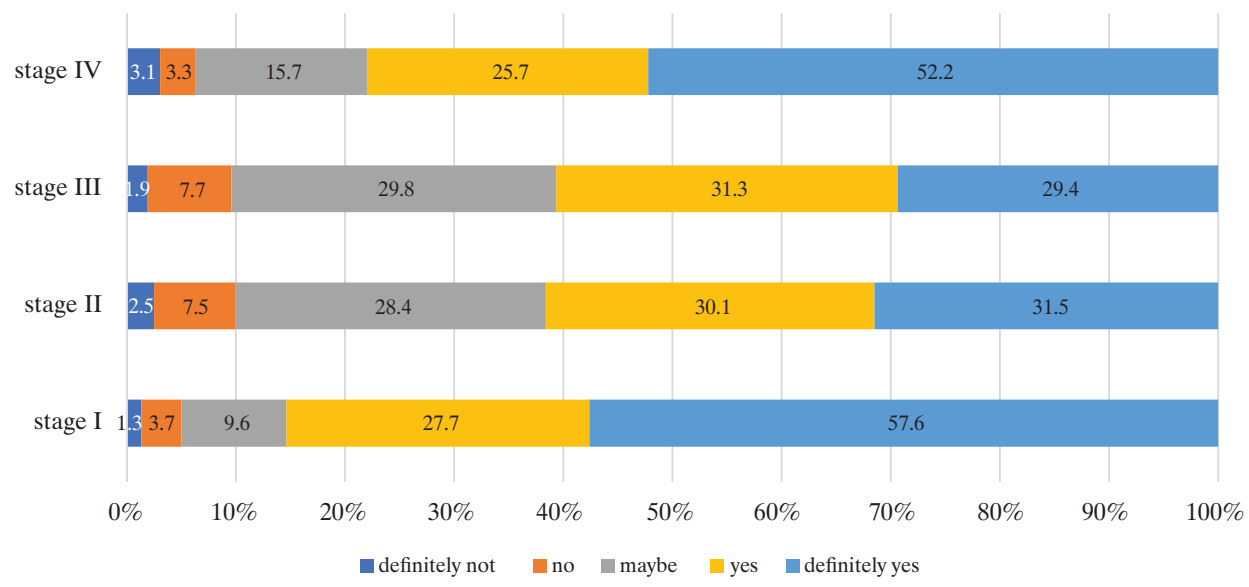

Figure 5. Respondents' perceptions of increased household poverty in Poland (\%)

Source: Own work based on the survey My situation in the coronavirus period (,Moja sytuacja w okresie koronawirusa") (Kalinowski, 2020b; Kalinowski \& Łuczak, 2021). 
Respondents indicated that the pandemic could significantly increase household poverty in Poland (Figure 5). In stage I, more than $85 \%$ of respondents believed that family poverty in the country would increase (answers: "yes" and "definitely yes"), with almost $58 \%$ being certain of this. In stages II and III, the situation was more optimistic and the percentage of persons who perceived that poverty could increase in the country decreased to a level of approximately $61 \%$. In the next stage of the study, the percentage of negative evaluations increased significantly (almost 78\%) returning to the level of stage I.

During a pandemic, it is also important to assess the possibility of losing one's job, however, respondents do not perceive that this problem could affect them significantly. In stage I, only approximately $19 \%$ of respondents perceived this problem and $10.5 \%$ were certain of losing their job; in the following two stages, optimism increased and in stage II, approximately $16 \%$ felt the possibility of this problem occurring, while in stage III, this group of respondents increased by only 2 p.p. In contrast, in stage IV, which was associated with another lockdown and an increase in coronavirus cases, concerns about losing one's job increased (over 23\%).

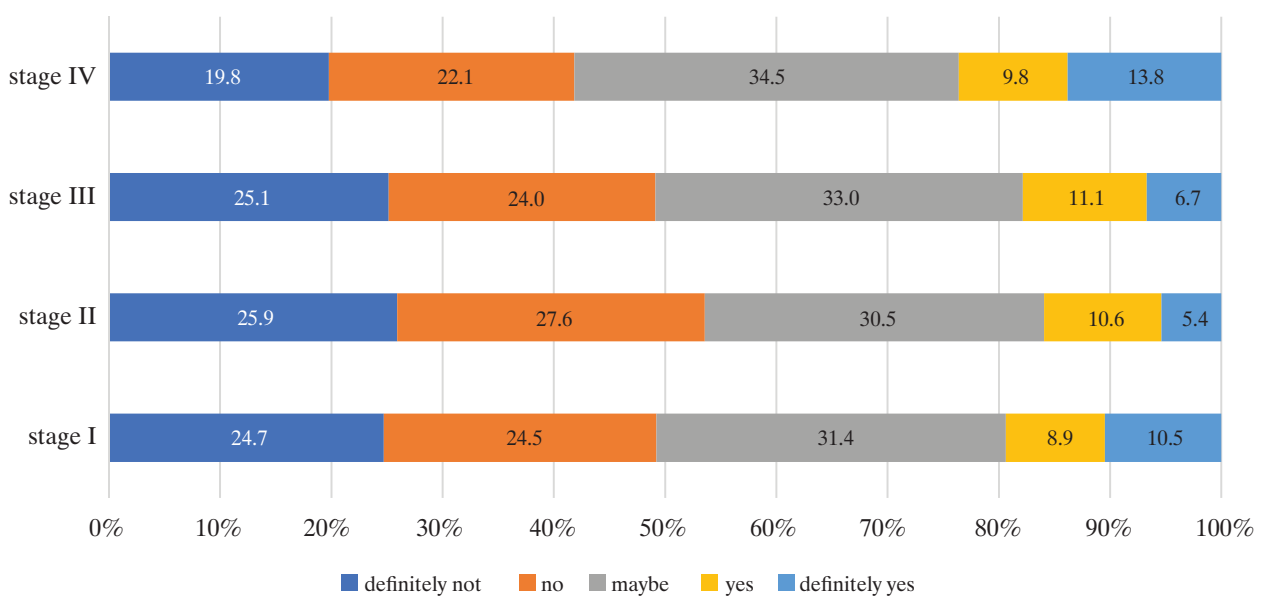

Figure 6. Respondents' perceptions of the possibility of losing their own job (\%)

Source: Own work based on the survey My situation in the coronavirus period (,Moja sytuacja w okresie koronawirusa") (Kalinowski, 2020b; Kalinowski \& Łuczak, 2021). 


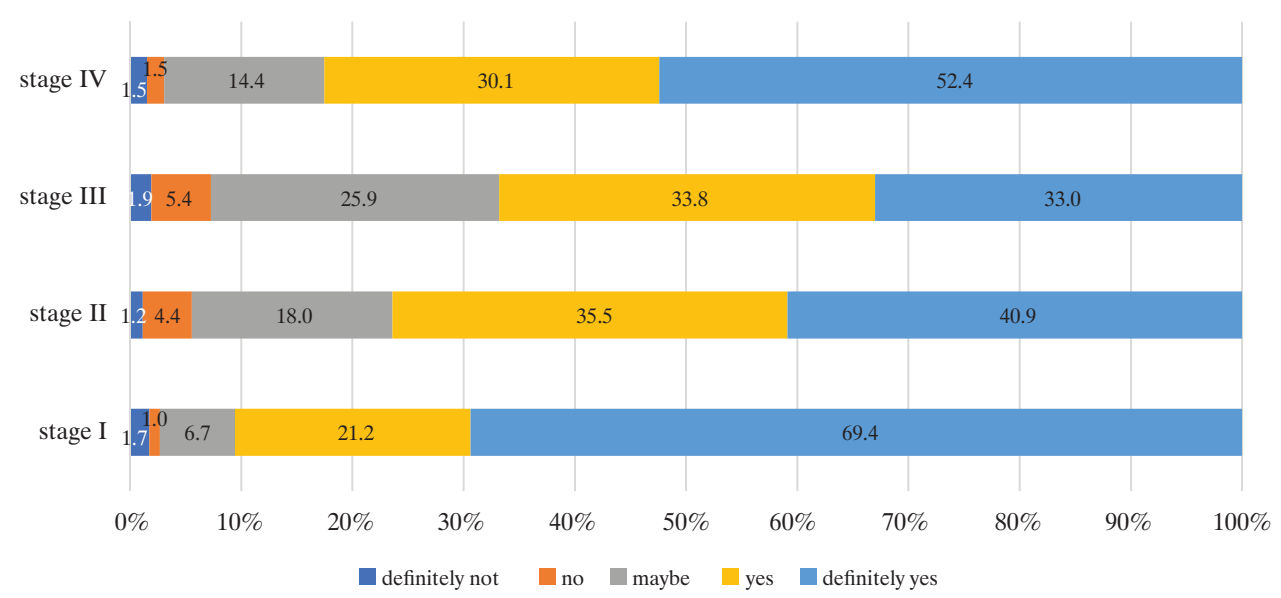

Figure 7. Respondents' perceptions of the increase in unemployment in Poland (\%)

Source: Own work based on the survey My situation in the coronavirus period (,Moja sytuacja w okresie koronawirusa") (Kalinowski, 2020b; Kalinowski \& Łuczak, 2021).

It is important to note that in rural areas in stage I of the study, over $90 \%$ of respondents perceived the possibility of an increase in unemployment in the country, with over $69 \%$ of respondents confident that this would occur (Figure 7). In stage II of the study, the percentage of respondents assuming an increase in unemployment decreased by about 14 p.p. to decrease further by almost 10 p.p. in stage III. In stage IV in September, more than $82 \%$ of respondents were concerned about the increase in unemployment in the country, and about $52 \%$ of respondents were definitely sure about the increase. It is worth mentioning that in all stages more than one-third of the respondents could not assess in which direction the change would occur. It should be added that the last stage coincided with another freeze of the economy. 

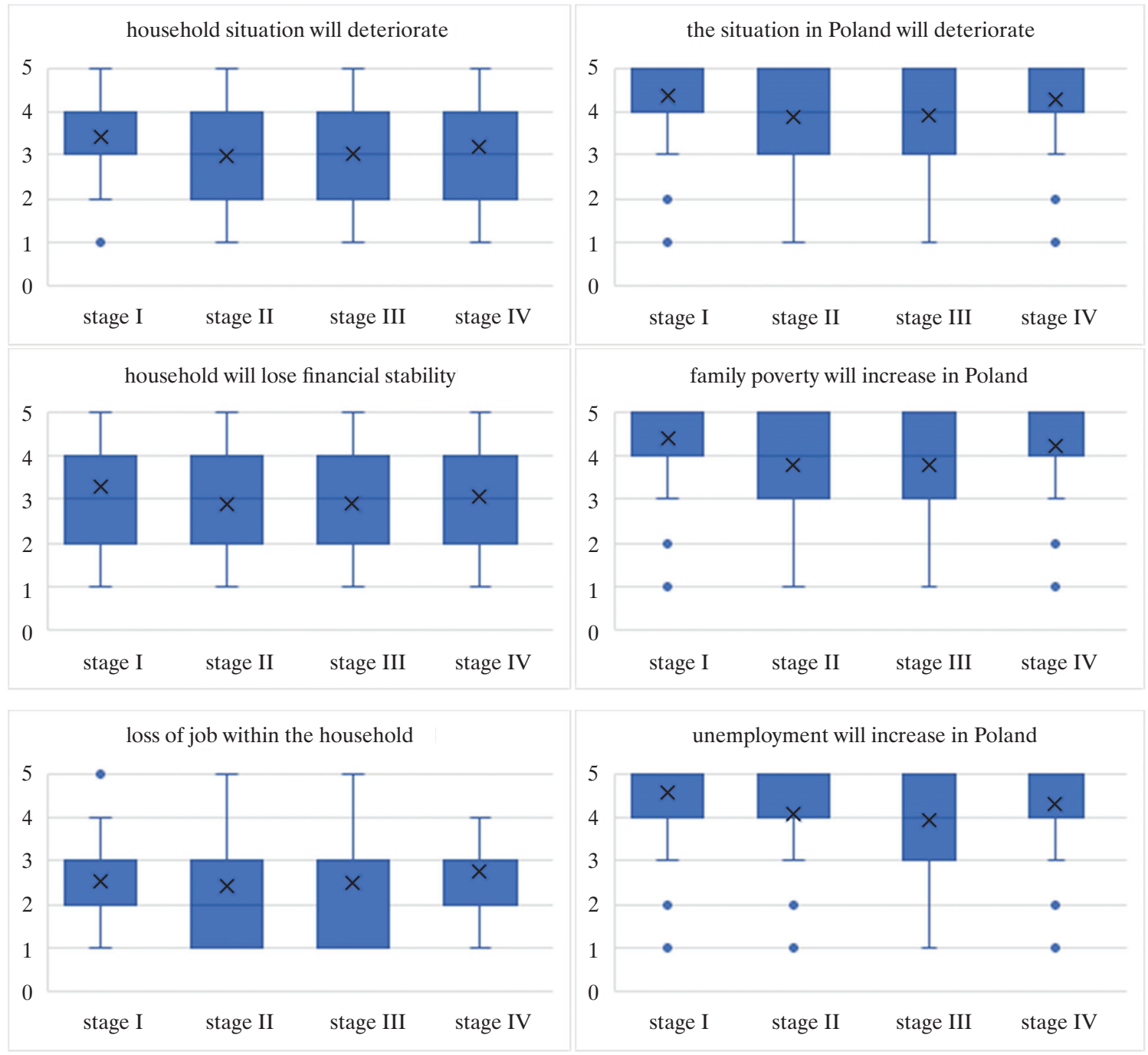

Figure 8. Box plot graphs for criteria describing the perceptions of residents living in rural areas about the future state of their own household and their opinions about the future situation in Poland in accordance with the stages of the study

Note: the box is composed of the first and third quartiles, the vertical line represents the median, $\times$ represents the mean. The width of the box corresponds to the interquartile range $(I Q R)$. The whiskers are drawn to the highest (lowest) value of the variable between the upper (lower) quartile and $1.5 I Q R$, small circle - data not included between the whiskers, an outlier.

Source: Own work based on the survey My situation in the coronavirus period („Moja sytuacja w okresie koronawirusa”) (Kalinowski, 2020b; Kalinowski \& Kuczak, 2021). 
To confirm the dichotomy of the self-perceptions of the situation of rural households and the situation in Poland, box plot graphs (box-whisker) based on descriptive statistics were made (Figure 8). It is noteworthy that there are significant differences in the position of the box plots for the assessment of the rural household's own situation and the situation in Poland. The lower values of the positional measures for the assessment of the situation of one's own household indicate better self-assessment compared to the assessment of the situation in the country, where the ratings are higher, which means that the assessment of the situation was lower. There is an observable very high similarity in the assessments in stage II and stage III. This is evidenced by the high values of the similarity index of structures (from 0.82 to 0.95 ) for all examined criteria (Table 1). It should also be noted that the opinions of the respondents in stage I of the study are highly consistent with those in stage IV of the study. Almost all criteria, apart from the fear of an increase in unemployment, are very compatible between these stages, as confirmed by a value of the similarity index of structures above 0.8 (Table 1). It should also be added that between stages I and II, as well as III and IV, the similarity of answers was greater within the framework of assessing the situation of one's own household than the situation in Poland. In addition, at each stage of the study, assessments within the household's own situation and the situation in Poland were highly consistent, as confirmed by Cronbach's alpha coefficient values ranging from 0.79 to 0.85 .

Table 1. Values of the similarity index of structures between stages of the study for the criteria describing the rural residents' perceptions of the future state of their own household and their opinions on the future situation in Poland

\begin{tabular}{|l|l|c|c|c|c|}
\hline \multirow{2}{*}{$\begin{array}{c}\text { Assessment } \\
\text { of the situation }\end{array}$} & \multicolumn{4}{c|}{ Criterion } & \multicolumn{4}{c|}{ Stages } \\
\cline { 2 - 6 } & & I-II & II-III & III-IV & I-IV \\
\hline \multirow{3}{*}{$\begin{array}{l}\text { in one' s own } \\
\text { household }\end{array}$} & deterioration of own situation & 0.74 & 0.90 & 0.90 & 0.86 \\
\cline { 2 - 6 } & loss of financial stability & 0.77 & 0.93 & 0.84 & 0.83 \\
\cline { 2 - 6 } & job loss & 0.89 & 0.92 & 0.84 & 0.86 \\
\hline \multirow{3}{*}{ in Poland } & $\begin{array}{l}\text { deterioration in the situation } \\
\text { of families }\end{array}$ & 0.65 & 0.92 & 0.71 & 0.94 \\
\cline { 2 - 6 } & increase in poverty & 0.59 & 0.95 & 0.61 & 0.85 \\
\cline { 2 - 6 } & increase in unemployment & 0.55 & 0.82 & 0.68 & 0.71 \\
\hline
\end{tabular}

Source: Own work based on the survey My situation in the coronavirus period (,Moja sytuacja w okresie koronawirusa") (Kalinowski, 2020b; Kalinowski \& Luczak, 2021) and the Statistica 13.3 software. 


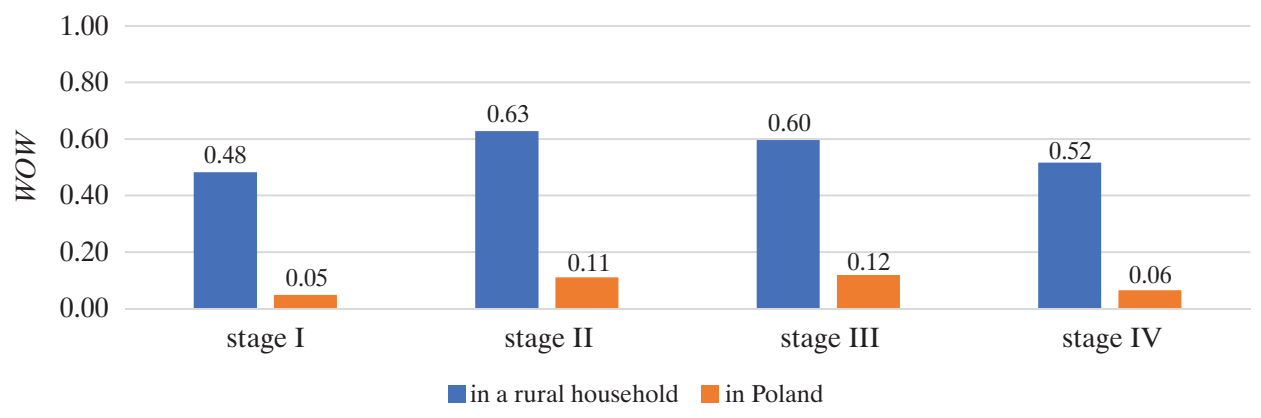

Figure 9. Rural optimism index (WOW) values as part of assessment of own household situation and situation in the country

Source: Own work based on the survey My situation in the coronavirus period („Moja sytuacja w okresie koronawirusa") (Kalinowski, 2020b; Kalinowski \& Łuczak, 2021).

It should be noted that the rural households under study were definitely more optimistic about their situation in terms of social security than the situation in the country. This can also be observed by the comparison of the values of the rural optimism index (Figure 9). The value of the optimism index for self-assessment of one's own household ranged from 0.48 to 0.63 and was at an average level. On the other hand, the assessment of the situation in the country was pessimistic, as this indicator had low values ranging from 0.05 to 0.12 , which indicates a very low level of optimism in the assessment of social security in the country.

\section{Conclusions}

In this paper, a subjective assessment of the social safety situation of rural households in Poland during the year of the coronavirus pandemic was undertaken. Perceptions of the future situation of their own households and opinions on the future situation in Poland were examined. Based on the research, the authors also obtained answers to the research questions posed regarding the rural population's perceptions about the future. Surveyed rural households in Poland were quite optimistic about their situation. This may be the result of rural areas being seen as safe in a pandemic. This is confirmed in the study by Malatzky et al. (2020). It should be noted that a similar sense of security was felt by rural respondents in the study, who did not have a strong belief in the possibility of deterioration in their own household yet perceived the possibility of deterioration in the country. Moreover, especially in the first and fourth study stages the assessments were significantly worse than in the other study stages. The reasons can be attributed to the reaction to the change, as various restrictions were in place in the country at the time of these research stages. Disruption of societies has also been observed in other countries following the introduction of restrictions. Excessive purchases of food, hygiene products or personal care products were observed in most European countries. 
The significantly worse perceptions in the first and fourth stages of the study allow only partial positive verification of the first research hypothesis that rural households in the studied pandemic period had a strong sense of the possibility that the situation in Poland would get worse. In contrast, the assessment of the future situation within households was positive. It is also not possible to conclude that rural households are worried about losing their own financial stability, however, respondents assessed that there may be an increase in family poverty during the pandemic period, which confirmed the second research hypothesis. Surprisingly, the self-assessment of the households' financial situation in Poland showed positive results. Studies from other countries are less optimistic. In Kenya and Uganda (Kansiime et al., 2021; Mahmud \& Riley, 2021), the pandemic and associated changes have significantly affected household incomes and food security.

Moreover, the third research hypothesis should also be positively verified, as respondents living in rural areas assess their jobs as stable and are not afraid of losing their jobs despite strong perceptions of the possibility of increased unemployment in the country determined by the global economic slowdown. Research in Italy conducted by Agnoletti, Manganelli and Piras (2020) has shown that provinces with a higher proportion of rural areas tend to have much lower exposure to COVID-19 while controlling the unemployment. However, it is important to bear in mind previous experience that shows that most pandemics have significantly reduced global economic output and increased unemployment (Tisdell, 2020). Hence, perceptions and fears about the situation in the country seem justified, while the authorities, when introducing restrictions during a pandemic, have to make compromises balancing job losses with economic activity. It should also be noted that in rural population surveys, respondents' sense of place identity, i.e., awareness of belonging to a rural community, has an emotional and valuing significance. Belanche, Casaló and Rubio (2021) support in their study that rural residents show higher levels of affective and valuing place identity than urban residents. On the basis of the conducted analyses, it can be observed that in the situation of a threat - the actual existence of an epidemic and its numerous negative effects - the evaluations of respondents in the rural areas still resound with the tribal instinct and a polarisation of views takes place. This is reflected in positive self-perceptions of households and, at the same time, negative perceptions of the situation of other households in the country. Subjectivity in assessments is related to the context of the assessment, i.e., the different experiences of the respondents. This is influenced by their previous experience of pandemics and the existing situation in the country. It is important to note that respondents' assessments are changing under the influence of the increasing threat of an epidemic and the associated restrictions and freezing of the economy (stages I and IV). Stronger perceptions both about the possibility of deterioration of their own and the country's situation were observed at the beginning of the pandemic and a year after its start, when successive waves of infections occurred and drastic restrictions were placed on the functioning of the economy and people's lives. To sum up the considerations, it should be emphasised that in the assessments of rural households there is a clear dichotomy of perceptions between the assessment of own household situation and the situation in Poland, which increases as the threat of the 
epidemic and its effects increase, including the escalating crisis in the country. The study clearly demonstrates that rural households feel and assess their own security much better than social security in the country. The increasing importance of social security and the need to maintain it in everyday life and work affects the country's development now and in the future. The authors believe that security in the social dimension is important for understanding the trajectory of COVID-19 impact on households. Hence, the main implication of the research is that the social security profile depends on a number of factors, and the multi-stage study conducted allows the monitoring the situation of households in Poland during the COVID-19 pandemic and can be repeated in the future. Similar to Haghani et al. (2020), the authors believe that scientific analysis and understanding of the various security implications of the COVID-19 pandemic may help society to better prepare for future pandemic outbreaks and support informed decision-making in view of societal values. Furthermore, it should be added that the research results obtained are important for the government, politicians and other decision makers who are involved in the prevention and mitigation of the COVID-19 pandemic.

\section{References}

Agnoletti, M., Manganelli, S., \& Piras, F. (2020). Covid-19 and rural landscape: The case of Italy. Landscape and Urban Planning, 204, 103955, https://doi.org/10.1016/j. landurbplan.2020.103955.

Akhtar, R. (2021). Coronavirus (COVID-19) Outbreaks, Environment and Human Behaviour. Cham: Springer. https://doi.org/10.1007/978-3-030-68120-3

Asmundson, G. J. G. \& Taylor, S. (2020). Coronaphobia: Fear and the 2019-nCoV outbreak. Journal of Anxiety Disorders, 70, 102196. https://doi.org/10.1016/j.janxdis.2020.102196

Bauman, Z. (2000). Liquid Modernity. Polity Press.

Beck, U. (2004). Spoteczeństwo ryzyka. W drodze do innej nowoczesności. Wyd. Scholar.

Belanche, D., Casaló, L. V., \& Rubio, M. A. (2021). Local place identity: A comparison between residents of rural and urban communities. Journal of Rural Studies, 82, 242-252. https://doi.org/10.1016/j.jrurstud.2021.01.003.

Bu, F., Steptoe, A., \& Fancourt, D. (2020). Loneliness during a strict lockdown: Trajectories and predictors during the COVID-19 pandemic in 38,217 United Kingdom adults. Social Science \& Medicine, 265, 113521. https://doi.org/10.1016/j.socscimed.2020.113521.

Chulasiri, P., Ruwanpathirana, T., Gunawardena, N., Wickramasinghe, C., \& Lokuketagoda, B. (2020). Perceptions of the current COVID situation and health, social and economic impact of the current scenario among a rural setting in Anuradhapura district. Journal of the Postgraduate Institute of Medicine, 7(2), E123 1-13. DOI: http://doi.org/10.4038/ jpgim.8298.

Cortes, G. M. \& Forsythe, E. (2020). Impacts of the Covid-19 Pandemic and the Cares Act on Earnings and Inequality. Upjohn Institute Working Paper 20-332. https://doi. org/10.17848/wp20-332. 
Cuadros, D. F., Branscum, A. J., Mukandavire, Z., DeWolfe Miller, F., \& MacKinnon, N. (2021). Dynamics of the COVID-19 epidemic in urban and rural areas in the United States. Annals of Epidemiology, 59, 16-20. https://doi.org/10.1016/j. annepidem.2021.04.007.

de Luca, C., Tondelli, S., \& Åberg, H. (2020). The Covid-19 pandemic effects in rural areas. TeMA - Journal of Land Use, Mobility and Environment, 119-132. https://doi. org/10.6092/1970-9870/6844.

Dutta, A. \& Fischer, H. W. (2021). The local governance of COVID-19: Disease prevention and social security in rural India. World Development, 138, 105234. https:// doi.org/10.1016/j.worlddev.2020.105234.

Gierszewski, J. (2018). Bezpieczeństwo społeczne jako dziedzina bezpieczeństwa narodowego. Historia i Polityka, 23(30), 21-38. DOI: http://dx.doi.org/10.12775/HiP.2018.002.

Halamska, M. (2020). Rural Crumbs of the Pandemic: Communities and Their Institutions. Introduction to the Thematic Issue. Wieś $i$ Rolnictwo, 3(188), 12-16. https://kwartalnik. irwirpan.waw.pl/wir/article/view/750 (accessed: 2021.06.29).

Hall, M. C., Prayag, G., Fieger, P., \& Dyason, D. (2020). Beyond panic buying: consumption displacement and COVID-19. Journal of Service Management, ahead-of-print. https:// doi.org/10.1108/JOSM-05-2020-0151.

Han, J., Meyer, B. D., \& Sullivan, J. X. (2020). Income and Poverty in the Covid-19 Pandemic. Social \& Personality Psychology eJournal. https://doi.org/10.3386/w27729.

Haghani, M., Bliemer, M. C. J., Goerlandt, F., \& Li, J. (2020). The scientific literature on Coronaviruses, COVID-19 and its associated safety-related research dimensions: A scientometric analysis and scoping review. Safety Science, 129, 104806, https://doi. org/10.1016/j.ssci.2020.104806.

Høyland, S. A. (2018). Exploring and modeling the societal safety and societal security concepts - A systematic review, empirical study and key implications. Safety Science, 110, C, 7-22. https://doi.org/10.1016/j.ssci.2017.10.019.

Human Development Report (1994). United Nations Development Programme. http:// hdr.undp.org/en/global-reports.

Ivan, R. (2011). Deconstructing security. The Romanian Journal of Political Science, 11(2), 105-129.

Igra, M., Kenworthy, N., Luchsinger, C., \& Jung, J. K. (2021). Crowdfunding as a response to COVID-19: Increasing inequities at a time of crisis. Social Science \& Medicine, 282, 114105. https://doi.org/10.1016/j.socscimed.2021.114105.

Jia, Z., Xu, S., Zhang, Z., Cheng, Z., Han, H., Xu, H., Wang, M., Zhang, H., Zhou, Y., \& Zhou, Z. (2021). Association between mental health and community support in lockdown communities during the COVID-19 pandemic: Evidence from rural China. Journal of Rural Studies, 82, 87-97. https://doi.org/10.1016/j.jrurstud.2021.01.015.

Kalinowski, S. \& Łuczak, A. (2021). Moja sytuacja $w$ okresie koronawirusa. Stage IV. Source material. 
Kalinowski, S. \& Wyduba, W. (2020). Moja sytuacja w okresie koronawirusa. Raport końcowy. Wyd. IRWiR PAN. https://depot.ceon.pl/bitstream/handle/123456789/20004/ Raport_Ko\%20cowy_IRWiR.pdf?sequence $=1$

Kalinowski, S. (2014). Pewni niepewności. In Życie na skraju - marginesy spoteczne wielkiego. Z. Galor, B. Goryńska-Bittner, S. Kalinowski (eds). Societas Pars Mundi.

Kalinowski, S. (2020a). Od paniki do negacji: zmiana postaw wobec COVID-19. Wieś i Rolnictwo, 3(188), 45-65. https://doi.org/10.7366/wir032020/03.

Kalinowski, S. (2020b). Moja sytuacja w okresie koronawirusa. Stages I-III. Source material.

Kansiime, M. K., Tambo, J. A., Mugambi, I., Bundi, M., Kara, A., \& Owuor, C. (2021). COVID-19 implications on household income and food security in Kenya and Uganda: Findings from a rapid assessment. World Development, 137, 105199. https:// doi.org/10.1016/j.worlddev.2020.105199.

Kerbage, A., Matta, M., Haddad, S., Daniel, P., Tawk, L., Gemayel, S., Amine, A., Warrak, R., Germanos, M., Haddad, F., \& Geagea, A. (2021). Challenges facing COVID-19 in rural areas: An experience from Lebanon. International Journal of Disaster Risk Reduction, 53, 102013. https://doi.org/10.1016/j.ijdrr.2020.102013.

Knight, F. H. (1921). Risk, Unicertainty and Profit. Hart, Schaffner and Marx.

Mahmud, M. \& Riley, E. (2021). Household response to an extreme shock: Evidence on the immediate impact of the Covid-19 lockdown on economic outcomes and well-being in rural Uganda. World Development, 140, 105318. https://doi.org/10.1016/j. worlddev.2020.105318.

Malatzky, C., Gillespie, J., Couch, D. L., \& Cosgrave, C. (2020). Why place matters: A rurally-orientated analysis of COVID-19's differential impacts. Social Sciences \& Humanities Open, 2(1), 100063. https://doi.org/10.1016/j.ssaho.2020.100063.

McCarthy, J. (2020). U.S. Coronavirus Concerns Surge. Government Trust Slides. https:// news.gallup.com/poll/295505/coronavirus-worries-surge.aspx.

McKay, S., Rowlingson, K. (1999). The Aims of Social Security. In Social Security in Britain. Palgrave. https://doi.org/10.1007/978-1-349-27562-5_1.

Naeem, M. (2021). Do social media platforms develop consumer panic buying during the fear of Covid-19 pandemic. Journal of Retailing and Consumer Services, 58, 102226.

Nolting, T. (2020). COVID-19 (SARS-CoV-2) in Germany: A holistic approach. Duesseldorf. https://www.researchgate.net/publication/345136477_COVID-19_SARS-CoV-2_in_ Germany_A_holistic_approach (accessed: 2020.12.01).

Roszkowska, E. \& Jefmański, B. (2021). Interval-Valued Intuitionistic Fuzzy Synthetic Measure (I-VIFSM) Based on Hellwig's Approach in the Analysis of Survey Data. Mathematics, 9(3), 201. http://dx.doi.org/10.3390/math9030201.

Skrabacz, A. (2012). Bezpieczeństwo społeczne. Podstawy teoretyczne i praktyczne. Dom Wydawniczy Elipsa.

Stownik języka polskiego (2021). PWN. https://sjp.pwn.pl/sjp/bezpieczenstwo;2443939.html (accessed: 2021.06.29).

Sobczyk, M. (2010). Statystyka opisowa. Wydawnictwo C.H. Beck. 
Sumner, A., Hoy, C., \& Ortiz-Juarez, E. (2020). Estimates of the Impact of COVID-19 on Global Poverty. WIDER Working Paper 2020/43, https://www.wider.unu.edu/sites/ default/files/Publications/Working-paper/PDF/wp2020-43.pdf

Tisdell, C. A. (2020). Economic, social and political issues raised by the COVID-19 pandemic. Economic Analysis and Policy, 68, 17-28. https://doi.org/10.1016/j. eap.2020.08.002.

Tavares, F. F. \& Betti, G. (2021). The pandemic of poverty, vulnerability, and COVID-19: Evidence from a fuzzy multidimensional analysis of deprivations in Brazil. World Development, 139, 105307. https://doi.org/10.1016/j.worlddev.2020.105307.

Webb, D. \& Wills-Herrera, E. (2012). Introduction. In D. Webb, E. Wills-Herrera (eds) Subjective Well-Being and Security. Social Indicators Research Series, 46. https://doi. org/10.1007/978-94-007-2278-1_1.

Yu, L.-R. \& Li, X.-Y. (2021). The effects of social security expenditure on reducing income inequality and rural poverty in China. Journal of Integrative Agriculture, 20(4), 1060-1067. https://doi.org/10.1016/S2095-3119(20)63404-9.

Zalega, T. (2008). Konsumpcja w gospodarstwach domowych o niepewnych dochodach. Wyd. Uniwersytetu Warszawskiego.

Zwęglińska-Gałecka, D. (2020). Koronakryzys. Lokalne zróżnicowanie globalnej pandemii. Wieś i Rolnictwo, 3(188), 67-90. doi: 10.53098/wir032020/04. 


\title{
Individual Experiences and Life Satisfaction of Informal Elderly Caregivers in Poland: A Study Based on In-depth Interviews ${ }^{2}$
}

\begin{abstract}
The Polish population is aging, generating a huge need for care, which for cultural reasons, and as a result of limited availability of professional care is predominantly the responsibility of family. In order to explore the experiences of informal elderly caregivers in Poland, 20 in-depth interviews were conducted. The aim was to understand what characteristics of the caregiving situation are meaningful for caregiver Subjective Wellbeing $(\mathrm{SWB})^{3}$ and what important, valuable beings/doings in terms of the Capability Approach (CA), caretakers cannot achieve because of their caretaking role. The study also aims at exploring what public policy tools/measures are perceived as those that could positively affect SWB. The results show that, the subjective evaluation of SWB is not only highly related to factors such as burden of care, characteristics of the care recipient, caregiver support and/

1 Correspondence: Wydział Nauk Politycznych i Studiów Międzynarodowych, Uniwersytet Warszawski, ul. Krakowskie Przedmieście 26/28, 00-927, Warszawa, Polska; email: klaudyna@hotmail.com

2 The article presents partial results of the doctoral dissertation entitled "Subjective Wellbeing and Provision of Informal Care to Parents - Recommendations for Public Policy Formation" written under the supervision of dr hab. prof UW Anna Kurowska.

3 Used interchangeably with life satisfaction.
\end{abstract}


or time spent caring but also on limitations that caregiving imposes on the ability to achieve valued functionings. Furthermore, while many characteristics of the caretaking situation are perceived by caregivers as negatively affecting their SWB there are also aspects which can increase their SWB. Finally, people have preferences when it comes to the types of help they want and these preferences are dependent on their individual situations.

Key words: subjective wellbeing, valued functionings, senior policy, informal elder caregivers

\section{Introduction}

The demographic setting across all OECD countries has changed drastically over recent decades and due to the increasing life expectancy and low fertility rates populations are aging. Poland belongs to the fastest growing aging societies within the European Union and it is estimated that by 2060 the share of people aged over 65 years will reach $45.3 \%$ of the entire population (European Commission, 2015). This generates a huge need for care. For cultural reasons, and as a result of the limited availability of professional caregivers, the predominant form of care for elders in Poland has been and still is, care provided informally by family members (Bakalarczyk, 2018). In Poland, there exists a well-established norm that it is the family who should provide care, especially to parents. This makes the current senior policy regime in Poland familialism by de-fault, a regime characterized by limited benefits and other types of limited support for informal caregivers (Saraceno \& Keck, 2010). The availability of public replacement support in the form of in-home and institutional care services, is hardly accessible and very scarce. Market solutions are not only expensive (even if co-financed), but also hard to access (Krzyżowski, 2011; Bakalarczyk, 2018). What this phenomenon means for Poland is that there is and will be a growing population of informal elderly caregivers who lack support, and their wellbeing should be of particular interest to policymakers when designing long-term care policies (Wizner et al., 2012).

While there exist studies, which focus on the SWB of informal caregivers there is a scare amount of research showing the differences in SWB amongst people who are burdened with informal care and those who are not. The relationship between informal caregiving and caregiver SWB has been found to depend on personal characteristics and situational factors (van den Berg et al., 2014; Rafnsson et al., 2017; Verbakel et al., 2018). Most studies suggest that informal caregiving negatively impacts SWB of caregivers (Lacey et al., 2018).

In Poland a few studies have been conducted in the field of caregivers and their life satisfaction, such as life satisfaction resulting from caregiving role (Grochowska, 2014; Stojak et al., 2019) or quality of life of informal caregivers (Perek-Białas \& Stypińska, 2010; Ślusarska et al., 2019). There exists no literature however, referencing SWB strictly (as measured by the SWLS). There is also a lack of studies providing detailed insight into the personal experiences of informal elderly caregivers, their opinions about the most desirable public policy solutions and how these tools would help increase caregiver SWB. 
The present study aims at addressing the above-mentioned gaps and exploring the characteristics of individual caregiving situations and how they are (perceived) as related to SWB of caregivers. The aim is also to understand people's experiences with informal caregiving and how caregiving interferes with the ability to achieve other doings and beings which caregivers value. Furthermore, the study aims at exploring what kind of support informal caregivers believe would enable them to achieve higher SWB and based on their experiences, formulate guidance on the kind of support informal parent's caregivers require from public authorities.

\section{Theoretical Framework}

The analysis of the research done in this study is grounded in the CA originally proposed and developed by Amartya Sen (Sen, 1983; Sen, 1999) and recognised in economics literature as an alternative to mainstream income-based measures of wellbeing (Robeyns, 2006). Sen (1999) argues that human life may be seen as a set of interrelated "beings and doings" called "functionings" and the concept of "valued functionings (VFs)" reflects the various beings and doings people value. Some examples of valued beings are being educated, being healthy, being well-nourished, while working, travelling and engaging in leisure is considered as valued doings (Kurowska, 2018). Together these doings and beings are what makes a human life valuable. Capabilities on the other hand, according to Sen (1999), are real opportunities a person has to achieve desired, VFs. Therefore, capability is a sort of a freedom to achieve various lifestyles. In theory, the more capabilities people have to achieve VFs, the better.

In the present study, the experiences of informal parental caregivers are examined in terms of their ability (capability) to achieve VFs. The questions are structured in a way which allow the author to identify respondent's VFs, whether they are able to achieve them and if not, whether providing informal care to their parents is an obstacle in being able to achieve them. The study also provides insight into whether there are VFs in caregivers lives which result from their caregiving role.

\section{Method}

20 in-depth, semi-structured interviews with informal caregivers to parent(s), parent(s) of partners/spouses or parent(s) in law were conducted. 5 of the respondents were men and 15 were women, all of the participants provided informed consent to participate in the study and to be recorded during the interview. The author used the snowball sampling method to reach respondents through personal contacts, social media (forums/groups), and Stowarzyszenie Syntonia ${ }^{4}$. The interviews took place between mid-November 2019 and mid-March 2020. To determine the size of the sample the principle of saturation was

${ }^{4}$ NGO which provides therapy, consultations and workshops to elderly, retired people as well as their caregivers and families in Warsaw. 
used which is defined as a point at which further collection of data no longer offers new information and no longer sparks new theoretical insights (Mason, 2010).

The first part of the interview consisted of the Katz Index (KI) of Activities of Daily Living (ADL), which describes a person's level of independent functioning (Katz et al., 1970), and the Lawton Instrumental Activities of Daily Living (IADL) scale (Lawton \& Brody, 1969), which assesses independent living skills, as well as, the 7-point Satisfaction with Life Scale (SWLS) which measures SWB (Diener et al., 1985). The second part consisted of open-ended questions and allowed respondents to freely express themselves based on their experiences, knowledge, feelings and understandings. The open-ended questions where divided into three parts 1) own experiences 2) subjective perception of life satisfaction and 3 ) policy solutions. The first part explored the history of care and the realities in which the carer of the elderly parent lives. Study participants were asked to describe the tasks they perform in relation to care and the why, where and how of caring. Respondents were asked whether the they received any help from third parties and what their relationship is with the care recipient. They were asked to identify the biggest problems associated with caring, whether providing care negatively affects any aspects of their lives, and if there are any things that they cannot do as a result of their caregiver role which would raise their SWB.

The second part focused on the subjective perception of SWB. Respondents were asked if their role as an informal parent's caregiver negatively affects their SWB, if it negatively affects any other aspect of their life and if there are other things that negatively affect their SWB. Respondents were also asked if there is anything in their current caregiver role that positively affects their SWB. In the last section participants were asked about their experiences and expectations in terms of senior policy tools and outside support. Respondents were asked to describe an ideal solution of help/support, which would make caregiving less of a burden and would allow them to achieve higher SWB. Information provided during the interviews was organized using thematic analysis, a technique that allows to identify patterns and themes in available data (Braun \& Clarke, 2006).

Results

\section{Time Spent Caring and History of Care}

The amount of time spent providing care to parents varied depending on individual situations. The ability for respondents to answer exactly how much time they spend providing care to their parents often depended on whether or not they lived with the care recipient. It was also correlated with the burden of care, as well as related to the health characteristics of the care recipient and the amount of people (or institutions) simultaneously involved in the care situation. Respondents were grouped into 3 categories. In the first group were those who would travel to their parents a few times a week (about 10-15 hours per week). In the second were those who lived with their parents and provided occasional help and in the third group were those who spent all their free time and resources providing care. 
Respondents in the first group were better able to provide an estimated amount of time spent on care each week: “...we take turns going to my mother's house with my brother about 2-3 times a week for a few hours....” (R7/F41). They found care provision to be a separate task with a timeframe which was somehow structured and which they treated as part of their weekly routine. In this group the distance from the caregiver's place of residence to the place of residence of the care recipient was important. Although the majority of respondents lived within the same city, one had to travel $125 \mathrm{~km}$ to provide care to her mother. She mentioned that: "...every weekend for the past 6 years I have been getting into my car and driving for over an hour to help out my mom with some responsibilities at home, do some shopping for her, prepare her for the upcoming week, I have to do this, it takes up all my free time, especially the distance..." (R3/F52). It is plausible to assume that many informal parent's caregivers will be in similar situations especially with the current trend of people migrating from rural to urban areas for work/education.

In the second group, people had a hard time determining how much time they spend on care provision. For these respondents the distinction between their regular responsibilities and more specifically responsibilities associated with providing care to an elder was slightly more blurred: "...I guess maybe a few hours a day, we live together so when there is something they can't do I do it but I don't know... it's really not easy to say..." $(R 2 / M 50)$. The respondents indicated for the most part, that of course there were things they had to assist their parents with and they were able to name these things however, it was difficult for them to give a number of hours or amount of time a week they were actually providing care.

In the last group, respondents most often said that care was a full time, round the clock activity: "...it is full time care, all day, all night even though my sister helps and we have 2 private caregivers helping out...” (R15/F57). The timeframe of their caretaking role wasn't limited to engaging in physical activities related to care but included also, constant awareness and alertness, worrying about the wellbeing of their care recipients and monitoring their activities: "...even when I'm not providing care per say, I have to be alert and make sure she doesn't run away...” (R20/F45). Within this group of respondents caretaking wasn't an additional responsibility; caretaking was a life situation affecting their lives in every aspect.

In terms of the length of time providing care to parents, respondents were grouped into two categories. The first consists of those who could indicate a specific life event that was linked to the onset of their care provision such as an injury, medical condition or other: "...we started to provide care to my mother when my father passed away 9 years ago...” (R16/F54). The second, consisted of those who said that their role as caregiver emerged gradually. Respondents whose caregiver roles were not elicited by a specific event had a more difficult time providing an exact time frame of when care provision started: "...more seriously for the past three years but before that also just more sporadically..." (R11/M31). Respondents in both groups often noticed that naturally, as their parents became older, they required more attention and help. 
Both when it comes to the time spent caring and the history of care, many respondents mentioned that care provision depends on current physical and psychological states that their parents go through. Depending on their current condition they require either more care and assistance or less: "... sometimes my dad calls me every day and asks how to do the simplest things or wants me to come and help and sometimes he even says there was no need for me to come..." (R4/M50). There were periods when care recipients were able to do things on their own and were able to mutually enjoy the time spent with their caregiver: “...sometimes on better days when her memory is better we spend some nice time together like mother and daughter..." (R9/F55).

\section{Characteristics of Care Recipient and Burden of Care}

An important aspect in analyzing informal parent's caregiver situations was the physical and psychological characteristics of the care recipients as well as the (resulting) burden of care. Burden of care refers to the impact that care provision has on the physical, psychological and social aspects of the caregiver (O'Neill \& Ross, 1991). The former was what often made care excessively difficult. Additionally, both the burden of care and care recipient characteristics run in parallel with each other and with the amount of time spent on care. When they are considered together they become very significant in terms of attitudes of respondents.

In terms of the characteristics of the care recipient there were two groups 1) those providing informal care to parents with no symptoms of dementia and 2) those providing informal care to parents with symptoms of dementia resulting in a decline in memory, language, problem-solving and other thinking skills that affect the ability to perform everyday tasks. Overall attitudes of respondents were much more negative when their parents were lacking the ability to normally interact with their surroundings. This was true even when respondents where providing care to people who were severely physically disabled but still mentally aware.

Respondents within the first group, who were providing care to parents (even if they required 24-hour supervision) but didn't show symptoms of dementia often seemed less affected by their role as caregiver and it had a smaller effect on their SWB when compared to the second group. They considered themselves lucky because they were able to sometimes leave their parents alone (if they lived together) and take care of their own matters or postpone/delay a visit (if they didn't live together) without worrying about their care recipient: “...at least my mom is aware of her surroundings and mentally healthy and I can leave to go to work...” (R17/F60). Respondents, often said that they would prepare things for their parents, leave them alone for a period of time, and attend to their other responsibilities: “...I work full time, so I prepare things as much as I can for the day and then she stays alone...” (R19/F41). Furthermore, elders who did not have dementia were able to maintain hobbies/past times such as reading, watching television, solving puzzles etc. meaning they could organize some of their free time and as a result not require full 
time attention: “...my mom reads, solves puzzles, watches TV shows, then I don't feel bad that she's alone...” (R1/F36).

Respondents within the second group, caring for parents with dementia, often mentioned that they felt as if they were prisoners of their situation because they were not able to leave their parents' side even for a second: "...it's not just care that is tiring - I feel like a slave...” (R15/F57). Dementia causes elders to be out of touch with reality and leads to troublesome situations. Respondents feared that their care recipients would do something endangering themselves or their surroundings: "...my mom is starting to forget things, she once hid money and couldn't find it, once she left the door open to her house and once she even left the gas stove on...” (R5/M68). Caregivers mentioned that this was the most difficult part of their caretaking role because these situations caused them to have to be constantly alert and to feel helpless. Elders with dementia were no longer able to maintain hobbies and would spend their time talking nonsense to their caregivers who felt obligated to maintain some type of interaction which was very draining: “...you know, my mom is just constantly talking nonsense, its tiring but I feel bad but it's all day, I wish I could find her something to do to keep busy..." (R15/F57). On the one hand respondents were tired, felt enslaved and discouraged but on the other hand they didn't want to ignore their demanding parents which caused them even more anxiety and stress. Additionally, patients with dementia often elicited aggressive behaviour and were likely to behave in ways that were unpleasant towards their caregivers. One respondent said that her mother often accused her of stealing money from her and that sometimes she would curse at her and call her names in front of other people: "...I am mentally exhausted, my friends are out enjoying life, sailing and I was being called a bitch, in stores at home, she was aggressive..." $(R 8 / F 32)$. Another respondent said that often her mother is aggressive vulgar, and/or cries for no reason which makes her feel completely helpless and unhappy: “...once at 1 am my mom woke me up and told me to give back something, I don't even know what and she then told me to get the f*** out of her house, I just went out on the balcony and cried..." (R6/M63).

The more care and the harder and more time consuming the activities related to care, the more time and other resources caregivers have to sacrifice and the larger the burden of care. Respondents who had parents whose physical or mental health conditions were worse had a higher burden of care. The burden of care described by respondents can also be visibly related to scores on the ADL and IADL. In general respondents who had parents scoring lower on either or both of the ADL and IADL scale had more responsibilities, spent more time and effort providing care and felt more burdened by the situation. More so, whether people had parents whose scores were lower on the IADL (activities such as paying bills, preparing food, dealing with money etc.) or on the ADL (activities such as help eating, showering, using the toilet etc.) didn't seem to matter because each situation had its own obstacles affecting caregivers' lives. Both physical and mental limitations differently but equally influence the burden of care.

Aside from mental health and dementia there is also the case of those respondents caring for parents with low physical mobility levels. Female respondents (especially if they were also older themselves) who were in a situation where caregiving meant a lot of 
physical labour often mentioned the strain on their own physical health exerted by care: “...my mom doesn't weigh little, sometimes after the whole day of helping her get up or move around I feel physically exhausted...” (R15/F57). Elderly parents who were incapable of performing ADL activities required the most physical assistance, were often overweight and respondents had to use a lot of physical strength to help them perform activities.

\section{Caregiver Support}

Another significant theme which emerged was related to the support caregivers were receiving and who they could or couldn't count on in their daily care related activities. In terms of caregivers' attitudes, most important was whether or not the caregiver could count on other family members for support. Respondents were grouped into two categories 1) those who took turns caring for their loved ones and 2) those who said they couldn't count on any help and they felt abandoned in their caretaking role. Furthermore, while there were two groups of respondents those who mentioned that they received outside, professional help and those who didn't, the former group seemed to be more critical about this help than thankful for it.

When it comes to familial support the first category encompassed those informal caregivers who had siblings, spouses and/or other family members who also provided care and took turns with responsibilities related to caretaking. Almost all the respondents in this group mentioned that they were very thankful to family members, especially siblings, for sharing the care responsibility both physically, emotionally but also financially: "...we take turns caring with my sister, sometimes my sister takes my mother sometimes she is with me, we also have a brother... he makes a lot of money so he helps out financially..." $(R 9 / F 55)$. Respondents mentioned that they are lucky enough to be able to have time for their own things when other family members take over and that this is extremely important to them. They often mentioned that the care responsibility was equally shared, that they supported each other, and somehow planned things in a way so that everyone could still manage to do things that were important to them: "...twice a week my brother and his wife take my mother home for a few days, then I can relax go away somewhere...” (R20/F45).

In the second group of respondents were those who didn't have any support from family members. Respondents in this group were often more negative and bitter about their situation: "...my brother's wife is sick so he can't help me and never does, sometimes he comes over for coffee but that's not help...” (R12/F63). They often said that there was no one they could count on if they needed help themselves.

When it comes to institutional/private support and help/care two categories emerged 1) those who took advantage of some form of outside help and 2) those who didn't. In most cases those respondents who took advantage of private/institutional help in the form of formal and/or paid caregivers were caring for parents who had more severe disabilities and required more extensive care. They mentioned they were not completely satisfied with the available services because they were either inadequate, hard to organize or generated additional work for the caregiver: "... we have a formal caregiver from the municipal social 
welfare centre but their hourly limit of work is already exceeded by 2000 hours and they can only come twice a week for 2 hours but each time we have to fill out a million papers... all this is an additional burden when I don't even have time to sleep I don't have time to go back and forth with paperwork..." (R16/F54). Furthermore, care recipients had a hard time accepting and trusting outside help which created conflicts: "... we had two caregivers but my dad couldn't get along with either one..." (R4/M50). It wasn't as obvious as in the case of help from other family members that those respondents hiring outside help were more relieved and less stressed and overwhelmed by their caretaking role.

Respondents in the second group also mentioned that professional, outside help was difficult to find and organize and respondents were sometimes wary of letting strangers into their homes: "...finding a private caregiver is very hard, when they hear where we live they all say no this is too far for me... there is no support from outside from the government, everything involves going out, calling, waiting, forms, paperwork, fill out papers...” (R17/F60), "...I am scared to let in a stranger into my home..." (R20/F45). Aside from the difficulties associated with finding appropriate outside help in this group, finances seemed to be a very important aspect. Respondents often mentioned, that as much as they would like to hire outside help they could not afford it: "...my mother's pension is very low and these type of solutions are very expensive, we can't count on any financial support...” (R7/F41). Some claimed that outside help was non-existent (usually referring to public help) or that they didn't know where or how to look for it: “...public institutions don't exist, there is a complete lack of them...” (R8/F32). One respondent said that while Day Welfare Homes were available in her area she didn't have the resources and time to transport her mother there every morning.

\section{Caregiving Life Satisfaction and Things People Value}

Respondents were directly asked whether caregiving affects their SWB. When asked about if caring for their parent affects their life satisfaction 10 respondents answered that care does not affect their life satisfaction. The remaining 10 who mentioned that caretaking did affect their SWB had parents who scored lower on the ADL and IADL scales; most of those caring for parents with dementia were in this group. For the group of interviewed caregivers, it can be seen that both in the case of ADL and IADL scores there is a weak positive relationship between SWB levels and scores on both ADL and IADL scales (the higher the score on the IADL/ADL the more independent the care recipient). All respondents were eager to explain their answers and regardless of whether, they said that caretaking affects their SWB or not, they provided similar explanations for which parts of caretaking and why it affects their SWB. The following themes emerged explaining why and how caretaking negatively affects SWB: 1) lack of time, 2) physical and emotional strain, 3) lack of support and 4) lack of available access to and quality of health and social care. While some respondents were hesitant to explicitly say that caretaking affects their SWB the role of being an informal parent's caregiver almost always negatively affected some area of their life. 
The most common explanation of why/how caretaking affects caregiver SWB was related to a general lack of free time. All respondents, at some point during the interview, mentioned that (free) time was something that was missing in their lives: “...the help and care is not the problem the time it consumes from everything else is..." (R3/F52). The amount of time spent providing care, which resulted in less time to do other things, had an impact on respondents' SWB especially if they were the only ones responsible for care provision. This was especially true for those respondents who provided 24-hour care; they mentioned that even when they were not doing care related activities they were still busy supervising their parents. Often respondents had their own families which they felt they were not paying attention to as a result of caring for their parents: "...I don't have time to see my grandchild and he is growing so quickly..." (R16/F57).

The fact that many informal parent's caregivers pointed to lack of time as a main factor contributing negatively to their SWB was also important because it meant that people were not able to do things that they valued doing. When asked about the things they were not able to do because of caretaking that could improve their SWB many mentioned things like caring for their own basic needs: "...I don't even have time to go to the hairdresser...” (R17/F60), participating in sports: “...for sure I would love to go back to sports, tennis, basketball I used to do a lot of sports and now I do not have the time..." (R4/M50), being able to work: "...I would go to work if I could, I always worked and I liked being busy, plus financially it would be helpful but I can't..." (R6/F63), being able to go on vacation: "...currently I do not have the time to go on a trip or vacation while before I was able to do these things..." (R19/F41), being socially active: “...I can't go out with friends, to the theatre to a restaurants because over the weekend I have to help and organize everything..." (R3/F52), caring and monitoring own health: "...I don't have time for my health, I used to be very interested in healthy cooking, living...” (R6/F63) and even sleeping: “...I am not sleeping because I have to watch my mom...” (R15/F57). The overall lack of time related to informal caretaking affects the ability of people to do other things they value.

The second theme which emerged was the physical and emotional strain related to care taking. As mentioned earlier, this was related to the burden of care as well as the characteristics of the care recipients. Respondents, especially those caring for parents with dementia but not only, often mentioned that while the care alone was not really affecting their SWB their elder parents were often very demanding emotionally and this emotional strain was what affected their SWB: “...I am very tired mentally tired all the time, too tired to enjoy things..." (R8/F32). The additional amount of work related to performing care activities was also considered by many to be physically straining. Respondents often mentioned that after a whole day of work or week of care they no longer had the physical or mental energy to be able to enjoy other things in life.

The third emerging theme was the lack of support from family directly related to caretaking but also weak family ties in general. Respondents mentioned that there was no one they could count on for help which made them feel abandoned and affected their SWB: “...lack of solidarity in the family and lack of support from my husband, he doesn't want my mom to move in..." (R13/F62). Some respondents who mentioned that caretaking 
wasn't negatively affecting their SWB realized that the reason for this was because they could count on other members of their family and care was provided in turns: "...no caretaking does not affect my life satisfaction negatively because I share it with my brothers and husband..." (R7/F41). Two respondents mentioned they had other family related problems which affected their SWB more than anything else.

The last emerging theme was the lack of available access to and quality of health and social care. Many individuals felt abandoned, frustrated and helpless and this affected their SWB. Respondents mentioned that the amount of paperwork was overwhelming and time consuming, that there was a lot of uncertainty and lack of information about what resources are available and how to take advantage of them. They felt that the government and public institutions which were supposed to resolve social problems and care for citizens where not doing anything to help: “... so what if there are available tools, I don't know what they are nobody tells me, I feel overwhelmed when I have to go to any public institution, they have never helped me it is really frustrating..." (R18/M59). Individuals mentioned that the options and tools available theoretically were in practice very inadequate in terms of their needs and the needs of their care recipients: "...my mother used to attend day welfare homes but it was hard for us to get her there, maybe if some transport was provided, she was on a wheelchair...” (R8/F32). Many respondents mentioned that health care services were not adequate and medical personnel was not properly trained to deal with elders, especially those with dementia: "...one time we had to call an ambulance and they came and took my mother and the paramedic was asking my mom about the medications she takes, she has no idea what she takes because she has Alzheimer's...” (R9/F55).

Lack of support from the social system and health care system was a very popular topic amongst respondents when asked about SWB. On top of being rather negative about the services or lack of them something equally important mentioned by respondents was that they had no source of information and training on how to perform caretaking responsibilities. One respondent mentioned that the most overwhelming aspect of caretaking affecting his SWB is that he has no idea what he is doing: “...the worst is that I do not know many things, I don't understand things, a caregiver has to know how to provide care, I was never in such a situation so how do I know how to act and manage and help my mom..." (R5/M68). While this respondent was lucky enough to be able to attend meetings and trainings organized by Syntonia these types of services are not common nor offered elsewhere. Respondents mentioned that finding outside training/workshops could improve their SWB but neither churches, nor public or private institutions offered any such help.

In terms of how caregiving affected respondents three groups of respondents emerged 1) those who didn't mention any positive effects of caregiving on their SWB, 2) those who said that caring was their responsibility and this role made them feel needed and fulfilled and 3) those who said that the social aspect of caring and time spent with their care recipients actually increased their SWB.

In the first group, those who didn't consider their caretaking role to have any positive impact on their SWB, were respondents caring for parents with some sort of mental condition and/or dementia. This can be attributed to the fact that respondents in this 
situation experience little or no meaningful social interaction with their care recipients: "...when something is happening in your life you want to go and talk about it with your mom and I can't do that I don't have her support, actually it's her I usually need to complain and talk about..." (R8/F32). Furthermore, the strain related to caring for an elder with dementia seemed to overshadow even feelings of fulfillment related to care which were mentioned in the second group of respondents.

In the second group of respondents' people often mentioned that care provided to their parents (and the parents themselves) was something that they were responsible for and that they felt complete and fulfilled by doing so. Respondents in this group mentioned that their SWB is higher because they are confident and aware that they are doing their part and fulfilling their responsibilities. They felt needed: “...it makes me happy that I feel needed...” (R5/M68) and felt that their loved ones are being properly cared for: "...important is realization that the person that I am caring for is safe and doesn't need anything...” (R1/F36).

Finally, in the third group, were those who found satisfaction in the social ties created within their caretaking situation. Respondents noted that caring for their parents attributed to a higher SWB and/or positive feelings. While on the one hand, caretaking limits the amount of time and resources for other family members, on the other, it can bring families together. The physical state of the care recipient is not very important in this matter, in order for this time to be meaningful care recipients have to be in good mental state. Respondents often mentioned that while providing care to their parents was tough in many ways they also enjoyed spending time with their parents: “...last week we had grandmothers' day and the whole family came it was very nice, we laughed and talked..." (R17/F60). They were able to catch up on many things that they didn't have time for before, and their parents could still comfort them and provide emotional and social support if they were going through difficult times: “...my mom is a very warm person and I can talk to her about my problems...” (R3/F52). One male respondent who went through a difficult divorce felt that caring for his parents was what keeps him hopeful and alive: "...it increases my life satisfaction, I feel needed, I have someone to talk to, my mom is the only ones I have left, I don't know what I will do when she is gone...” (R5/M68).

\section{Desired Public Policy Solutions}

Respondents were asked to consider their personal situations and provide "ideal" support which they would want and which would increase their SWB. All respondents mentioned that they would (to at least some extent) entrust care to someone from the outside be it public care or private care. Given their experiences respondents were also able to provide many different tools and resources (benefits, in-home help/assistance, transport logistics, social support services etc.) which would help them with their caretaking role and make caretaking less of a burden.

Respondents who weren't already receiving some form out outside help from family or professional caregivers always mentioned that they would be willing to hire/accept 
outside caregivers. This remained true even for respondents who believed that 24-hour institutional care was completely out of the picture: “...my mother would absolutely not agree to all day institutional care unfortunately but I would love to be able to even pay and hire a caregiver..." (R10/F60). While respondents mentioned that ideally these caregivers should be specialized in caring for elders (provide rehabilitation services, activate the elderly, encourage physical activity etc.) for the most part they would be satisfied simply if a professional/private caregiver would provide them with time away from caretaking, time that they could use for themselves: "...it would do a lot for me if I could have some time off and during that time would come someone who could help with rehabilitation or simply care for a few hours..." (R1/F36). Respondents also mentioned that they would gladly take their parents to Day Welfare Homes but they either weren't available or participation was hard to organize: “...it would be good to be able to give elders away for the day but this doesn't exist or at least I haven't been able to find such a solution...” (RR19/F41). Although many respondents would entrust care to outside helpers this was not always possible. For the most part problems associated with receiving help from in-home caregivers was related to the fact that a good reliable, trustworthy caregiver was hard to find and relatively expensive.

5 respondents said that they would definitely, immediately place their family members in an institution; 4 of them had parents who had different symptoms of dementia. For two reasons this was not possible 1) finances and 2) parents not willing to be moved. Respondents mentioned that 24-hour care facilities were extremely expensive even for those people who were relatively well-off and for those who could share the cost with other family members: "...I would love to be able to afford an institution or for it to be accessible...” (R13/F62). Respondents also mentioned that their parents did not want to leave their house and that they couldn't forcefully place them in an institution: “...my mom would never go to such an institution, how can I force her?...” (R18/M59). Although overall respondents were less likely to want to take advantage of 24-hour institutional help many mentioned that they were aware that their parents were getting older and that with time they would require more help and a time could come when they would prefer/require 24-hour institutional care facilities to be made available because they would no longer be able to provide care for various reasons: "...I realize that one day I might have to give her away, I simply won't have the strength to continue although I hope not...” (R3/F52). While overall respondents are not likely to give their parents away to care facilities and want to provide care as long as they can (of course ideally with the support of others) they also realize that there is only so much they can do and that they may face a situation where this type of care would be most suitable, meaning that it should be accessible.

Respondents provided interesting and informative ideas, solutions and tools which should be made available to increase their SWB. The results can be grouped into five categories 1) time-off care (solutions providing alternative care for elders which in result give the caregiver time do attend to other responsibilities or rest), 2) caregiver social and educational support (tools aimed at providing workshops, training and knowledge about providing care for caregivers), 3) procedural solutions (simplifying procedures 
necessary to receive social and medical help), 4) help/activities for elders (most diverse category including different tools and solutions aimed improving/monitoring/managing the health and wellbeing of elders, creating activities for them and helping them with daily functioning) and 5) financial support (funding of medication, rehabilitation, in-cash benefits etc.).

In the first category (time-off care), the most popular discussed option to increase SWB of caregivers was having easy reliable access to trained, educated and reasonably priced, professional in-home caregivers (provided either by the private or public sector). Almost all respondents agreed that this would definitely help informal parent's caregivers and should be offered: "...in-home caregivers are the ideal solution because they can come and take a little bit of weight off of me..." (R11/M31). Respondents mentioned that in-home caregivers would allow them to better plan their days and provide them with more time for other responsibilities or for rest. Respondents however, also mentioned that availability of caregivers would be helpful even if these caregivers only helped out with tasks not directly related to care such as help with shopping: “...it would be helpful if someone for example would do our shopping or bring us something like medication because with the rest of the care I can manage..." (R7/F41). Finally, respondents often mentioned that this type of help would not necessarily have to be provided according to any specific schedule but rather that in times of need caregivers would be available on an on-call basis: "... an on-call caregiver, if you are in an emergency situation, you need to get something done she comes and helps you out or takes over...” (R10/F60). As an alternative to in-home caregivers' respondents also mentioned that they would be willing to use the services of day-care centres for elders. Essentially, for these respondents it was important to be able to have a place where they could leave their parents, usually for the duration of the work day or for them to be able to attend to other responsibilities or simply rest: “...I think ideally there should be some daytime institution where elders could go so that caregivers would be able to know they are cared for in that time..." (R14/F55). While respondents did mention that they were aware of the fact that these places existed they said that they should be more available and more importantly that specific activities must be put in place to activate and interest elders. Another preferred solution, within the first category was respite care, which respondents agreed was very important. Respondents mentioned that while caring was not always a very difficult task it was definitely a time consuming, long-term activity. They were often not only providing care to parents but also caring for their children, working professionally and keeping the household running. This meant that they were unable to enjoy time off and they were not able to go away on vacation: “...we used to travel a lot but now it's impossible I wouldn't mind and I don't think my mother would be upset either if we left her with someone for two weeks or so and go away during that time..." (R18/M59). Finally, as mentioned earlier respondents also considered 24-hour institutional care to be an important aspect of senior policy. While for many respondents, at the given moment this would not be their preferred solution, they did mention that this tool must be made available. Respondents mentioned that these institutions should be available and that they should be affordable because sometimes there are situations where this option 
is the only possibility: "...I know some situations are such that people must have the option to leave their loved one in a full-time care facility, for example if the family is too far or can't provide care for whatever reason..." (R18/M59).

Within the second category we find a need for training and education to be provided to caregivers as well as emotional, psychological and social support. Respondents mentioned that they are willing to help and care for their parents but sometimes they simply don't know how to properly do so (this was especially true for male caregivers): “... a caregiver needs to know how to care for someone, so he needs to have some form of educational support, someone who will teach how to care..." (R5/M68). Respondents mentioned that it was hard to deal and react to parents with symptoms of dementia or other illnesses both physical and mental because they had no experience in the matter. On top of education and training it was also important for caregivers to be able to receive psychological, emotional support from professionals or simply to be able to talk to someone about their situation: "... support groups would definitely be necessary because people find out that they are not alone, that others are in the same situation and you can exchange experiences..." (R12/F63).

The third category encompasses actions and solutions directed at simplifying procedures for attaining tools. Many respondents mentioned that while they are aware of existing public policy tools which could help them in their caretaking role often the amount of paperwork and time consumed to apply for them was simply not something they could do: "...I tried to get a public caregiver once and when I saw what I had to do I didn't..." (R4/M50)". They mentioned that elders often had to visit doctors yet the line ups were very long, doctors were not properly trained, there was a lack of geriatric doctors and access to these services was difficult: “...we need more geriatric doctors so they know how to help elders..." (R8/F32). Respondents mentioned that this hardship was the case for both social services, as well as medical services and while public policy has to consider the specific types of tools and resources available it is also extremely important to make it easier and less time consuming to access them.

The fourth category was the most diverse and solutions were directed specifically at the wellbeing of elders which in turn was said to affect the wellbeing of caregivers. Respondents were aware that activities which promoted physical and mental health had a positive impact on their caregiving situation. Within this category the most popular was the idea that public policy should ensure activities for seniors, motivating them to keep mentally and physically active: "...it is important to activate the brain to work for elder people then the longer they are able to function in society...” (R8/F32). Providing in-home and outside rehabilitation services was also popular amongst respondents: “...we need rehabilitation services because elders are healthier physically and able to do more if they are rehabilitated..." (R1/F36). A common idea, was for governments or private companies to organize transportation services for elders as well as improve infrastructure: “...for me the hardest part is getting my mom to the doctor, I've done it before where I would just push her wheelchair down the street...” (R15/F57). While some elders where still mentally active they were unable to physically move which made them prisoners of their homes especially if 
caregivers where not equipped with the necessary equipment and vehicles. Furthermore, especially if elders lived in smaller areas, sometimes they required the time and help of their children for things that they theoretically could do themselves because of a lack of infrastructure and/or transportation possibilities for them to do these things on their own. Solutions and tools provided as examples, aside from providing transportation and infrastructure were: creating communities and/or special neighbourhoods dedicated for elders, telemedicine (because not every situation required a visit to the doctor), and/or electronic pulse monitoring (because many things can be achieved easily using today's technology).

Last but not least, financial aid was mentioned by respondents. Surprisingly enough even though quite a few respondents mentioned some form of financial strain related to care provision, financial aid in the form of different benefits did not seem to be the predominant form of help they expected or thought was the best solution. Most respondents who in some way favoured financial tools were more likely to say funding should be made available for things like day care, 24-hour institutional care and/or outside caregivers: "... supplementary payments for care facilities so that people could afford them..." (R7/F41), “... a division of the costs of caregivers and institutions...” (R14/F55), “...funding for hygiene products because they cost a lot...” (R12/F63), “...more medications that could be funded, they are expensive..." (R19/F41). Respondents often mentioned the fact that the pension of their care recipient was very low and didn't cover basic daily needs: "...I wish my mom had enough pension for me not to have to worry about not being able to afford her care..." (R17/F60).

Overall, respondents agreed on the idea that everyone's situation is different and different approaches should be considered. When asked about the ideal solution respondents realized that there was no single answer. Many noticed that while providing care is definitely not an easy task, and there is definitely not enough being done to help them, they also had trouble answering what ideally should be offered. Respondents were also aware that the more diverse the array of tools and solutions available the better. Additionally, there could be solutions which could be costlier but not suitable for everyone. For example, if someone is completely against the idea of placing their parents in a full-time institution, no matter how many of these institutions will become available and whatever their price be they simply will not take advantage of such a solution.

\section{Discussion and Conclusion}

The effect of caregiving on SWB is very complex. While caregiving may bring satisfaction and reward in some situations (Quinn et al., 2010) for many caregivers it is a stressful experience (Pot et al., 1997; Hajek \& Konig, 2016; Niimi, 2016). Furthermore, SWB is not without flaws and its main criticism is hedonic adaptation; measures of SWB may not be accurate because people have the ability to adapt to poor conditions and negative life situations (Graham, 2009). As mentioned earlier, for cultural reasons, and as a result of the limited availability of professional caregivers, the predominant form 
of care for elders in Poland has been and still is, care provided informally by family members (Bakalarczyk, 2018), there exists a well-established norm that it is the family who should provide care and perhaps the Polish population is experiencing hedonic adaptation. However, while simply being an informal parent's caregiver seemed not to be important for individual's evaluations of SWB, there were many characteristics, as also shown by other studies related to the care situation (Shakeel et al., 2015; Niimi, 2016; Rafnsson et al., 2017; Verbakel et al., 2018) which respondents said did affect their SWB. Respondents mentioned that the time caretaking consumed, the lack of institutional support or support from other family members, mental (especially symptoms related to dementia) and physical health characteristics of the care recipient and difficulties accessing health and social resources were something that affected their SWB.

Amongst the characteristics mentioned above the two most important, reoccurring and overreaching factors that seemed to be affecting the SWB of parent's caregivers were time and dementia. Many respondents mentioned that caretaking consumed not only, any free time they had but also, time available for other responsibilities, hobbies, needs and rest. Difficult or non-existent access to outside help, support and healthcare resulted in a lack of (free) time experienced by respondents; a lack of (free) time seemed to be the most common explanation of the negative effects of caretaking on SWB. Respondents mentioned that they had to give up spending time with other family members or friends, that they were not able to go out, that they had to give up sports, that they didn't have time to care about their own health and many more. This is extremely important because it means that caretaking affected their ability to achieve those VFs. How can someone pursue passions and hobbies or stay healthy if they don't have the time to do so?

However, caring for parents could also positively affect wellbeing and respondents often said that caring for their parents contributed to a higher SWB and/or positive feelings. Social network size and the quality and quantity of positive interpersonal relationships has a positive relationship with SWB levels (Wang, 2014; Li, 2016). This means that the bond between children and parents (especially if they were mentally healthy and not experiencing dementia which hinders the ability to form meaningful bonds), the ability for intergenerational exchange of experiences and knowledge, the time spent together as well as the feeling of purpose and fulfillment could increase SWB levels. Here, the second aspect which caregivers said affected their SWB, dementia of the care recipient, which also seemed to have the strongest negative effect on the SWB of the caregiver severely affected the ability for a caregiver-care recipient bond; it caused elders to be out of touch with reality, to be unable to form meaningful bonds with others, as well as, to elicit aggressive behaviour. Based on respondents' answers, but specifically those whose parents didn't have dementia, it didn't seem that shifting the burden of care onto institutions would necessarily increase SWB of the caregiver. In general, respondents were more likely to mention that if they had the proper knowledge, resources and accessibility to the instruments they needed to provide care to their parents and generate some free time for themselves, their life satisfaction would be greater. Respondents valued the chance they had to spend time with their parents and mentioned that they felt good about being able 
to help because it gave them a sense of purpose, belonging and responsibility. If informal parent's caregivers receive the tools and support they need to be able to provide proper care and to be able to balance caring for their parents with other responsibilities and hobbies, then caretaking maybe would not decrease SWB of informal caregivers but it could actually have a positive impact on SWB levels.

People have preferences when it comes to providing care to parents and these preferences are significant for the SWB of informal caregivers. The solutions people prefer and expect from the government are neither fully familialistic nor fully de-familialistic and this generates the conclusion that public policy in Poland should head in the direction of optional familialism and tools and solutions offered to elders and their potential caregivers should be diverse. Providing only familialistic solutions could greatly affect the wellbeing of informal parent's caregivers whose care recipients have dementia. Providing only de-familialising tools, on the other hand, could counter the positive effects of caretaking. Furthermore, a support for optional familialism (Leitner, 2003), does not imply advocating "quantity over quality" because both are important. However, "quantity" is not only favourable because of the number of tools but because it allows individuals to choose what they prefer and this possibility can increase their wellbeing. The results of the study also indicated a need for policy instruments which would allow informal caregivers to attend to other responsibilities, needs and hobbies. Various instruments such as adequate day care institutions, respite care and most importantly reliable, accessible and on-call caregivers could provide tired and overworked caregivers with the opportunity to relax and achieve VFs that they could otherwise not achieve. The results of the study also showed, that not only did different instruments need to be available, they should be easy to use (to apply for) and of good quality. Often access to some of the tools available was difficult not only because of their limited nature but also due to the fact that the bureaucratic process was lengthy and required a lot of time (which was already limited due to care related responsibilities).

While optional familialism seems to be the obvious choice, an ideal society where absolutely every possible tool and solution is available is impossible. Policies are limited by financial resources and funds available for different tools and solutions. SWB measures, and understanding the situations of informal caregiver could guide policy in terms of which services are offered to which groups. To illustrate this, if we assume that dementia brings with it the most negative effects on caregiver SWB then priority in institutions should be given to patients with confirmed dementia. Offering cash benefits to someone who needs training on care provision will not be of any help, unless at the same time policy makers focus on creating paid training centres for informal caregivers. Similarly, 24-hour institutional care will not be an option for someone who knows that placing their parent/ elder in an institution will cause everyone distress. Even if such a facility is available while most may not take advantage of it will be an option for those unable and unwilling to provide care. While it may be reasonable to believe that full time facilities may completely unburden the family from care and in turn increase their SWB, perhaps an hour, a day or a week of free time for the caregiver may be enough to significantly increase their SWB. 
Summarizing, the most important results of this study 1) The subjective evaluation of SWB, in view of respondents' caretaking roles, is not only highly dependent on things such as the burden of care, the characteristics of the care recipient, the support the caregiver receives and the time spent caring but also in turn on the limitations caregiving imposes on caregiver ability to achieve beings and doings which they value. Additionally, all these things are highly interrelated and dependent on one another with a major connecting factor being time. 2) While many characteristics related to the caretaking situation negatively affect SWB there could be/are also aspects of the caregiving situation which can increase levels of SWB and with proper tools and solutions these positive aspects can be intensified. 3) Polish respondents have individual preferences when it comes to the types of help (tools and resources) they need and there is an agreement that various, flexible tools and an optional familialism regime, are needed and the needs are determined by the characteristics of individual situations.

\section{References}

Bakalarczyk, R. (2018). Polityka wsparcia nieformalnych opiekunów niesamodzielnych osób starszych. Na podstawie zmian prawnych $w$ latach 2003-2015. Wydawnictwo Uniwersytetu Warszawskiego.

Braun, V. \& Clarke, V. (2006). Using thematic analysis in psychology. Qualitative Research in Psychology, 3(2), 77-101.

Diener, E., Emmons, R. A., Larsen, R. J., \& Griffin, S. (1985). The Satisfaction with Life Scale. Journal of Personality Assessment, 49, 71-75.

European Commission. (2015). The Ageing Report: Economic and budgetary projections for the 28 European Member States (2013-2060), European Economy 3.

Graham, C. (2009). Happiness around the world. Oxford University Press.

Grochowska, J. (2014). Feeling of satisfaction and being burdened with duties among informal care givers of the elderly according to the level of efficacy of care recipients. Medycyna Ogólna i Nauki o Zdrowiu, 20(1), 46-50.

Hajek, A. \& Konig, H. H. (2016). Informal Caregiving and Subjective Well-Being: Evidence of a Population-Based Longitudinal Study of Older Adults in Germany. Journal of the American Medical Directors Association, 17(4), 300-305.

Katz, S., Down, T. D., Cash, H. R., \& Grotz, R. C. (1970). Progress in the development of the index of ADL. The Gerontologist, 10(1), 20-30.

Kurowska, A. (2018). (De)familialization and (De)genderization - competing or complementary perspectives in comparative policy analysis? Social Policy \& Administration, 52(1), 29-49.

Krzyżowski, Ł. (2011). In the Trap of Intergenerational Solidarity: Family Care in Poland's Ageing Society. Polish Sociological Review, 1(73), 55-78.

Lawton, M. P. \& Brody, E. M. (1969). Assessment of older people: Self-maintaining and instrumental activities of daily living. The Gerontologist, 9(3), 179-186. 
Lacey, R. E., McMunn, A., \& Webb, E. (2018). Informal caregiving patterns and trajectories of psychological distress in the UK Household Longitudinal Study. Psychological Medicine, 1(9).

Leitner, S. (2003). Varieties of familialism. The caring function of the family in comparative perspective. European Societies, 5(4), 353-375.

Li, Y. (2016). Social mobility, social network and subjective well-being in the UK. Journal of the Academy of Social Sciences, 11(2-3), 222-237.

Mason, M. (2010). Sample Size and Saturation in PhD Studies Using Qualitative Interviews. Forum Qualitative Sozialforschung, 11(3), 1-20.

Niimi, Y. (2016). The "Cost" of informal care: an analysis of the impact of elderly care on caregivers' subjective well-being in Japan. Review of Economics of the Household, 14(4), 779-810.

O'Neill, G. \& Ross, M. M. (1991). Burden of Care: An important Concept for Nurses. Health Care Women Int., 12(1), 111-121.

Perek-Białas, J. \& Stypińska, J. (2010). Łączenie pracy i opieki nad osobą starszą — wpływ na jakość życia opiekuna. In D. Kałuża, P. Szukalski (red.), Jakość życia seniorów w XXI wieku. Ku Aktywności. (136-148). Uniwersytet Łódzki.

Pot, A. M., Deeg, D. J. H., \& Van Dyck, R. (1997). Psychological well-being of informal caregivers of elderly people with dementia: Changes over time. Aging \& Mental Health, $1(3), 261-268$.

Quinn, C., Clare, L., \& Woods, R. T. (2010). The impact of motivations and meanings on the wellbeing of caregivers of people with dementia: a systematic review. International Psychogeriatrics, 22(1), 43-55.

Rafnsson, S. B., Shankar, A., \& Steptoe, A. (2017). Informal caregiving transitions, subjective well-being and depressed mood: Findings from the English Longitudinal Study of Ageing. Aging and Mental Health, 21(1), 104-111.

Robeyns, I. (2006). The Capability Approach in Practice. The Journal of Political Philosophy, 14(3), 351-376.

Saraceno, C. \& Keck, W. (2010). Can we identify intergenerational policy regimes in Europe? European Societies, 12, 675-696.

Sen, A. (1983). Poor, Relatively Speaking. Oxford Economic Papers, 35(2), 153-169.

Sen, A. (1999). Development as Freedom. Knopf.

Shakeel, S., Rana, S. A., \& Malik, N. I. (2015). Burden of Care, Mental Health and Subjective Well Being of Family Caregivers of Elderly Patients. Pakistan Journal of Professional Psychologists, 6(1), 1-16.

Ślusarska, B., Bartoszek, A., Kocka, K., Deluga, A., Chrzan-Rosak, A., \& Nowicki, G. (2019). Quality of life predictors in informal caregivers of seniors with a functional performance deficit - an example of home care in Poland. Clinical Interventions in Aging, 14, 889-903.

Stojak, Z., Jamiołkowski, J., Chlabicz, S., \& Marcinowicz, L. (2019). Levels of Satisfaction, Workload Stress and Support Amongst Informal Caregivers of Patients Receiving or 
Not Receiving Long-Term Home Nursing Care in Poland: A Cross-Sectional Study. International Journal of Environmental Research and Public Health, 16(7), 1189-1198.

Verbakel, E., Metzelthin, S. F., \& Kempen, G. I. J. M. (2018). Caregiving to Older Adults: Determinants of Informal Caregivers' Subjective Well-being and Formal and Informal Support as Alleviating Conditions. The journals of gerontology. Series B, Psychological sciences and social sciences, 14: 73(6), 1099-1111.

Van den Berg, B., Fiebig, D. G., \& Hall, J. (2014). Well-being losses due to care-giving. Journal of Health Economics, 35(100), 123-131.

Wang, X. (2014). Subjective well-being associated with size of social network and social support of elderly. Journal of Health Psychology, 21(6), 1037-1042.

Wizner, B., Skalska, A., Klich-Rączka, A., Piotrowicz, K., Grodzicki, T. (2012). Stan zdrowia i sprawność osób starszych. In M. Mossakowska, A. Więcek, P. Błędowski (red.), PolSenior. Aspekty medyczne, psychologiczne i ekonomiczne starzenia się ludzi w Polsce. (82-83). Termedia. 
The Editorial Board of the Problemy Polityki Spotecznej.

Social Policy Issues would like to thank the following for their valuable contribution as peer-reviewers in 2020 :

Denise Bronson - Ohio State University, Stany Zjednoczone

Maciej Cesarski - Szkoła Główna Handlowa w Warszawie, Polska

Ute Dubois - Isg International Business School, Francja

Ewa Duda-Mikulin — University of Bradford, Wielka Brytania

Ann-Zofie Duvander - Stockholm University, Szwecja

Peter Fabián - Silesian University in Opava, Czechy

Krystyna Faliszek - Uniwersytet Śląski w Katowicach Katowice, Polska

Ewa Gałecka-Burdziak — Szkoła Główna Handlowa w Warszawie, Polska

Vasiliki Georgiadou — Panteion University, Grecja

Dobroniega Głębocka — Uniwersytet im. Adama Mickiewicza w Poznaniu, Polska

Jasmin Joecks — University of Tuebingen, Niemcy

Arkadiusz Karwacki - Uniwersytet Mikołaja Kopernika w Toruniu, Polska

Jerzy Krzyszkowski - Uniwersytet Łódzki, Polska

Mirosław Księżopolski - Uniwersytet Warszawski, Polska

Dagmar Kutsar - University of Tartu, Estonia

Jan Maciejewski — Uniwersytet Wrocławski, Polska

Jadwiga Mazur - Uniwersytet Pedagogiczny im. Komisji Edukacji Narodowej

w Krakowie, Polska

Ulla Pape - Free University of Berlin, Niemcy

Francesca Petrella - Aix-Marseille University, Francja

Aneta Piekut - University of Sheffield, Wielka Brytania

Przemysław Pluciński - Uniwersytet im. Adama Mickiewicza w Poznaniu, Polska

Andrea Rácz - Eötvös Loránd University, Węgry

Christian Schweiger - Chemnitz University of Technology, Niemcy

Simona Stanescu — Romanian Academy of Science, Rumunia

Dorota Szawarska - Uniwersytet Warszawski, Polska

Steven Tuch - George Washington University, Stany Zjednoczone

Bogusława Urbaniak - Uniwersytet Lódzki, Polska

Wojciech Woźniak - Uniwersytet Łódzki, Polska 